\title{
Aminopyridine stabilized group-IV metal complexes and their applications
}

\author{
Muhammad Hafeez $^{1} \cdot$ Muhammad Riaz $^{1}$
}

Received: 4 April 2016/Accepted: 3 October 2016/Published online: 17 October 2016

(c) The Author(s) 2016. This article is published with open access at Springerlink.com

\begin{abstract}
During the last two decades, group-IV metalsbased aminopyridinato complexes have attracted a tremendous research interest because of immense industrial needs for the catalyst which would be of higher activity and selectivity with lower toxicity and lower cost. Chemistry of titanium (Ti) and zirconium ( $\mathrm{Zr}$ ) complexes was more extensively explored as compared to hafnium (Hf) complexes. Direct synthesis, salt metathesis, amine elimination, alkane elimination, silyl chloride elimination, hydrogen chloride elimination and toluene elimination protocols have been used for the synthesis of group-IV metal complexes. Changes in ligand and complex design were made to optimize these catalysts for olefin polymerization. Most of these complexes have shown good catalytic activities when activated with dry methyl aluminoxane. Ligand transfer to aluminum was found in these complexes, particularly with less bulky ligands, and this ligand transfer problem was overcome by tridentate ligands but the activities of these complexes were not competitive to complexes with bidentate aminopyridinato ligands. Majority of these complexes produce high-molecularweight polymers with broader molecular weight distributions, and Hf-complexes produce longer chain polymers than their comparative $\mathrm{Ti}$ and $\mathrm{Zr}$ aminopyridinato complexes. It could be deduced that group-IV metals inherit the potential for optimal polymerizing catalysts probably, because of their almost vacant $d$-orbitals, these act as hard acids which on combination with soft bases carry the opportunity to design and develop polymerization catalysts
\end{abstract}

Muhammad Hafeez

smhafeezkhan@yahoo.com

1 Department of Chemistry, University of Azad Jammu and Kashmir, Muzaffarbad 13100, Pakistan which could overcome the problems associated with existing systems.

Keywords Group-IV polymerizing catalysts .

Aminopyridinato ligands · Homogenous catalysts .

Olefin polymerization

\section{Introduction}

Polymer-based products have become critical necessities ranging from household appliances to aerospace jets [1]. Global need for olefinic and other polymers is tremendously growing every year, for example, consumption of only polyethylene and polypropylene was 90,327 and 60,904 thousand metric tons, respectively, during the year 2014 [2]. Major industrial production of these polymers primarily utilizes group-IV metal catalysts [3-6]. A revolution was initiated by Zeigler and Natta by the discovery of group-IV metal catalysts due to their enormous industrial application which also inspired intensive research and development of these catalysts for olefin polymerization [4] that ultimately led to the development of group-IV metallocene catalysts for olefins polymerization using Alalkyls as co-catalyst [7-26]. Following breakthrough occurred in 1970 with the discovery of $\mathrm{Cp}_{2} \mathrm{TiCl}_{2} / \mathrm{AlMe}_{2} \mathrm{Cl}$ and $\mathrm{Cp}_{2} \mathrm{TiMe}_{2} / \mathrm{AlMe}_{3}$ catalysts, but their catalyzing abilities were low. The activity of $\mathrm{Cp}_{2} \mathrm{TiCl}_{2}$ enhanced to $424 \mathrm{~kg} \mathrm{PE}_{\mathrm{cat}} \mathrm{mol}^{-1} \mathrm{~h}^{-1}$ when small amount of water was added due to the formation of methyl aluminoxane (MAO) by the hydrolysis of Al-alkyls [27-50]. Industrial applications of metallocene-based catalysts have been tremendous; however, their limitations, for example, very high costs and inability to polymerize polar olefins, have forced the researches for alternatives, and amido ligands have 
been the most notable success because: (1) these ligands make two bonds with the metal resulting into a fourmembered chelate ring system and (2) they enable the incorporation of variety of functionality in remaining two substituents on $\mathrm{N}$-atom and hence to dictate variety in their reactivity and selectivity (Scheme 1) [28, 29, 51-65]. Aminopyridinato ligands could be derived from deprotonated 2-aminopyridines, critical sub-class of amido ligands, which could provide additional advantages due to their binding modes flexibility. Synthesis of the majority of group-IV metals catalysts utilizes salt metathesis, amine elimination, alkane elimination, silyl chloride elimination, hydrogen chloride elimination and direct synthesis [29]. Chemistry of $\mathrm{Ti}$ and $\mathrm{Zr}$-complexes in terms of their structural and olefin polymerization catalysis aspects has been studied more extensively than Hf-complexes [66-110]. Catalytic potential of Ti-complexes has been explored in ethylene, propylene and styrene polymerization, and copolymerization reactions. In the light of industrial applications and scientific interest, we are providing the relevant updates on group-IV metals complexes with aminopyridine ligands including general mechanism, structural aspects and application in olefin polymerization catalysis as well as other closely related relevant developments. We expect that it will serve the relevant scientific community for further enhancements.

\section{General mechanism of olefin polymerization using MAO}

Mechanism of polymerization catalyzed by group-IV metal catalysts is schematically illustrated below in Scheme 2 which includes activation, propagation and termination steps.

\section{Titanium complexes}

Kempe et al. have synthesized the first aminopyridinato Ticomplex in 1996 and their further research resulted into several Ti(IV) complexes [46, 47]. Some other researchers such as Markku, Smithies', Wheatley's and Sakai group have also synthesized the titanium complexes $[42,46]$. The main focus for the synthesis of titanium complexes was their coordination/organometallic chemistry as well as application in olefin polymerization and hydroamination
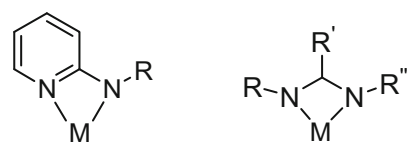

Scheme 1 Binding modes of aminopyridinato (left) and amidinato (right) ligands $\mathrm{M}=$ group 4 metal; $\mathrm{R}, \mathrm{R}^{\prime}, \mathrm{R}^{\prime \prime}=$ substituent) catalysis [45]. Mostly, the titanium precursor $\mathrm{TiCl}_{4}$ and lithium/sodium/potassium salts of the respective ligands have been employed and the mono/bis/tris/tetrakis-Ap-titanium complexes (depending upon the stoichiometric ratio of ligand and metal salt) have been synthesized, but mono/ bis complexes contain two cis chlorides and, hence, are more interesting for catalytic applications [42]. The neutral Ti-complexes have been converted into cationic complexes using methylaluminoxane (MAO) as co-catalyst [42]. The MAO is synthesized from controlled hydrolysis of $\mathrm{AlMe}_{3}$; however, all the molecules of $\mathrm{AlMe}_{3}$ are not converted into MAO and its traces remain unreacted (these traces either remain free in bulk of MAO or remain associated with MAO formula units) [47]. The MAO is available commercially in the form of its solutions in aromatic hydrocarbons. Some researchers have used commercial form for polymerization reactions, but the disadvantage of using this $\mathrm{MAO}$ as in case of aminopyridinato-Ti-complexes is its $\mathrm{AlMe}_{3}$ content which reacts with the active catalysts, and these are converted into the Ap-aluminum complexes which do not have the capability to polymerize olefins [44]. To reduce the free $\mathrm{AlMe}_{3}$ content (associated content could not be removed under vacuum) of the commercial MAO, some researchers have removed its volatiles (aromatic hydrocarbon $+\mathrm{AlMe}_{3}$ ) under vacuum, and the solid thus obtained was named as dry methylaluminoxane ( $d$-MAO). Although through this method, the $\mathrm{AlMe}_{3}$ content of commercial MAO could be minimized, its complete removal is not possible [44].

\section{Synthesis of Ti-catalysts with halogen-substituted aminopyridines}

Mono and bis(aminopyridinato) Ti-catalysts (1-3) containing 2-(2, 6-difluoroanilino)pyridine and 2-(2-chloroanilino)pyridine ligands have been synthesized by Markku and coworkers via salt metathesis (Scheme 3; Fig. 1) [42]. The reported yields of the complexes are 87-96\%, and these higher yields are plausibly due to single-step reaction with the formation of sodium chloride as the side product. The sodium chloride is insoluble in the organic solvents and could be easily separated resulting in the clean separation of the products. The sodium and potassium salts of the ligands are preferable for such synthesis because of the easy separation of corresponding metal salts through filtration. Instead, the use of lithium salts of ligands is less advantageous as one has to do repeated filtrations for the separation of the lithium chloride from the desired product. Previously, the salt metathesis protocol employing $n$-BuLi for synthesis of such complexes was considered less suitable because of the low yield of resulting complexes probably due to the reduction of $\mathrm{Ti}(\mathrm{IV})$ into $\mathrm{Ti}(\mathrm{III})$ by the lithiated ligand [47]. 
Scheme 2 Mechanism of group-IV metals catalysts catalyzed polymerization

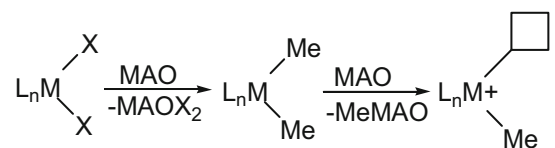

Activation of group (IV) complexes with MAO.

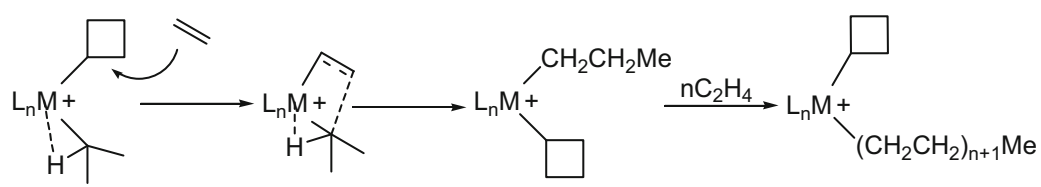

Chain propagation in olefin polymerization.

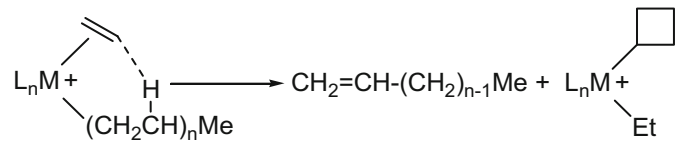

Chain transfer to monomer.

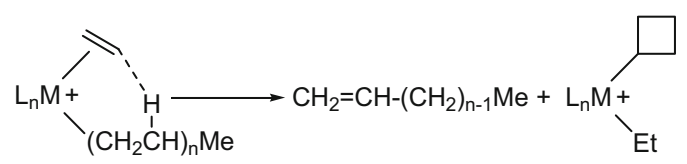

Chain transfer to aluminum.

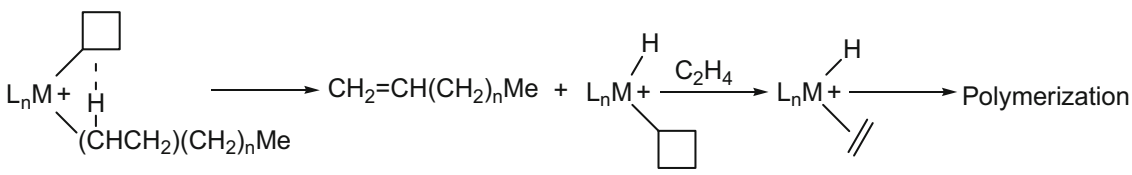

$\beta$-H elimination, termination of polymer chain growth.

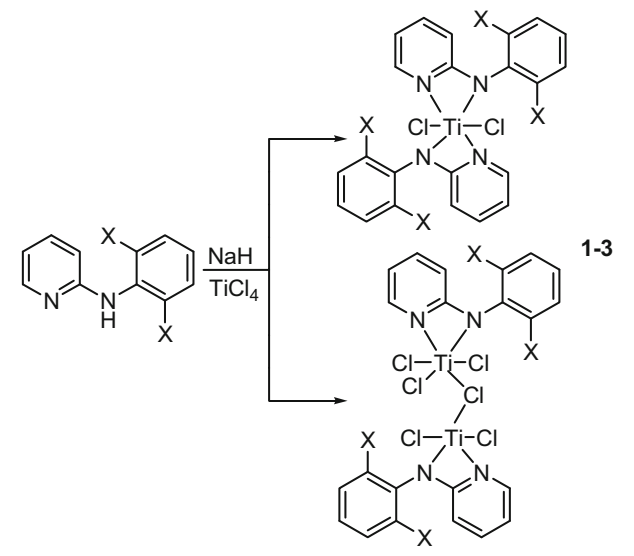

Scheme 3 Synthesis of Ti-complexes 1-3 (1, 2: $X=F, 3: X=H$ or $\mathrm{Cl})$

\section{Ethylene polymerization with Ti-complexes $1-3$}

The aminopyridinato-Ti-complexes have been employed for olefin polymerization. Different substituents such as alkyl, phenyl and silyl have been introduced on the aminopyridinato ligand, and each different substituent on the ligand framework affects the catalytic activity of the

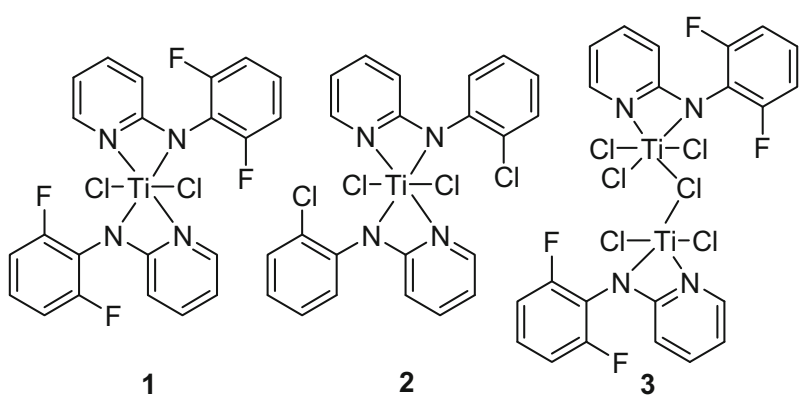

Fig. 1 Structures of Ti-complexes 1-3

resulting complex [42, 47]. The ligand framework also affects the molecular weight and molecular weight distribution (polydispersity) of the resulting polymers [42]. The silyl aminopyridinato-Ti-complexes when employed for ethylene polymerization have shown moderate activities. These complexes were also effective for the homopolymerization of propene and butene. Latter studies indicated that alkyl and phenyl groups were superior for enhancing catalytic activities as compared to silyl group [23].

Markku et al. have employed halogen (chloro or fluoro)containing phenylaminopyridinato-Ti-complexes (1-3) to 
catalyze ethylene polymerization with methylaluminoxane (MAO) as co-catalyst [42]. The maximum catalytic activity (640 kg PE mol $\mathrm{Kat}^{-1} \mathrm{~h}^{-1}$ ) was found for dimeric Ti-complex $\mathbf{3}$ and minimum activity was observed for complex 2 . These results indicate that in case of dimeric-Ap complexes, the fluoro substituent on ortho position has a beneficial effect for ethylene polymerization. Normally, electron-withdrawing groups at ortho position of the ligand are less beneficial for the activity of the complexes [42]. The fluoro ligand is electron-withdrawing by inductive effect and electron-donating by resonance effect, and might be during catalytic reaction, the latter effect is more operative to stabilize the active cationic metal center. Bulky ligands are also advantageous for stabilizing cationic metal center, but the steric bulk of the ligand in case of complex $\mathbf{3}$ is small and, hence, could not be linked with the observed catalytic activity [42]. However, a detailed theoretical and experimental investigation of such complexes is required to explore a structure-activity relationship. Complex 2 contains a chloro substituent on ortho position of each ligand and is least active for ethylene polymerization. The bis-Ap complex $\mathbf{1}$ was least active for ethylene polymerization (Table 1) [42]. Interestingly, the complex 3 afforded very long chain polymer $\left(M_{\mathrm{w}}=1,392,000 \mathrm{~g}\right.$ $\mathrm{mol}^{-1}$ ) when employed for polymerization at $80{ }^{\circ} \mathrm{C}$, but broader polydispersity (6.9) indicated that more than one catalytically active species were present in the reaction mixture. However, at lower temperature, the catalytic activity of complex 3 is lower (61-378 kg PE mol-Cat $\mathrm{h}^{-1}$ ), but it behaves as a single-site catalyst at this temperature, manifested by comparatively narrow molecular weight distribution of obtained polymers [42]. The melting points of all the polymers obtained with catalyst $\mathbf{1 - 3}$ are in the range of $133-136.7^{\circ} \mathrm{C}$ which are indicative of high-density polyethylene (HDPE).

\section{Synthesis of bis(alkylphenyl)titanium trichloride complexes}

The ligand framework controls the properties of a complex, and change of substituents on ligand could change the activity, selectivity, molar mass distribution as well as the chain length of resulting polymer. The alkyl substituents on aminopyridinato ligand could be beneficial for enhancing catalytic activity as well as for getting high-molecularweight polymers [29, 46]. Markku et al. have synthesized the alkyl-substituted aminopyridinato ligands and corresponding Ti-complexes (4-7) by treating the respective aminopyridinato ligand with $\mathrm{NaH}$ followed by reaction with $\mathrm{TiCl}_{4}$ [46] (Scheme 4; Fig. 2). The authors did not mention the yield of the ligands and complexes. As compared to ligands used for the synthesis of complexes 1-3, the ligands used for the synthesis of complexes 4-7 are bulkier, and both mono- and bis-Ap complexes are expected [46].

\section{Ethylene polymerization with Ti-complexes 4-7}

Ti-complexes 4-7 (Fig. 2) are mildly active for ethylene polymerization in the presence of methylaluminoxane (MAO) as a co-catalyst [46]. Mechanistically, alkyl substituent(s) near the $\mathrm{Ti}$ center restrict ethylene coordination, and hence, alkyl substituent(s) away from metal center enhance(s) catalytic activity [46]. Alkyl-substituted aminopyridinato Ti-catalysts were more active than nonsubstituted ones, probably due to electron-donating effect of alkyl groups which is helpful for stabilizing the cationic metal center. Maximum catalytic activity (48 kg PE $\mathrm{cat} \mathrm{mol}^{-1} \mathrm{~h}^{-1}$, Table 1) was observed with catalyst $\mathbf{6}$ but was lower than aminopyridinato complexes with adamantyl and trialkyl-silyl ligands because the latter ligands are more bulky $[42,46]$. Furthermore, it could be deduced from the molecular structure of the complex 6 that bulky groups on the para position of the ligand framework are advantageous for more catalytic activity as well as for getting higher molecular weight polymers $\left(M_{\mathrm{w}}=500,000 \mathrm{~g} \mathrm{~mol}^{-1}\right.$, Table 1) [46]. The alkyl substituents on the ligand also prevent the $\beta$-hydrogen elimination which causes an enhancement in chain elimination/termination ratio and thus giving long-chain polymers. In addition to this, these alkyl groups also lower the ethylene insertion transition state, and this phenomenon is also beneficial for greater polymer chain length [46]. The formation of polymers with higher polydispersities were observed for alkyl(phenylaminopyridinates) that could be rationalized to existence of both mono and bis(amino-pyridinato) Ti-complexes in the solution state, and possible ligand coordination with aluminum of $\mathrm{AlMe}_{3}$ as well as electron donation from amido nitrogen to Ti-metal center due to electron donation effect of alkyl groups [46]. Enhanced electron density from amido nitrogen, weakens (even breaking of this bond) the (pyridine)-N-Ti bond which produces mixture of complex conformations in solution state, and ultimately, this synthesizes polymers of various chain lengths [46]. Ti-pyridine-N bond for such systems is not very stable, and even during catalysis, this bond is broken and the ligand rotates around the amido nitrogen bond. Such a phenomenon has been explained by Kempe et al. in the form of $\mathrm{N}$-dissociation mechanism for bis-Ap complexes [23, 29]. In addition, sodium salt of the ligand may reduce the $\mathrm{Ti}(\mathrm{IV})$ into a mixture of $\mathrm{Ti}(\mathrm{III})$ which results into a mixture of $\mathrm{Ti}$ (III) and $\mathrm{Ti}(\mathrm{IV})$ complexes which produce polymer fractions of variable masses. Previously, bridged phenyl-aminopyridinato Ti-catalysts where the rotation around the pyridine nitrogen is blocked due to 
Table 1 Ethylene and styrene polymerization activity of Ti-aminopyridinato complexes

\begin{tabular}{|c|c|c|c|c|c|c|}
\hline Structure \# & Temp. $\left({ }^{\circ} \mathrm{C}\right)$ & Pressure (Bar) & Activity $\left(\mathrm{kg} \mathrm{PE} \mathrm{mol} \mathrm{Cat}^{-1} \mathrm{~h}^{-1}\right.$ ) & $M_{\mathrm{w}} \mathrm{g} \mathrm{mol}^{-1}$ & $M_{\mathrm{w}} / M_{n}$ & Co-catalyst and ratio \\
\hline 1 & 60 & 5 & 133 & 604,000 & 4.5 & MAO 3000 \\
\hline 2 & 80 & 8 & 56 & $1,392,000$ & 6.9 & MAO 3000 \\
\hline 3 & 60 & 5 & 640 & 344,000 & 12.4 & MAO 3000 \\
\hline 4 & 60 & 5 & 27 & 630,000 & 20.0 & MAO 3000 \\
\hline 5 & 60 & 5 & 47 & 390,000 & 20.3 & MAO 3000 \\
\hline 6 & 60 & 5 & 48 & 500,000 & 26.6 & MAO 3000 \\
\hline 7 & 60 & 5 & 30 & 390,000 & 22.9 & MAO 3000 \\
\hline 8 & 80 & 5 & 189 & 651,000 & 2.5 & MAO 3000 \\
\hline 9 & 60 & 5 & 95 & 239,000 & 2.4 & MAO 3000 \\
\hline 10 & 60 & 5 & 285 & 799,000 & 3.0 & MAO 3000 \\
\hline 11 & 80 & 5 & 1880 & 172,177 & 3.3 & MAO 500 \\
\hline 12 & - & - & - & - & - & - \\
\hline 13 & 30 & 5 & 2840 & 93,686 & 2.5 & MAO 500 \\
\hline 14 & 50 & 5 & 1320 & 67,190 & 2.3 & MAO 500 \\
\hline 15 & 50 & 5 & 960 & 89,093 & 2.7 & MAO 500 \\
\hline 16 & 50 & 5 & 880 & 63,716 & 2.9 & MAO 500 \\
\hline 17 & 80 & 2 & 540 & $1,275,000$ & 12.1 & MAO 500 \\
\hline $17^{\mathrm{a}}$ & 90 & - & 110 & 729,000 & 12.8 & MAO 500 \\
\hline 18 & - & - & - & - & - & - \\
\hline 19 & 80 & 2 & 620 & 482,000 & 11.6 & MAO 500 \\
\hline $19^{\mathrm{a}}$ & 90 & - & 240 & 68,800 & 2.2 & MAO 500 \\
\hline 20 & 80 & 2 & 280 & - & - & MAO 500 \\
\hline $20^{\mathrm{a}}$ & 90 & - & 76 & 68,200 & 2.0 & MAO 500 \\
\hline 21 & 80 & 2 & 380 & 729,000 & 12.8 & MAO 500 \\
\hline $21^{\mathrm{a}}$ & 90 & - & 100 & 72,700 & 3.6 & MAO 500 \\
\hline 22 & 80 & 2 & 296 & $1,323,000$ & 11.1 & MAO 500 \\
\hline $22^{\mathrm{a}}$ & 90 & - & 90 & 66,100 & 3.7 & MAO 500 \\
\hline 23 & - & - & - & - & - & - \\
\hline 24 & 80 & 2 & 180 & 206,000 & 7.2 & MAO 500 \\
\hline $24^{\mathrm{a}}$ & 90 & - & 46 & 49,500 & 4.0 & MAO 500 \\
\hline 25 & 30 & 2 & 28 & - & - & MAO 500 \\
\hline 26 & 60 & 10 & 124 & $2,030,000$ & 10.7 & MAO 2000 \\
\hline
\end{tabular}

a Styrene polymerization

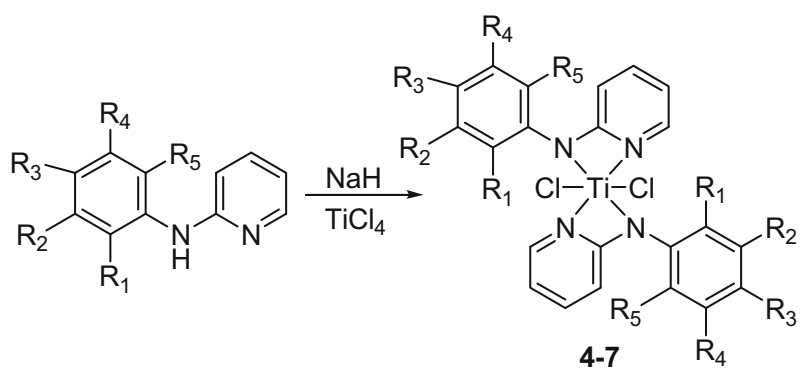

Scheme 4 Synthesis of Ti-complexes 4-7; 4 ( $\mathrm{R}_{1}=$ ethyl, $\mathrm{R}_{2}=\mathrm{R}_{3}$ $\left.=R_{4}=R_{5}=H\right), 5\left(R_{1}=R_{2}=R_{4}=H, R_{3}=R_{5}=\right.$ methyl $), 6$ $\left(\mathrm{R}_{1}=\mathrm{R}_{2}=\mathrm{R}_{4}=\mathrm{R}_{5}=\mathrm{H}, \mathrm{R}_{3}=\mathrm{n}\right.$-propyl), $7\left(\mathrm{R}_{1}=\mathrm{R}_{2}=\mathrm{R}_{3}=\mathrm{R}_{4}\right.$ $=\mathrm{H}, \mathrm{R}_{5}=$ t-butyl) peculiar structure of the ligand have been found to be useful to control the polydispersity issue [14, 19].

\section{Synthesis of Ti-complexes with 2-phenylaminopyridine ligands}

The examples of the mono-ApTiCl 3 complexes are rare. The previous efforts for the synthesis of such complexes were unsuccessful, and, instead of $\mathrm{ApTiCl}_{3}$ complex, resulted into the formation of $\left[\mathrm{ApH}_{2}\right]^{+}\left[\mathrm{ApTiCl}_{4}\right]^{-}$salt [42]. Recently, Markku et al. have synthesized Ap-trichloro complex (8) by treating the ligand precursor 2-phenylaminopyridine and $\mathrm{TiCl}_{4}$ in equal molar ratio under $\mathrm{HCl}$ 


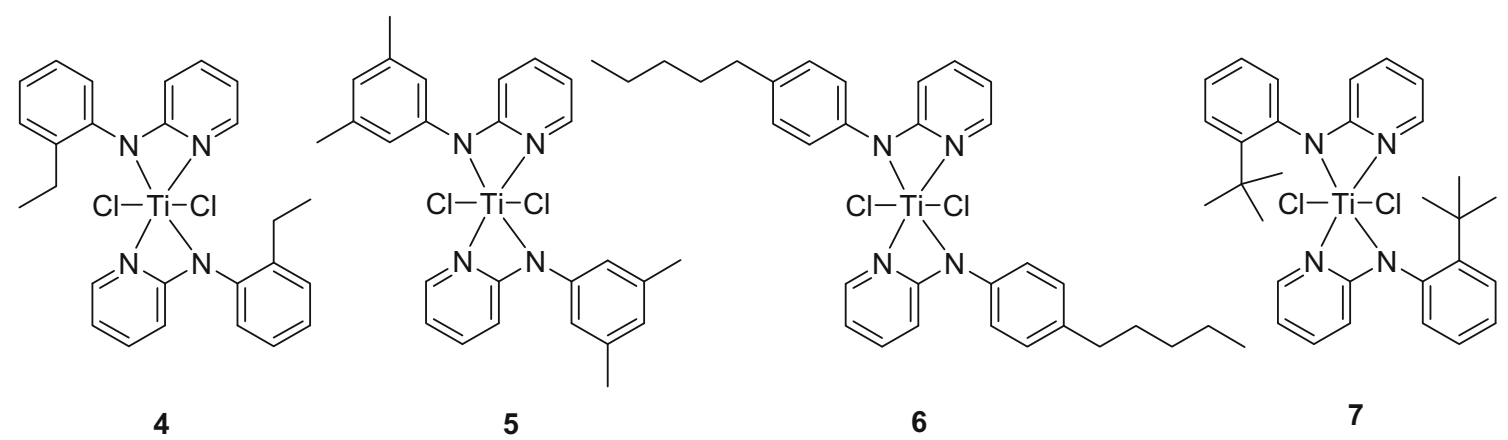

Fig. 2 Structures of Ti-complexes 4-7

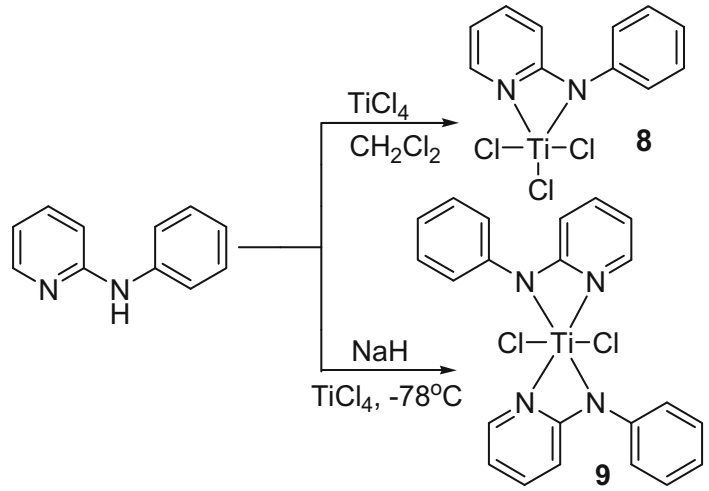

Scheme 5 Synthesis of Ti-complexes 8, 9

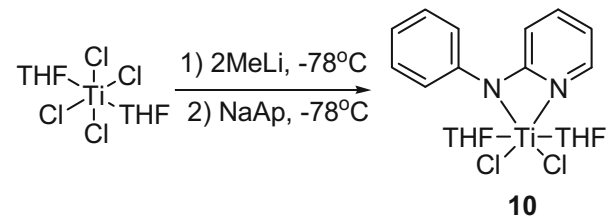

Scheme 6 Synthesis of Ti-complex 10

elimination reaction (Scheme 5) [39]. To avoid the salt formation, the ligand solution was added dropwise to the $\mathrm{TiCl}_{4}$ solution, and in such addition method, first, the pyridine part of the ligand coordinates with the metal followed by the bond formation with amido nitrogen. However, removal of second chloride to synthesize a bis-Ap complex with the same procedure was not possible. To synthesize bis-Ap complex (9), the ligand was first deprotonated using $\mathrm{NaH}$, and then, sodium salt of the ligand was reacted with $\mathrm{TiCl}_{4}$ (Scheme 5) [39]. Whereas complex 10 was synthesized by reacting the $\mathrm{TiCl}_{4}(\mathrm{THF})_{2}$ with two equivalents of MeLi and subsequent reaction with sodium salt of aminopyridine ligand (Scheme 6) [39]. Crystal structure of complex 9 has no symmetry elements, and the overall geometry of the complex is distorted octahedral due to presence of two four-membered chelate rings of the two aminopyridinato ligands (Fig. 3). Cl1-Ti1$\mathrm{Cl} 2$ angle $\left(97.03^{\circ}\right)$ is wider compared to similar angle in

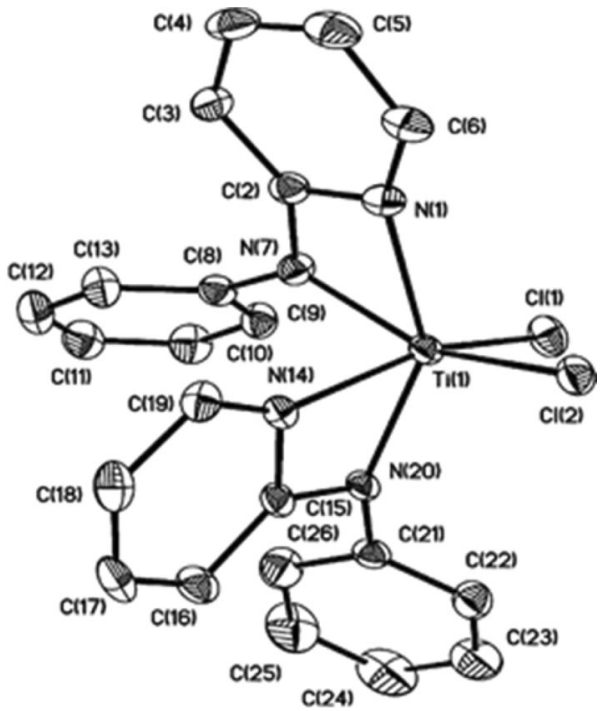

Fig. 3 Molecular structure of complex 9

$\mathrm{Cp}_{2} \mathrm{TiCl}_{2}\left(94.43^{\circ}\right)$ and indicates a comparatively less-hindered Ti-metal center in the latter [39]. Higher yield of complex $8(87 \%)$ is attributed to clean elimination of $\mathrm{HCl}$ gas unlike the poor yield of complex $9(5 \%)$ perhaps due to the formation of side products (for example $\mathrm{Ap}_{3} \mathrm{TiCl}$ ). A better yield of the 9 could be achieved by adding $\mathrm{TiCl}_{4}$ in a flask followed by the slow addition of ligand [39]. Poor yield of complex $10(14 \%)$ is linked to the reduction of Ti(IV) into Ti(III) during the reaction. The complex 8 could be synthesized at room temperature; however, complexes $\mathbf{9}$ and $\mathbf{1 0}$ require very low temperature $\left(-78^{\circ} \mathrm{C}\right)$ which limits the synthesis of these complexes on large scale [39].

\section{Ethylene polymerization with Ti-complexes 8-10}

Cationic complexes were obtained using dry MAO as cocatalyst for ethylene polymerization [39]. High-molecularweight polyethylene with narrow molecular weight distribution was obtained. The open structure of these complexes 
[because of wider angle $\left(97.03^{\circ}\right)$ between the chloro groups attached to metal center] is not helpful for chain elimination, and hence, it favors for obtaining the long-chain polymers (Fig. 3). Higher polymerization activities were observed compared to similar reported complexes [29]. Ti(III) catalyst (10) was more active $\left(285 \mathrm{~kg} \mathrm{PE} \mathrm{cat} \mathrm{mol}^{-1} \mathrm{Ti}^{-1} \mathrm{~h}^{-1}\right)$ than more electron-deficient Ti(IV) catalysts $(\mathbf{8}, \mathbf{9})$ which could be rationalized to comparatively low Lewis acidity of Ti(III) complex (Table 1). In addition to this, complex $\mathbf{1 0}$ has two coordinated THF which could be released during catalytic reaction, and the resulting catalyst has more space for incoming monomer, and hence, activity would be higher [39]. The molecular weight distribution of the polymers is in the range of (2.5-4.2) which indicates that catalysts 8-10 behave close to a single-site catalyst during polymerization. This observation is contradictory to catalyst $\mathbf{1 - 7}$, where broader molar mass distribution was observed. High molecular weight $\left(804,000 \mathrm{~g} \mathrm{~mol}^{-1}\right)$ was obtained for complex 8 when 5 bar pressure and $60{ }^{\circ} \mathrm{C}$ temperature were employed. However, keeping the same pressure and increasing the temperature to $80{ }^{\circ} \mathrm{C}$ decreased the molecular weight $\left(M_{\mathrm{w}}=651000 \mathrm{~g} \mathrm{~mol}^{-1}\right)$ of the polymer [39]. Hence, it could be inferred that high pressure and comparatively low temperature are beneficial for getting highmolecular-weight polymers.

It is important to note that the polymerization activities of Ap complexes, the molar masses and molar mass distribution of the resultant polymers depend upon a number of factors such as $\mathrm{MAO} /$ catalyst ratio, the free trimethylamine content of the MAO and other important factors such as temperature, solvent, stirring rate and size of the reactor used for olefin polymerization [39, 42, 46]. So, it is suggested that the catalysts should be tested with variation of these factors so that the real catalytic potential could be evaluated. In addition to this, the group (IV) complexes of these ligands, particularly Ti ones, are highly air- and moisture-sensitive, and much care is required to set the conditions that the particular catalyst remains intact till the start of polymerization reaction [29, 39, 42, 46].

\section{Synthesis of Ti-complexes with bulky aminopyridine ligands}

The aminopyridinato ligands-based Ti-complexes had certain limitations such as lower activity, broader molar mass distribution of the polymers, ligand transfer to aluminum atom of $\mathrm{AlMe}_{3}$ and higher amount of co-catalyst (MAO) required for the polymerization reaction [29, 42, 46]. Kempe et al. assumed that increasing the steric bulk of the aminopyridinato ligand could address these problems and synthesized Ti-complexes with bulky Ap ligands [37]. Such bulky Ap ligands could be synthesized in higher yields by $\mathrm{Pd}(0)$-catalyzed coupling reactions of anilines with 2,6-dibromopyridines. Prior to complex formation reaction, the ligands are converted into their lithium/sodium/potassium salts by reacting the corresponding ligand with $n$-BuLi or with sodium and potassium hydride [37, 55]. Equimolar reaction of potassium salt of aminopyridine [ $\mathrm{N}$-(2,6-diisopropylphenyl)-[6-(2,4,6-triisopropylphenyl)pyridin-2-yl-amine $]$ and $\left[\mathrm{TiCl}_{4}(\mathrm{THF})_{2}\right]$ gave the tetrahydrofuran ring-opening product $\mathbf{1 1}$ in $68 \%$ yield (Scheme 7) [37]. Plausibly, free chloride is generated during reaction which attacks on the activated $\mathrm{C}-\mathrm{O}$ bond of THF causing ring-opening reaction, and such a reaction for Ti was recently reported by Kempe et al., whereas previous reports were based upon zirconium, boron, uranium and yttrium complexes [48]. The literature has revealed that lithiated aminopyridine or the lithium salt of the aminopyridine ligand gave poor yield of the desired product probably due to reduction of Ti(IV), and using potassium salt of the ligand instead of lithium salt improves the yield [29, 42, 46]. Main disadvantage of using potassium salt is the ring-opening reaction of coordinated THF. Also, using potassium salt of the aminopyridine ligand has been proved to be an efficient method for the synthesis of lanthanide complexes [56, 60, 61]. The coordinated THF with the metal center enhances its reactivity as well as solubility in organic solvents, and hence, use of $\mathrm{TiCl}_{4}$ $(\mathrm{THF})_{2}$ is suggested for such reactions instead of $\mathrm{TiCl}_{4}$. The synthesis of complex 12 was achieved by treating two

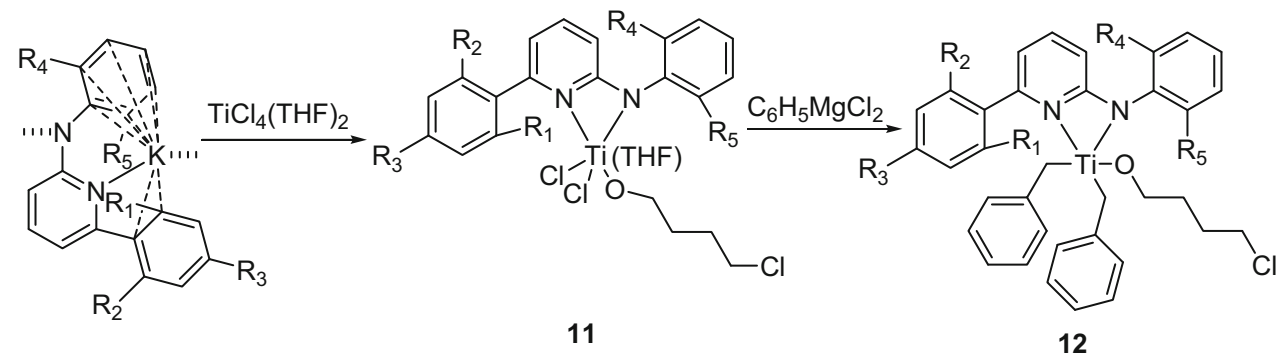

Scheme 7 Synthesis of Ti-complexes $\left(\mathrm{R}_{1}=\mathrm{R}_{2}=\mathrm{R}_{3}=\mathrm{R}_{4}=\mathrm{R}_{5}=\right.$ isopropyl $)$ 


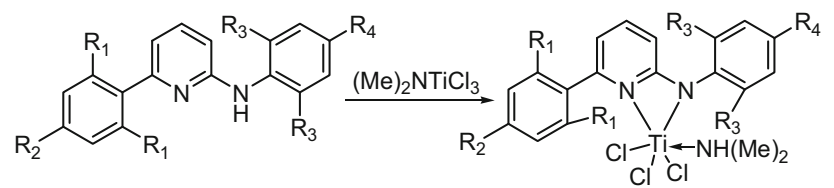

Scheme 8 Synthesis of Ti-complexes 13-16; $13\left(R_{1}=R_{2}=R_{3}=i-\right.$ Pr, $\left.\quad R_{4}=H\right), \quad 14 \quad\left(R_{1}=M e, \quad R_{3}=i-P r, \quad R_{2}=R_{4}=H\right), \quad 15$ $\left(\mathrm{R}_{1}=\mathrm{R}_{2}=\mathrm{i}-\mathrm{Pr}, \mathrm{R}_{3}=\mathrm{R}_{4}=\mathrm{Me}\right), \mathbf{1 6}\left(\mathrm{R}_{1}=\mathrm{R}_{2}=\mathrm{R}_{3}=\mathrm{R}_{4}=\mathrm{Me}\right)$

equivalents of benzylmagnesium chloride with 11 [37]. The yield of the complex $\mathbf{1 2}$ is only $47 \%$, and such a lower yield is attributed to the formation of side products.

Aminopyridine ligand was reacted with dimethylamidotitanium-trichloride to synthesize mono(aminopyridinato)titanium trichloride complexes through amine elimination which gave complexes 13-16 in high yields (Scheme 8). The liberated amine makes bond with the proton released from ligand framework and again coordinates with the metal center resulting into six coordinated Ti-complexes and the examples of such complexes with aminopyridinato ligands are rare [29, 39, 46].

\section{Olefin polymerization with Ti-complexes 11-16}

Ti-complexes (11-16, Fig. 4) were employed for ethylene and propylene polymerization and copolymerization of their monomers and found that mono(aminopyridinato)-Ti-complexes remained stable for the whole reaction time $(15 \mathrm{~min})$ with a slight decrease in activity over the time [39]. These catalyst systems are less active when activated with commercial MAO but activity improved by using dry MAO [39]. Temperature increase enhanced the activity (2840 kg PE mol cat. $\mathrm{h}^{-1}$ ) of Ti-complex 13 (having a bulkier ligand), whereas its other complexes (14-16) with less bulky ligands were comparatively less active [39]. Introduction of an alkoxy ligand (alkoxy ligand is the result of ring-opening reaction of coordinated THF) in $\mathbf{1 1}$ decreased its activity $\left(1880 \mathrm{~kg} \mathrm{PE} \mathrm{mol} \mathrm{lat}_{\text {at. }}^{-1} \mathrm{~h}^{-1}\right)$ as compared to 13 , probably due to steric crowding and electronic effects of alkoxy group. Hence, with these catalyst systems, the steric bulk of the ligand is a decisive factor for the olefin polymerization activity. The catalysts 11 and $\mathbf{1 3}$ to $\mathbf{1 6}$ possess higher polymerizing ability than similar Ti-complexes which is believed to be due to the steric bulk of the bulkier ligands [39]. However, catalyst $\mathbf{1 3}$ showed less activity $\left(200 \mathrm{~kg} \mathrm{PE} \mathrm{mol}_{\text {cat }}^{-1} \mathrm{~h}^{-1}\right)$ for propylene polymerization, but its activity was enhanced $\left(32,000 \mathrm{~kg} \mathrm{PE}\right.$ mol $\left._{\text {cat. }}^{-1} \mathrm{~h}^{-1}\right)$ by the addition of ethylene which produced a high-molecularweight polymer $\left(M_{\mathrm{w}}=104,374 \mathrm{~g} \mathrm{~mol}^{-1}\right)$ copolymer with narrow molecular weight distribution (2.1) [39]. Replacing propylene by 1-hexene did not afford 1-hexene-ethylene copolymer, and, instead, enhanced the polymerization activity $\left(33,000 \mathrm{~kg} \mathrm{PE} \mathrm{mol}_{\text {cat. }}^{-1} \mathrm{~h}^{-1}\right)$ and its mechanism investigation would be interesting. Catalyst $\mathbf{1 6}$ is less active $\left(14,600 \mathrm{~kg} \mathrm{PE} \mathrm{mol}_{\text {cat. }}^{-1} \mathrm{~h}^{-1}\right)$ for this copolymerization as compared to 13 , and such a behavior is attributed to less steric bulk of the attached ligand. Also, cyclic olefin monomers such as dicyclopentene, norbornene and 5-ethylidene2-norbornene have been used for copolymerization reactions [39]. Introduction of 2-ethylidenenorbornene (ENB) to ethylene using $\mathbf{1 3}$ with dry MAO resulted in a glassy transparent polymer. The activity of $\mathbf{1 3}$ for this polymerization was found $11,400 \mathrm{~kg} \mathrm{PE} \mathrm{mol}$ cat. $^{-1} \mathrm{~h}^{-1}$. Terpolymerization was achieved by reducing the amount of ENB and introducing propylene into the system which gave a rubber-like polymer [39]. Although these catalysts have shown good activities for ethylene homopolymerization, yet the resultant polymers have low molecular weight as, for example, the complex 13 produced polymer with $M_{\mathrm{w}}=172,177 \mathrm{~g}$ $\mathrm{mol}^{-1}$. The complexes 11-16 produced polymers with narrow molecular weight distribution (2.3-3.3). It is believed that the catalysts having molar mass distribution equal to 2 are real single-site catalysts [4]. Keeping in mind this definition, the catalytic behavior of complexes 11-16 is close to

Fig. 4 Structures of Ticomplexes 11-16

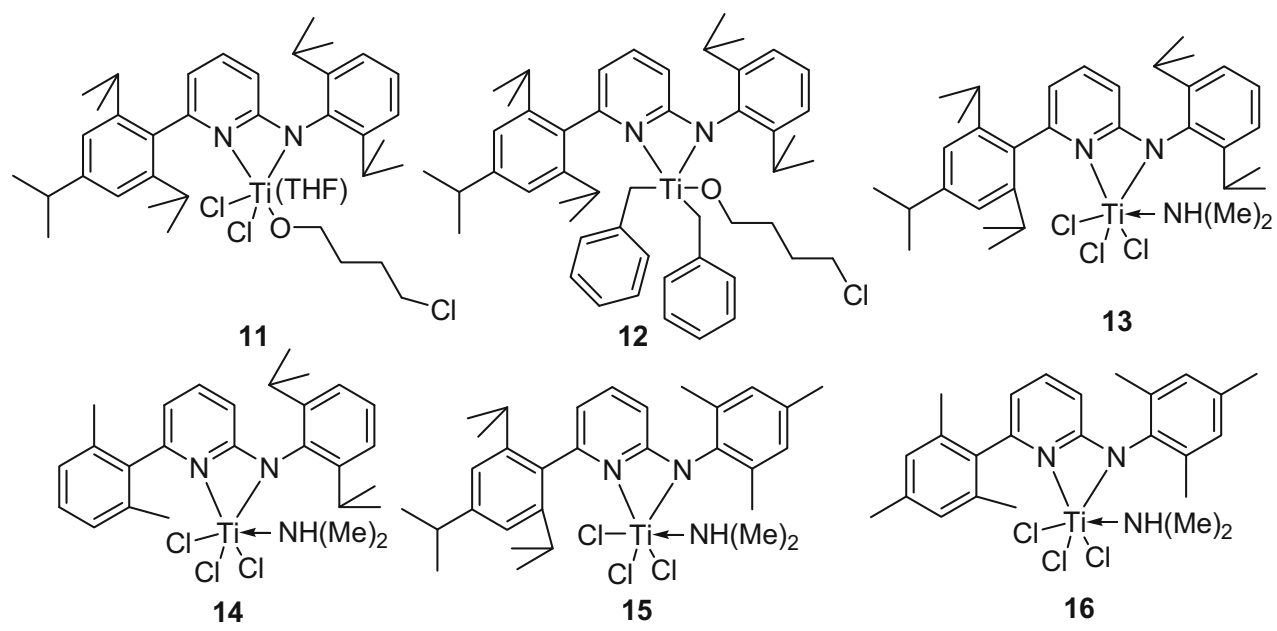


Scheme 9 Electron rich aminopyridine ligands<smiles>[R]c1cccc(N[Al]N[Al]=[Fe])n1</smiles>

single-site catalysts. Even further low molecular weight distribution (1.9-2.4) was observed for ethylene-propylene, ethylene-propylene-norbornene and propylene-norbornene copolymers obtained from these catalysts [39]. Hence, it could be inferred that these catalyst systems act as a singlesite catalyst for polymerizing comparatively bulky monomers particularly in copolymerization reactions. The catalysts 11-16 have the advantage that a lower catalyst-to-MAO ratio (1:500) is required, whereas for similar reported catalysts (1-10), a higher catalyst-to-MAO ratio was used for ethylene polymerization.

\section{Synthesis of Ti-complexes with electron-rich bulky ligands}

Electron-rich bulky ligands were prepared by reacting 2, 6-dichloropyridine with respective aniline (2, 6-diisopropylaniline or 2, 4, 6-trimethylaniline) through in situ generated $\mathrm{Ni}(0)$ catalyst, and that was followed by thermal amination with corresponding N-heterocycle (piperidine, morpholine and pyrrolidine) at elevated temperature $\left(180{ }^{\circ} \mathrm{C}\right)$ (Scheme 9; Figs. 5, 6) [44]. Ni(0)-catalyzed reaction makes feasible the alkylation of 2 ,

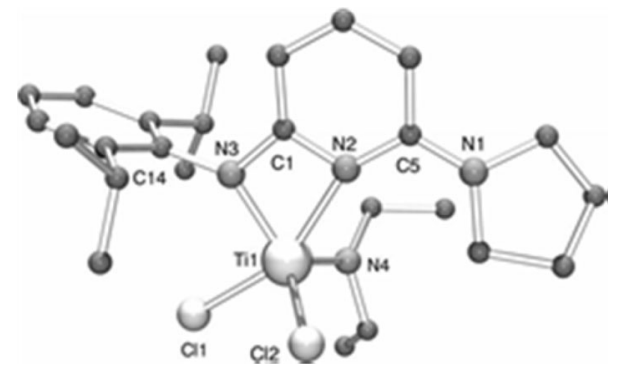

Fig. 5 Molecular structure of Ti-complex 20 6-dichloropyridine with corresponding aniline. Major advantages of this reaction are cost-effective $\mathrm{Ni}(0)$ catalyst and shorter reaction time, though poor yield $(\sim 45 \%)$ is a main disadvantage. However, thermal amination reaction of chloroaminopyridine with respective $\mathrm{N}$-heterocycle afforded the corresponding aminopyridine ligands in higher yields (83-89 \%) [44]. Other advantages of such a synthesis are the transition metal catalysts-free coupling of $\mathrm{N}$-heterocycle with the chloroaminopyridine and easy separation of solid byproducts (ammonium salt of corresponding N-heterocycle) by filtration.

Introduction of two amines on the pyridine ring enhances the electron-donating ability of the ligands (Scheme 10) which has also been indicated through crystal structure of complexes $(\mathbf{1 7}, \mathbf{2 0}, \mathbf{2 3})$, and the sum of angles around nitrogen of $\mathrm{N}$-heterocycle is $353^{\circ}-360^{\circ}$ (for example, the sum of bond angles in complex $\mathbf{2 0}=360^{\circ}$, Fig. 5) which reveals $\mathrm{sp}^{2}$ hybridization of $\mathrm{N}$-atom. Lone pair of nitrogen is involved in resonance with the $\pi$ electrons of pyridine ring and, hence, increases the electrondonating capability of pyridine nitrogen [44].

${ }^{1} \mathrm{H}-\mathrm{NMR}$ studies at lower temperature indicated an increased rotation barrier which is evidenced for higher electron density between nitrogen of N-heterocycle (piperidine, morpholine and pyrrolidine) and carbon of pyridine fragment. Such higher electron density could be expected with the involvement of lone pair of electron present on $\mathrm{N}$-heterocycle (for example piperidine) with the carbon of pyridine ring to make a pi bond (one sigma and a pi bond formation results in a double bond between these atoms). The presence of such a double bond could be confirmed by low-temperature proton NMR studies. In case of single bond, the piperidyl fragment gives three signals for protons due to its fast rotation around the piperidine- $\mathrm{N}-$

Fig. 6 Structures of Ticomplexes 17-24
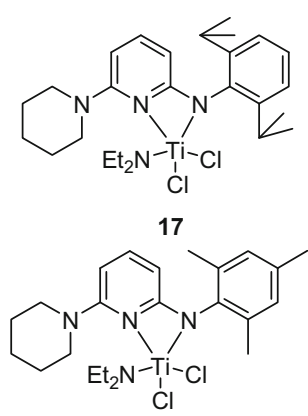

21<smiles></smiles>

18

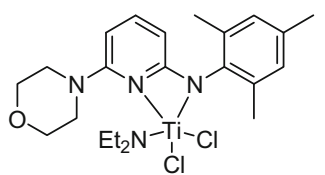

22

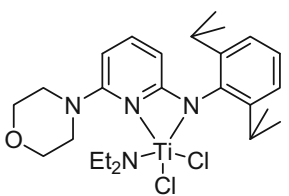

19

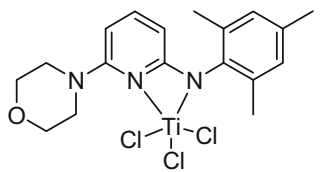

23

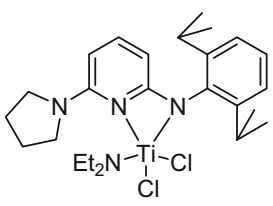

20

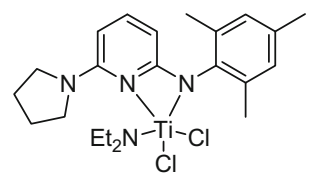

24

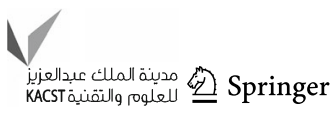




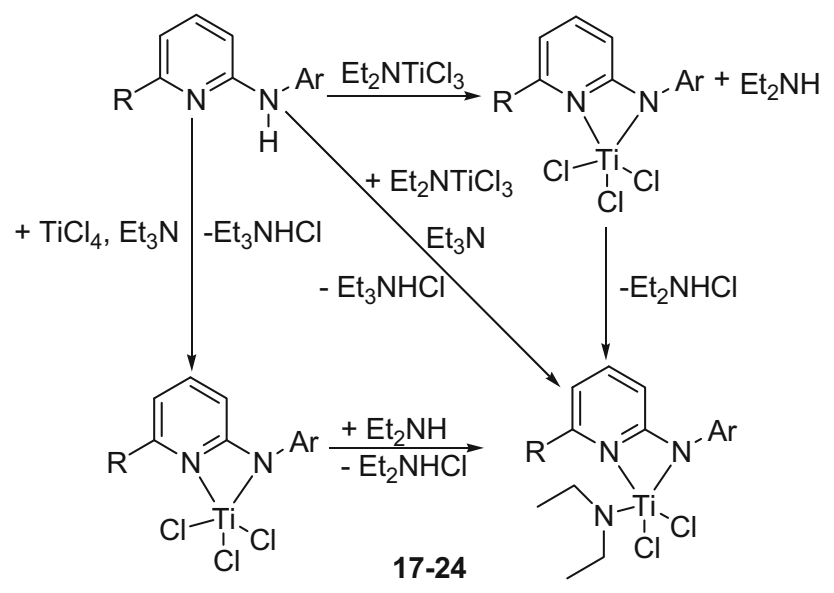

Scheme 10 Synthesis of Ti-complexes 17-24

C-pyridine bond. In case of formation of double bond between piperidine- $\mathrm{N}$ and pyridine- $\mathrm{C}$ atom, the electron could be delocalized and the double-bond character could not be confirmed experimentally; however, such a delocalization could be stopped at lower temperature $(-50$ to $-40{ }^{\circ} \mathrm{C}$ ). In such a situation, the piperidyl fragment could not rotate due to double-bond formation (piperidine- $\mathrm{N}=\mathrm{C}$ pyridine bond) and affords five signals for piperidyl fragment. Phenyl-substituted aminopyridinato complexes of group (IV) metals catalysts were found unstable when activated with MAO for olefin polymerizetion and that is believed to be due to the weaker pyridine-N-metal bond. Authors hypothesized that increasing electron donation capability of pyridine-N would result into more stable group-IV metal complexes which could polymerize the olefins in the presence of MAO [44]. Ti-complexes (17-24) with electron-rich aminopyridine ligands were synthesized by reacting the corresponding ligand with the $\mathrm{Et}_{2} \mathrm{NTiCl}_{3}$ or $\mathrm{TiCl}_{4}$ at room temperature, and the molecular geometry of these complexes was found to be distorted trigonal bipyramidal by their single-crystal $\mathrm{X}$-ray diffraction analysis (Fig. 5). Lower yields (45-49 \%) were observed for diethylamidotitanium trichloride complexes and were rationalized to the simultaneous formation of both $\mathrm{Ap}\left(\mathrm{Et}_{2} \mathrm{~N}\right) \mathrm{TiCl}_{2}$ and $\mathrm{ApTiCl}_{3}$ complexes $(\mathrm{Ap}=$ aminopyridine $)$. That was also confirmed by reacting aminopyridine ligand with $\mathrm{Et}_{2} \mathrm{NTiCl}_{3}$ in the presence of double amount of diethylamine and that resulted into exclusive formation of $\mathrm{ApTiCl}_{3}$ complex (Scheme 10) [44]. The selective and high yield (75\%) of the $\mathrm{ApTiCl}_{3}$ complex is also possible by reacting the Ap ligand with $\mathrm{TiCl}_{4}$ in the presence of tri-ethylamine [44]. In such a reaction, tri-methylamine acts as a stronger base and is helpful for the abstraction of $\mathrm{HCl}$ and, thus, promoting the complex formation. Main advantage of this synthesis is the elimination of small molecule (diethylamine) as by-product. However, long time required to remove the released amine under vacuum and formation of two different Ticomplexes $\left[\mathrm{Ap}\left(\mathrm{Et}_{2} \mathrm{~N}\right) \mathrm{TiCl}_{2}\right.$ and $\left.\mathrm{ApTiCl}_{3}\right]$ are disadvantageous because their separation is a tedious job, in addition to their poor yields. Importantly, selective formation of $\mathrm{ApTiCl}_{3}$ could be achieved by using the double amount of diethylamine (Scheme 10) [44].

\section{Ethylene polymerization with Ti-complexes 17-24}

The Ti-complexes 17-24 were employed for ethylene and styrene polymerization. The ethylene polymerization was made in small-sized reactor, while styrene polymerization was carried out in glass bottles $(100 \mathrm{~mL}$ each) inside the glove box [44]. The Ti-complexes 17-24 were inactive for ethylene polymerization in the presence of commercial MAO (co-catalyst); however, moderate activities were observed with dry methyl aluminoxane (dry-MAO) as cocatalyst [44]. Inactivity of these catalysts was found to be due to the use of commercial MAO (containing free $\mathrm{AlMe}_{3}$ ) which induces ligand transfer from catalyst to Alatom of $\mathrm{AlMe}_{3}$ during polymerization [44]. Activity increased with increasing steric bulk of the aminopyridinato ligand as well as increasing temperature (Table 1). The maximum ethylene polymerization activity (620 kg PE mol cat. ${ }^{-1}$ ) was observed with complex 19. If we see the molecular structure of this complex, there are certain structural features which make this complex more active. The ligand in case of this complex is bulkier and, hence, is helpful to stabilize the cationic metal center and gives higher activity. Although dry MAO has been employed for these polymerization reactions, even small traces of $\mathrm{AlMe}_{3}$ remain to be present in dry MAO as well. This $\mathrm{AlMe}_{3}$ deactivates the catalyst by reacting with the Ap ligand through pyridine nitrogen. However, in case of complex 19, the additional binding site in the form of morpholine oxygen is also present which could be helpful for reacting with $\mathrm{AlMe}_{3}$, thus enhancing the catalyst life in the reaction mixture and resulting into higher catalytic activity [44]. These catalysts were active for ethylene polymerization but were stable only for few minutes. The nitrogen of $\mathrm{N}$-heterocycle (piperidine, morpholine and pyrrolidine) increases the electron-donating ability of aminopyridinato ligand, but free trimethylaluminum of MAO coordinates with this nitrogen as well. Resultantly, the aminopyridinato-Ti-complex is converted into aminopyridinato-Al-complex or heterobimetallic complex which has been confirmed (NMR scale reactions) by the formation of hetero-bimetallic complex by the reaction of aminopyridinato ligand with trimethylaluminum [44]. Broader polydispersities of obtained polymers also indicated the presence of several active species (presumably due to the decomposition of catalyst) during the reaction $[42,44]$. The polymers obtained were of higher molecular 
weight than the polymers obtained with complexes containing bulky aminopyridinato ligands (13-16); hence, it could be inferred that more electron donation from ligand to the metal center is beneficial for obtaining high-molecular-weight polymer [39, 44]. The complex 17 gave very high molecular weight polymer $\left(M_{\mathrm{w}}=1,275,000 \mathrm{~g}\right.$ $\mathrm{mol}^{-1}$ ). However, some amounts of low-molecular-weight fractions were also observed. ${ }^{1} \mathrm{H}-\mathrm{NMR}$ studies of the lowmolecular-weight polyethylene fraction indicated fully saturated polymer, and this behavior is only possible when the polymer chain is terminated with aluminum which, upon hydrolysis, gives fully saturated material [44].

\section{Styrene polymerization with Ti-complexes 17-24}

The examples of the styrene polymerization with aminopyridinato ligands are rare, and recently, Ti-aminopyridinato complexes containing electron-rich ligands have been applied for styrene polymerization and their catalytic activity increased as a function of temperature, and maximum activity was observed at $90{ }^{\circ} \mathrm{C}[39,42,44]$, because increase in temperature enhances the alkylation on catalyst from MAO which is favorable for higher activity (Table 1). Their catalytic activity also increased with increasing the steric bulk of the ligand; however, their activities were lower than closely related amidinate-Ti-complexes [48-51]. The maximum catalytic activity $\left(240 \mathrm{~kg} \mathrm{PE} \mathrm{mol} \mathrm{mat}^{-1} \mathrm{~h}^{-1}\right)$ was observed with the Ti-catlayst 19. This catalyst was also quite active for ethylene homopolymerization and its activity for styrene polymerization is plausibly due to its stability in the presence of $\mathrm{AlMe}_{3}$ [44]. Broader polydispersities of the polymers were indicative of the presence of several catalytically active species in the reaction medium. However, interestingly, complexes 19 and $\mathbf{2 0}$ behaved as a single-site catalyst as manifested by their comparatively narrow molecular weight distribution values (2.2 and 2.0, respectively). Though these catalysts were less active for styrene polymerization, they synthesized polymers of high molecular weight, for example, Ti-complex 17 produced polymer having $M_{\mathrm{w}}=729,000 \mathrm{~g} \mathrm{~mol}^{-1}$ [44]. Electron-donating ligands stabilize the Ti-complexes which slow down the chain transfer rate and, resultantly, produce longer chain polymers. Tacticity of obtained polymers was found to be syndiotactic when ${ }^{1} \mathrm{H}$ and ${ }^{13} \mathrm{C}$-NMR (these spectra were measured at $80^{\circ} \mathrm{C}$ ) spectra of the polymers were compared with reported spectra of these polymers [48-51, 57, 60, 61].

\section{The stability of Ti-complexes in the presence of MAO}

The controlled hydrolysis of $\mathrm{AlMe}_{3}$ generates MAO, but it cannot be fully hydrolyzed and its traces remain unreacted. Rationally, free $\mathrm{AlMe}_{3}$ might be responsible for instability of these complexes and, hence, for lower activity towards olefin polymerization, because it fastly reacts with these complexes and form aluminum aminopyridinato complex or hetero-bimetallic complexes $[15,44]$. To confirm this hypothesis, ${ }^{1} \mathrm{H}$ NMR scale reactions were made, in which Ti-complexes reacted faster with $\mathrm{AlMe}_{3}$ resulting into the corresponding methyl complexes $\left(\mathrm{ApAlMe}_{2}\right)$ and heterobimetallic species [44].

\section{Ti-complexes with bulky tridentate ligands}

The literature reports of Ap complexes with oxazolinefunctionalized ligands are rare, and recently, Ti-complex 25 was synthesized by treating oxazoline-functionalized aminopyridinato ligand with $\mathrm{Et}_{2} \mathrm{NTiCl}_{3}$ in a moderate yield (43\%) (Scheme 11) [33]. A plausible reason of low yield for this complex is the formation of two types of complexes: one in which Ap ligand may coordinate with its two nitrogen atoms and one in which all the three nitrogen atoms of the ligand are attached with the Ti metal center. It could be hypothesized that the introduction of a third donor atom in ligand framework (nitrogen atom of oxazoline moiety) in the form of oxazoline moiety could overcome the problem of ligand transfer from metal to Al atom of Alalkyl. Therefore, a tridentate aminopyridinato ligand, instead of bidentate aminopyridinato ligand, in the presence of Al-alkyls, could result into more active Ti-catalysts for ethylene polymerization [33].

\section{Ethylene polymerization with Ti-complex 25}

Catalyst $\mathbf{2 5}$ was found inactive for ethylene polymerization when $\mathrm{AlMe}_{3}$-containing MAO was used for generation of cationic species [33]. Activation of this catalyst with dry MAO also gave moderate activity $\left(28 \mathrm{~kg} \mathrm{PE} \mathrm{mol}_{\text {cat. }}^{-1} \mathrm{~h}^{-1}\right.$, Table 1) similar to the other reported Ti-complexes containing planar tridentate ligands [52, 53]. The planar structure of the catalyst is supportive for ethylene coordination which enhances the formation of higher molecular weight polymers. This catalyst was active for the entire reaction time which indicated a less active but stable catalyst. Mechanistically, third coordinating atom gives stability to the catalyst in the presence of Al-alkyls but, probably, blocks the coordination site for ethylene insertion and hence, less ethylene polymerization activity [33].

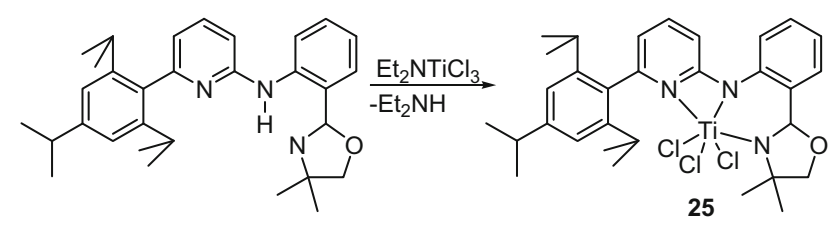

Scheme 11 Synthesis of Ti-complexes with tridentate ligands 


\section{Synthesis of Ti-complexes with aminosilyl-substituted aminopyridinato ligands}

Xin-E Duan et al. have reported the synthesis of Ti-complexes with aminosilyl-substituted aminopyridinato ligands. $\quad N-[(N, N$-dimethylamino $)$ dimethylsilyl $]-2$-pyridylamine was treated with $n$-BuLi to obtain $N-[(N, N-$ dimethylamino)dimethylsilyl]-2-pyridyl amidate which, upon second reaction with $n$-BuLi, afforded the corresponding lithium salt which, upon treating with $\mathrm{TiCl}_{4}(-$ $\mathrm{THF})_{2}$, afforded dinuclear complex (26) with elimination of two $\mathrm{Me}_{2} \mathrm{NMe}_{2} \mathrm{SiCl}$ molecules through a mechanism similar to the removal of $\mathrm{Me}_{3} \mathrm{Si}$ group (Scheme 12) [35]. This elimination of $\mathrm{Me}_{2} \mathrm{NMe}_{2} \mathrm{SiCl}$ group is, perhaps, because of small ionic radius of the Ti-cation and higher Lewis acidity. Aminopyridinato ligands are coordinated to Ti-metal center in typical $\eta^{2}$ manner as well as in bridging mode, giving a unique status to this molecule in the entire class of Ti-aminopyridinates [29, 35].

Coordinating $\mathrm{N}$-atoms and pyridyl rings in $\mathbf{2 6}$ were found to be coplanar (distorted pentagonal bipyramidal geometry of the molecule) which results in conjugation in the entire molecule and is, presumably, responsible for extra stability of the molecule [35]. The N-Ti bond lengths in $\mathbf{2 6}$ are similar to already reported Ti-complexes with aminopyridinato ligands, but coordination sphere of two Ti-atoms in this complex is different (one $\mathrm{Ti}$ is sevencoordinated, while second $\mathrm{Ti}$ is six-coordinated) [29, 42, 46] (Fig. 7).

The yield of the complex (26) is moderate (48\%); however, its synthesis involves multiple steps. In addition to this, very low temperature $\left(-78^{\circ} \mathrm{C}\right)$ is required for complex synthesis [33]. These shortcomings limit the industrial-scale synthesis of these compounds. Some more ligands containing substituted aminopyridines and corresponding titanium complexes could be synthesized to check the olefin polymerization potential of these complexes. Careful choice of solvent, other reaction conditions and handling practices could improve the overall yield of the complexes.

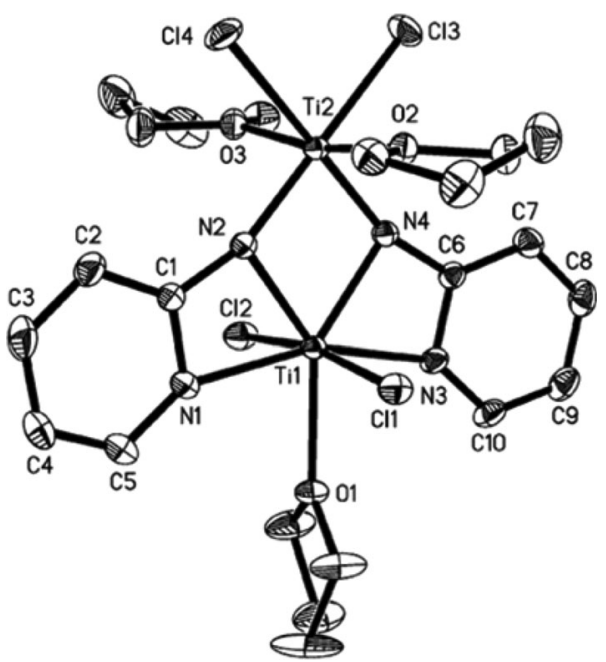

Fig. 7 Molecular structure of complex 26

\section{Ethylene polymerization with Ti-complex 26}

Ti-complex 26 was activated with MAO for polymerization of ethylene, and the effect of various factors such as temperature and MAO-to-metal ratio was studied, and optimum activity (124 kg PE mol cat. $\mathrm{h}^{-1}$ ) was observed at $60{ }^{\circ} \mathrm{C}$ [33]. Ti-catalyst 26 was found to be more active than catalysts with less bulky ligands (catalysts 1-10 and 17-24) [33]. However, the activity is still not good enough, because a higher pressure of ethylene (10 bar) as well as a higher catalyst-to-MAO ratio (1:2000) has been used. Notably, for catalyst 26, the activity as well as molecular weight of the polymer increased with increasing catalystto-MAO ratio [33]. Catalyst $\mathbf{2 6}$ produced higher molecular weight polymer $\left(M_{\mathrm{w}}=11,600 \mathrm{~g} \mathrm{~mol}^{-1}\right)$ than similar $\mathrm{Ti}$ and $\mathrm{Zr}$-catalysts and is attributed to its planar structure which facilitates the co-ordination of ethylene [49-53]. However, broader polydispersities indicated the presence of several catalytically active species in the reaction mixture, and a detailed theoretical as well as experimental investigation is required for enhancing the catalytic
Scheme 12 Synthesis of Ticomplexes 26, 31

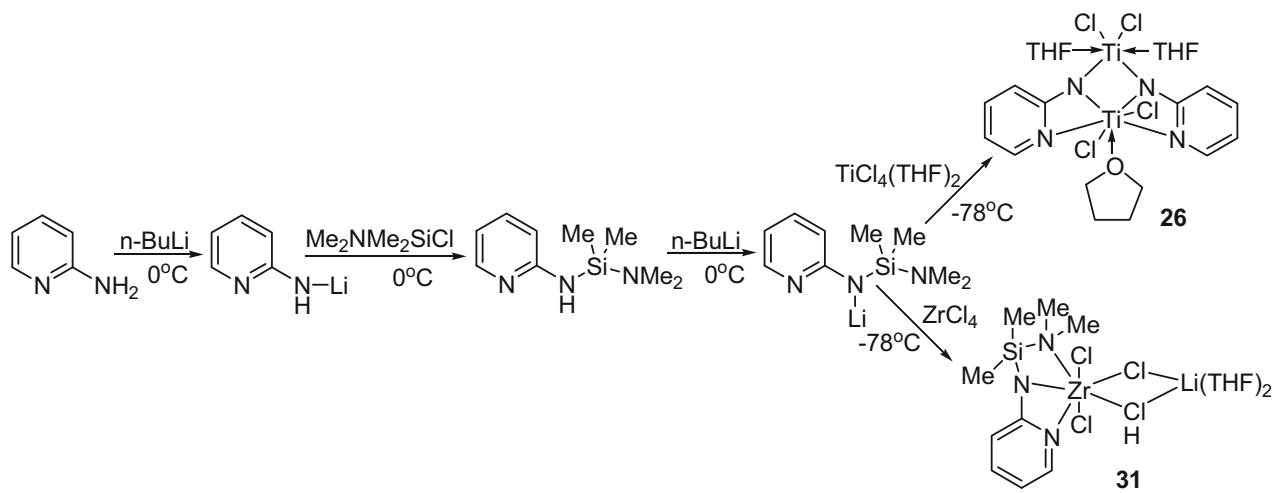


potential of such complexes and to control the polydispersity index [33].

\section{Synthesis of acetylene Ti-complexes stabilized by aminopyridinato ligands}

In the literature, there are examples of acetylene Ti-complexes-stabilized cyclopentadienyl complexes, and such examples of Ti-complexes with Ap ligands are rare [29, 42, 46]. Recently, Kempe et al. have reported an acetylene complex stabilized by Ap ligands. Complex 27 was synthesized by treating two equivalents of $2-[(2$, 6-diisopropyl-phenyl)amino]pyridine ligand and one equivalent of bis(dimethyl)amido titanium trichloride (Scheme 13) [32]. This reaction proceeds with the elimination of diethylamine molecule and the major advantage of this synthesis is the high yield $(95.67 \%)$ of the target complex. [32]. Kempe et al. reported the first example of aminopyridinato ligand-stabilized acetylenetitanium complex. This complex was synthesized by treating complex 27 with bis(trimethylsilyl)-acetylene in the presence of magnesium (Fig. 8). Such complexes were reported earlier for cyclopentadienyl ligand [27]. In complex 27, aminopyridinato ligand is coordinated with $\mathrm{Ti}$ in a strained fashion $[\mathrm{N}-$ Ti-N angle $\left.=64.22(18)^{\circ}\right]$. The acetylenic carbon atoms and silicon atoms form a planar orientation (Fig. 8). The bond length of coordinated acetylene $[\mathrm{C} \equiv \mathrm{C}(1.338$ (13) $\AA]$ is longer than the normal $\mathrm{C} \equiv \mathrm{C}$ bond $(1.181 \AA)$, and the value is close to $\mathrm{C}=\mathrm{C}$ bond length $(1.331 \AA)$. Average $\mathrm{C}-$ Ti distance of the coordinated carbon atoms is 2.090 (7) $\AA$. Carbon-carbon-silicon bond angle is $138.9(2)^{\circ}$ and that is indicative of an $\mathrm{sp}^{2}$-hybridized C-atom [32].

In this reaction, magnesium metal acts as a reducing agent and reduces $\mathrm{Ti}(\mathrm{IV})$ complex to $\mathrm{Ti}(\mathrm{II})$ complex, and during this reaction, magnesium chloride is produced as a by-product. The reported yield for this complex is $45 \%$. The low yield of the target complex shows the less

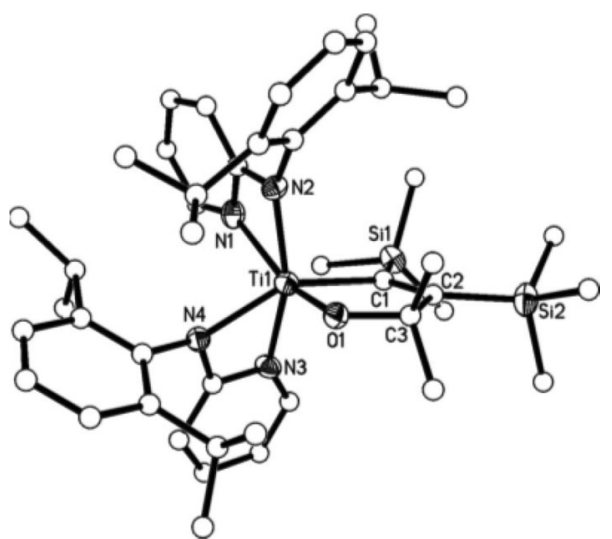

Fig. 8 Molecular structure of complex 30

conversion of $\mathbf{2 7}$ to $\mathbf{2 8}$. In addition to this might be the reaction proceeds with the formation of side products (for example, aminopyridinato magnesium complex). Such complexes were also reported earlier for cyclopentadienyl ligand [27]. Catalyst $\mathbf{2 8}$ has shown insertion reaction with acetone and afforded titanaoxacyclopentene as a product. The major advantage of this reaction is the fast conversion of reactants into the product at room temperature and high yield of the resulting product. Reduction of compound $\mathbf{2 7}$ with $\mathrm{KC}_{8}$ afforded Ti-complex $\mathbf{2 9}$ containing three $\mathrm{Ap}$ ligands. The overall yield of this compound was found to be very low (only $12 \%$ ). This low yield of the complex could be attributed to the formation of bis-Ap complex (containing two Ap ligands). In addition to this, for such a reduction reaction, $\mathrm{KC}_{8}$ is used in large excess [32]. This is a porous material and it adsorbs a large amount of product. Anyhow, the yield could be improved by washing the residue several times with excess of $n$-hexane. Another limitation of this reaction is the preparation of $\mathrm{KC}_{8}$. This reaction proceeds by heating $\left(80^{\circ} \mathrm{C}\right)$ potassium metal and graphite powder for several hours along with fast stirring
Scheme 13 Synthesis of Ticomplexes 27-30

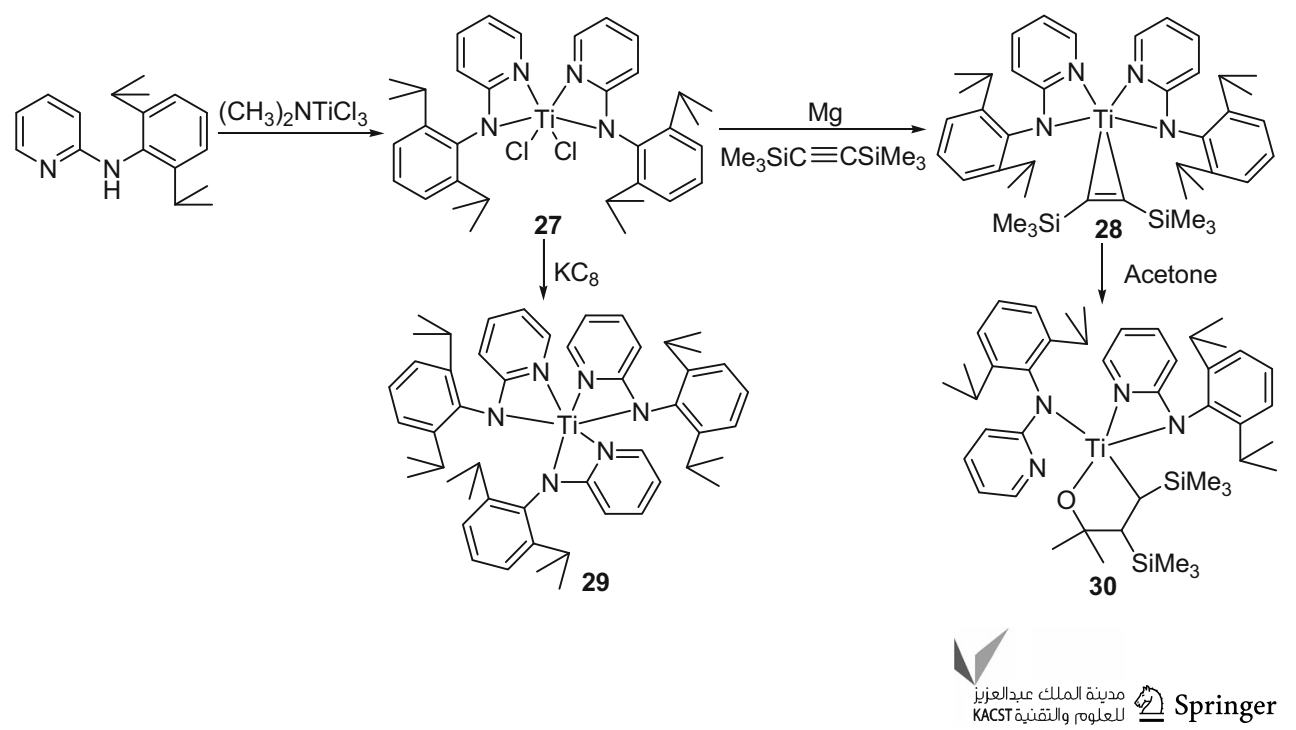


and requires extreme care as potassium metal becomes pyrophoric with heating [27, 32].

\section{Ethylene polymerization with Ti-complexes 27-30}

Cationic complex could be generated from complex 27 with the removal of chloride and, hence, could be used for olefin polymerization [32].

\section{Zirconium complexes}

In recent years, the zirconium chemistry with regard to aminopyridinato ligands has received much attention. The main focus was on the synthesis of new complexes with the variation of ligand steric bulk, and mono, bis, tris and tetrakis(aminopyridinato) complexes have been synthesized $[20,24,26]$. The main advantage for the synthesis of such complexes was the development of coordination/ organometallic chemistry of these complexes and their application in olefin polymerization. Different protocols have been applied for the synthesis of $\mathrm{Zr}$-complexes, and salt metathesis and toluene elimination reactions were found to be more advantageous due to the higher yield of the resulting complexes $[20,24,26,30]$.

\section{Synthesis of Zr-complexes with aminosilyl- substituted aminopyridinato ligands}

Recently, aminosilyl-substituted $\mathrm{Ti}$ and $\mathrm{Zr}$-complexes were synthesized and applied as polymerization catalysts to tailor a variety of new polymers. Zr-complex $\mathbf{3 1}$ was synthesized through a similar procedure applied for Ti-complex 26 (Scheme 12) [35]. Complex 31 is mononuclear in which aminopyridinato ligand is attached with $\mathrm{Zr}$ metal center in a strained $\eta^{2}$-coordination mode. Interesting structural features of monoanionic tridentate ligand used for the synthesis of complex 31 include: anionic $\eta^{2}$ functionality $\left(\eta^{2}\right.$-aminopyridinato) of this ligand and a neutral donating amino group with three asymmetric nitrogen atoms. Third nitrogen donor in case of tridentate ligands gives additional stability to the metal complexes and catalytic intermediates (Fig. 7) [35]. Unlike Ti-complex 26, the $\mathrm{Me}_{2} \mathrm{NMe}_{2} \mathrm{SiCl}$ group remains intact in the ligand structure which is probably due to larger ionic radius of $\mathrm{Zr}$ and lower Lewis acidity [35]. Overall geometry of this complex is distorted pentagonal bipyramidal, and coordinated nitrogen, adjacent carbon, silicon atoms and pyridyl ring are co-planar with $\mathrm{Zr}$-metal center [35]. The yield of this complex is lower (41\%), possibly due to the formation of some side products. Very low temperature $\left(-78{ }^{\circ} \mathrm{C}\right)$ for the reaction and low yield are the main disadvantages of this synthesis.

\section{Ethylene polymerization with Zr-complex 31}

Ethylene polymerization experiments were made by activating Zr-catalyst 31 with $\mathrm{MAO}$, and catalytic activity increased with temperature and catalyst-to-MAO ratio [35]. Maximum activity $\left(152,000 \mathrm{~kg} \mathrm{PE} \mathrm{mol}\right.$ Cat. $\left.^{-1} \mathrm{~h}^{-1}\right)$ was observed at $70{ }^{\circ} \mathrm{C}$ using catalyst-to-metal ratio (1:2500), and at this optimum temperature $\left(70{ }^{\circ} \mathrm{C}\right)$, further increase in catalyst-to-MAO ratio decreased the activity. Hence, it could be inferred that catalyst is stable thermodynamically up to $70{ }^{\circ} \mathrm{C}$, and beyond this temperature, it decomposes which lowers the catalytic activity. This catalyst system gives high-molecular-weight $\left(M_{\mathrm{w}}=1,380,000 \mathrm{~g} \mathrm{~mol}^{-1}\right)$ polymers which could be attributed to its planar structure, and such a structure facilitates the chain propagation. The broader polydispersities of the polymers are plausible due to the presence of other catalytically active species and poor solubility of the catalyst $\mathbf{3 1}$ in the reaction medium [35].

\section{Synthesis of dimeric Zr-complex with ansa- bis(aminopyridinato) ligand}

The group (IV) metal complexes bearing bridged bis(amidinato) ligands proved to be the good polymerization catalysts and attracted the other researchers to synthesize similar bis-Ap ligands containing an alkyl-silyl bridge and corresponding $\mathrm{Zr}$-complexes [29, 33]. Such a ligand system would be more electron-deficient and, when attached with a metal center, could drag the electron density from metal resulting in an enhancement in its electrophilic character (Fig. 9) [36]. Ligand precursor $\left(\mathrm{H}_{2} \mathrm{~L}\right)$ was synthesized by lithiation of 2-aminopyridine and subsequent reaction with 1, 2-bis(chl-orodimethylsilyl)ethane which was lithiated to give dilithium aminopyridine salt that, upon treating with $\mathrm{ZrCl}_{4}$, afforded the dimeric complex 32 (Scheme 14) [36, 54-56]. Each Zratom in $\mathbf{3 2}$ is hepta-coordinated and is linked by chloro bridges that results in a planar bimetallic core skeleton similar to already reported complexes [29]. The main limitation of this reaction is the very low temperature $\left(-78^{\circ} \mathrm{C}\right)$, and hence, the complex could not be synthesized on commercial scale. However, higher yield $(81 \%)$ of the complex 32 is the main advantage of this reaction. In addition to this, the compound $\mathbf{3 2}$ has shown luminescent character under UV light, and further investigations are required to find its applications in electroluminescence field [36]. Catalyst $\mathbf{3 2}$ would be more active for ethylene polymerization as compared to tris-(aminopyridinato) complexes, because only one ligand containing four donor atoms is attached with metal center (leaving more space for monomer to reach the metal center), whereas in tris(aminopyridinato) complexes, six atoms are attached with 


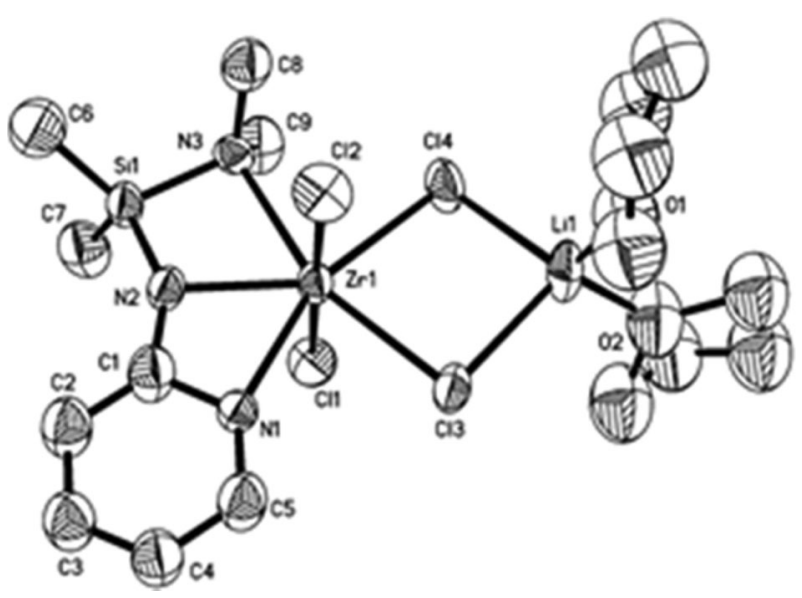

Fig. 9 Molecular structure of $\mathrm{Zr}$-complex 32

metal center, consequently making the latter more sterically hindered and, hence, less active for ethylene polymerization. [36].

\section{Ethylene polymerization with Zr-complex 32}

In previous studies, Kempe et al. have applied ansabis(aminopyridinato)Ti complexes for ethylene polymerization, and maximum activity $\left(6.28 \mathrm{~kg} \mathrm{PE} \mathrm{mol}\right.$ Cat. $\left.^{-1} \mathrm{~h}^{-1}\right)$ has been reported with these complexes [47]. Catalyst 32 was also used for ethylene polymerization using MAO as co-catalyst at room temperature and atmospheric pressure [36]. Catalytic activity was $181 \mathrm{~kg} \mathrm{PE} \mathrm{mol} \mathrm{Cat}^{-1} \mathrm{~h}^{-1}$ which is lower than $\mathrm{Cp}_{2} \mathrm{ZrCl}_{2}\left(627 \mathrm{~kg} \mathrm{PE} \mathrm{mol} \mathrm{Cat}^{-1} \mathrm{~h}^{-1}\right)$ standard but better than tris(aminopyridinatozirconium) complexes $\left(110 \mathrm{~kg} \mathrm{PE} \mathrm{mol}\right.$ Cat. $\left.^{-1} \mathrm{~h}^{-1}\right)$, presumably because of less coordinating atoms and less steric crowding on $\mathrm{Zr}$-atom in the former case [36, 47]. Dimeric complex (more sterically crowded) breaks down into monomeric form during the reaction that probably provides more space to $\mathrm{Zr}$-atom for ethylene coordination [36]. However, this complex could be very interesting for ethylene polymerization studies with the variation of experimental conditions. The complex could show better catalytic performance by increasing the temperature as well as catalyst-to-MAO ratio.

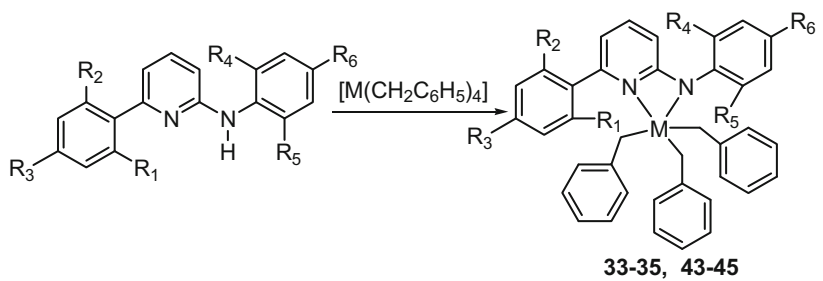

Scheme 15 Synthesis of $\mathrm{Zr} / \mathrm{Hf}$ tribenzyl complexes with bulky ligands; 33/43 $\left(\mathrm{R}_{1}=\mathrm{R}_{2}=\mathrm{R}_{3}=\mathrm{R}_{4}=\mathrm{R}_{5}=\right.$ isopropyl, $\left.\mathrm{R}_{6}=\mathrm{H}\right)$, 34/44 $\left(R_{1}=R_{2}=\right.$ methyl, $R_{3}=R_{6}=H, R_{4}=R_{5}=$ isopropyl), 35/45 $\left(\mathrm{R}_{1}=\mathrm{R}_{2}=\mathrm{R}_{3}=\right.$ isopropyl, $\mathrm{R}_{4}=\mathrm{R}_{5}=\mathrm{R}_{6}=$ methyl), 33$35(\mathrm{M}=\mathrm{Zr}), \mathbf{4 3}-\mathbf{4 5}(\mathrm{M}=\mathrm{Hf})$

\section{Synthesis of Zr-trialkyl complexes with bulky aminopyridinato ligands}

Tri-benzyl $\mathrm{Zr} / \mathrm{Hf}$ complexes could be synthesized through toluene elimination route which gives mono-amino-pyridinato- $\mathrm{Zr} / \mathrm{Hf}$ complexes unlike salt metathesis reactions that produce bis-aminopyridinato complexes of these metals $[24,30]$. Furthermore, toluene elimination route is an attractive choice because of higher yield of the complexes and easy removal of by-product (toluene). Zr-complexes (33-35) were synthesized by treating the corresponding aminopyridine ligand with tetrabenzyl zirconium at room temperature (Scheme 15) [30, 57]. Crystal structures of these compounds showed that one of the benzyl is $\eta^{2}$-coordinated; however, in solution form, all the three benzyls are equal and molecular geometry of all these complexes is distorted octahedron [30]. Longer bond lengths of pyridine$\mathrm{N}-\mathrm{Zr}$ and shorter ones of amido- $\mathrm{N}-\mathrm{Zr}$ are indicative of localized bonding. Anionic charge is localized on amido nitrogen atom which results into a classic amido- $\mathrm{Zr}$ bond rather than amidopyridinate form (Fig. 10). Zr-catalysts (33-35) were reacted with $\mathrm{B}\left(\mathrm{C}_{6} \mathrm{~F}_{5}\right)_{3}$ to synthesize zwitterionic complexes (Scheme 16). ${ }^{1} \mathrm{H}-\mathrm{NMR}$ indicated that phenyl ring of borate moiety is coordinated with $\mathrm{Zr}$-metal center, and these complexes have similar structures both in solid (confirmed by crystal structure) as well as liquid phase. Crystal analysis of compound 37 showed that [ApZr $\left.\left(\mathrm{CH}_{2} \mathrm{C}_{6} \mathrm{H}_{5}\right)_{2}\right]^{+}$cation is $\pi$-coordinated to the $\mathrm{BCH}_{2}$ $\mathrm{C}_{6} \mathrm{H}_{5}$ moiety of $\left[\mathrm{B}\left(\mathrm{CH}_{2} \mathrm{C}_{6} \mathrm{H}_{5}\right)-\left(\mathrm{C}_{6} \mathrm{~F}_{5}\right)_{3}\right]^{-}$anion $[30,58]$.
Scheme 14 Synthesis of dimeric $\mathrm{Zr}$-complex 32 with ansa-bis(aminopyridinato) ligand

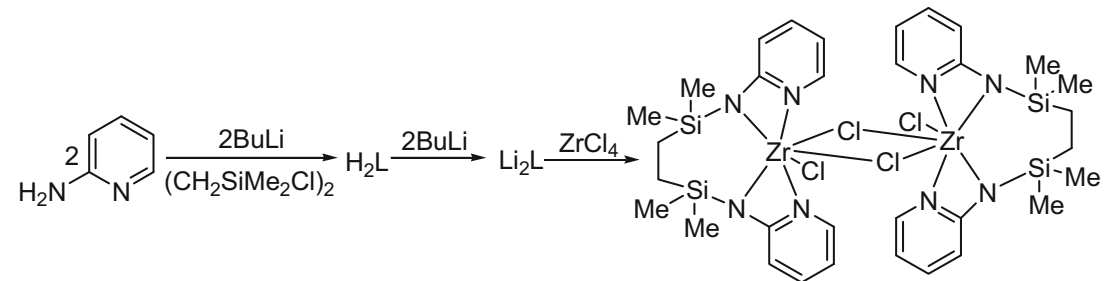

32

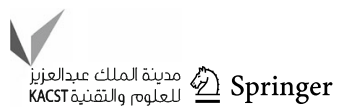



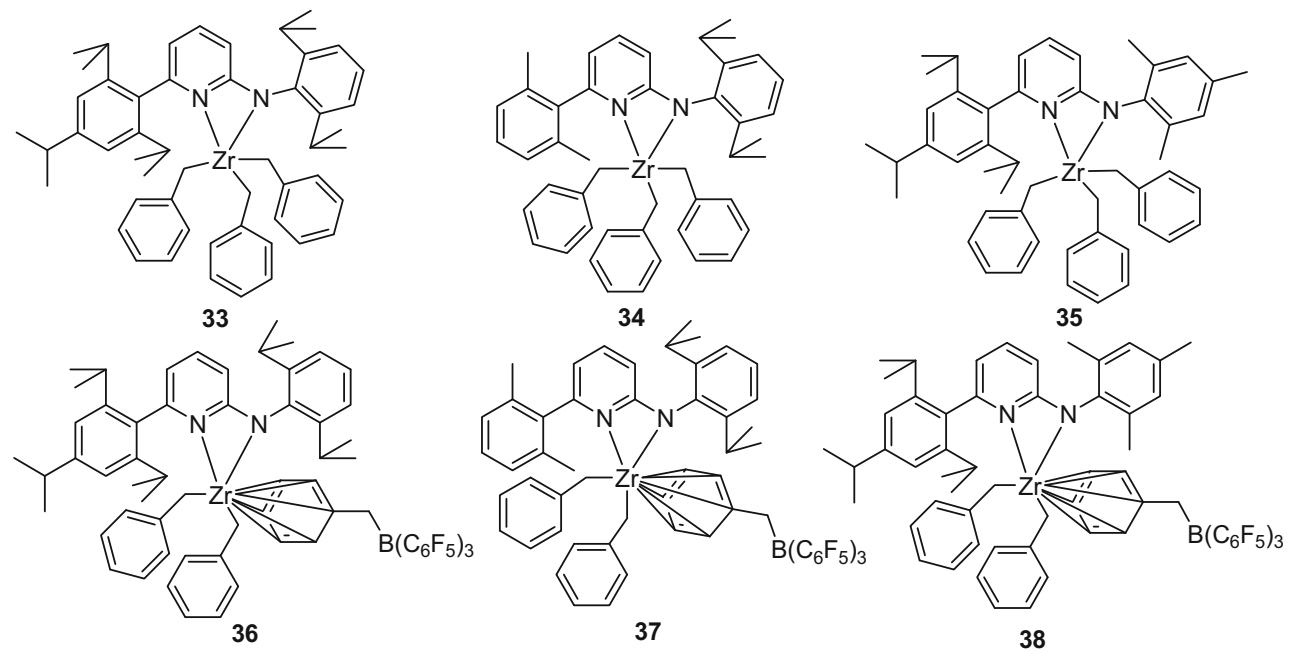

Fig. 10 Structures of $\mathrm{Zr}$-complexes 33-38

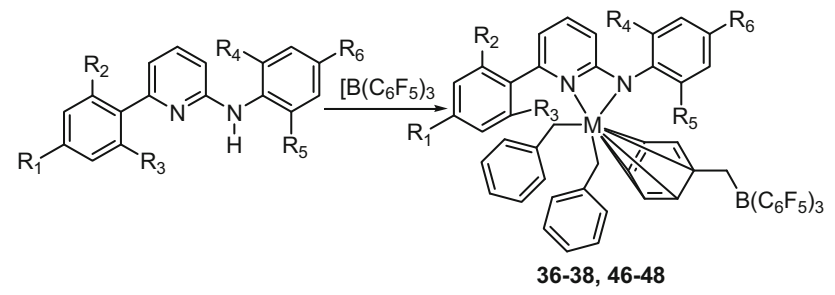

Scheme 16 Synthesis of $\mathrm{Zr} / \mathrm{Hf}$ zwitterionic complexes with bulky ligands; 36/46 $\left(\mathrm{R}_{1}=\mathrm{R}_{2}=\mathrm{R}_{3}=\mathrm{R}_{4}=\mathrm{R}_{5}=\right.$ isopropyl, $\left.\mathrm{R}_{6}=\mathrm{H}\right)$, $37 / 47\left(\mathrm{R}_{2}=\mathrm{R}_{3}=\right.$ methyl, $\mathrm{R}_{1}=\mathrm{R}_{6}=\mathrm{H}, \mathrm{R}_{4}=\mathrm{R}_{5}=$ isopropyl), 38/48 $\left(\mathrm{R}_{1}=\mathrm{R}_{2}=\mathrm{R}_{3}=\right.$ isopropyl, $\quad \mathrm{R}_{4}=\mathrm{R}_{5}=\mathrm{R}_{6}=$ methyl), 36-38 $(\mathrm{M}=\mathrm{Zr}), \mathbf{4 6}-48(\mathrm{M}=\mathrm{Hf})$

\section{Ethylene polymerization with Zr-complexes 33-38}

Complexes (33-38) were studied for ethylene polymerization and the effects of different co-catalysts were also investigated [30]. Very low activity was observed for $\mathbf{3 3}$ at $50{ }^{\circ} \mathrm{C}$ upon activation with $\mathrm{B}\left(\mathrm{C}_{6} \mathrm{~F}_{5}\right)_{3}$ probably because of $\eta^{6}$-coordination of phenyl ring of borane with the active metal center and, hence, blocking the active site for ethylene coordination. Also, addition of $\mathrm{H}_{2}$ to produce the respective more active hydride species did not enhance the activity. However, activating the catalyst 33 with tri-isobutyl aluminum (TIBA) before injecting into the reactor and increasing the temperature to $80^{\circ} \mathrm{C}$, resulted an increase in catalytic activity $\left(120 \mathrm{~kg} \mathrm{PE} \mathrm{mol} \mathrm{Cat}_{\text {Cat. }}^{-1}\right.$ ), and a polymer of lower polydispersity (1.9) was obtained. Increase in catalytic activity with increasing temperature could be rationalized that at higher temperature, phenyl ring of the borane moiety cannot bind with the active metal center which is beneficial for better activity. This catalyst system produced the polymer with higher molecular weight $\left(M_{\mathrm{w}}=1,256,000 \mathrm{~g} \mathrm{~mol}^{-1}\right)$ [30]. Under similar conditions, switching the co-catalyst to ammonium borate,
$\left[R_{2}(\mathrm{CH} 3) \mathrm{NH}\right]^{+}\left[\mathrm{B}\left(\mathrm{C}_{6} \mathrm{~F}_{5}\right)_{4}\right]^{-}$further enhanced the catalytic activity (1080 kg PE mol Cat. $\mathrm{h}^{-1}$ ), plausibly due to faster abstraction of the benzyl to generate the cationic species. However, the molecular weight was decreased $\left(M_{\mathrm{w}}=16,100 \mathrm{~g} \mathrm{~mol}^{-1}\right)$, and broader molecular weight distribution was observed [30]. The addition of $\mathrm{H}_{2}$ did not enhance the activity, rather, decreased the average molecular weight of resultant polymer though $\mathrm{H}_{2}$ in this case plays a significant role for the chain termination. Interestingly, complexes 34/35 with less bulky ligands were found to be less active for ethylene homopolymerization. Hence, it could be deduced that very bulky Ap ligands are advantageous for higher activity of the Zr-tribenzyl complexes. Catalyst 33 was found to be less active for propylene polymerization (100 kg PE mol $\left.\mathrm{Cat}^{-1} \mathrm{~h}^{-1}\right)$, but when ethylene was introduced into the same reaction mixture, the activity $\quad\left(6200 \mathrm{~kg} \mathrm{PE} \mathrm{mol}\right.$ Cat. $\left.^{-1}\right)$ was significantly enhancced [30, 59]. As a conclusion, tribenzyl Zr-complexes are not very efficient catalysts for ethylene polymerization and are less active for propylene homopolymerization but are active for ethylene-propylene copolymerization. The zwitterionic complexes 36-38 were also employed for ethylene homopolymerization, and on activating the complex $\mathbf{3 6}$ with ammonium borate, the maximum activity was $680 \mathrm{~kg} \mathrm{PE} \mathrm{mol}$ Cat. $^{-1} \mathrm{~h}^{-1}$. Higher molecular weight $\left(M_{\mathrm{w}}=455,000 \mathrm{~g} \mathrm{~mol}^{-1}\right)$ polyethylene with broader molecular weight distribution (102.9) was observed. The broader polydispersity reflects the presence of several catalytic species in the reaction mixture [30].

\section{Synthesis of $\mathrm{Zr}$-dichloride complexes with bulky aminopyridinato ligands}

Zr-complexes (39 and 40) were synthesized in a moderate yield (54-56\%) by treating corresponding potassium salt 
of ligand with $\mathrm{ZrCl}_{4}(\mathrm{THF})_{2}$ (Scheme 17; Fig. 11) [26]. Based on lower yield of resulting complexes, the salt metathesis is less attractive for synthesis of $\mathrm{Zr}$-complexes as compared to toluene elimination synthetic route [30]. However, such complexes could be interesting if these could provide better catalytic activities and polymers with some new properties. The moderate yield of these complexes could be attributed to incomplete reaction at room temperature and formation of other side products (for example $\mathrm{ApZrCl}_{3}$ ) along with complexes 39 and $\mathbf{4 0}$ [26]. The further reaction of these complexes with MeLi afforded complexes 41 and 42, respectively (yield 52-62\%,) and lower yields of these complexes could be due to formation of side products [26]. Also, previous reports of lithium alkyls for synthesis of Ti-complexes revealed lower yield, and hence, to increase the yield of 39/40, sodium alkyls (for example $\mathrm{CH}_{3} \mathrm{Na}$ ) or potassium alkyls (for example $\mathrm{CH}_{3} \mathrm{~K}$ ) could be employed.

\section{Olefin polymerization with Zr-complexes $39-42$}

Lower ethylene polymerization activities were observed for complexes $\mathbf{3 9}$ and $\mathbf{4 0}$ at lower temperature; however, higher molecular weight polymers with broader molecular weight distribution were observed [26]. It has been observed that though the steric difference of ligands in case of $\mathbf{3 9}$ and $\mathbf{4 0}$ is very small, yet a huge difference in their ethylene polymerization activity was observed when these complexes were activated with MAO. Complex 39 is highly active for ethylene polymerization at higher temperature (at $80^{\circ} \mathrm{C}$, the activity of this complex was $2760 \mathrm{~kg} \mathrm{PE} \mathrm{mol}_{\text {cat }}^{-1} \mathrm{~h}^{-1}$ ), and narrow molecular weight distribution (2.0) indicates its single-site nature [26]. Such an activity and molecular weight distribution are indicative of a stable catalyst system in the presence of aluminum alkyls. In contrast to catalyst 39, the activity $\left(280 \mathrm{~kg} \mathrm{PE} \mathrm{mol}_{\text {cat }}^{-1} \mathrm{~h}^{-1}\right)$ of the catalyst $\mathbf{4 0}$ was lower under similar conditions. To investigate the catalytic behavior of these complexes, ${ }^{1} \mathrm{H}$ NMR scale reactions of $\mathbf{3 9}$ and $\mathbf{4 0}$ with dry MAO were made, and it was found that compound 40 decomposes to insoluble products immediately and compound 39 reacts very slowly [26, 30]. Hence, it is inferred that $\mathbf{4 0}$ is unstable in the presence of (aluminum

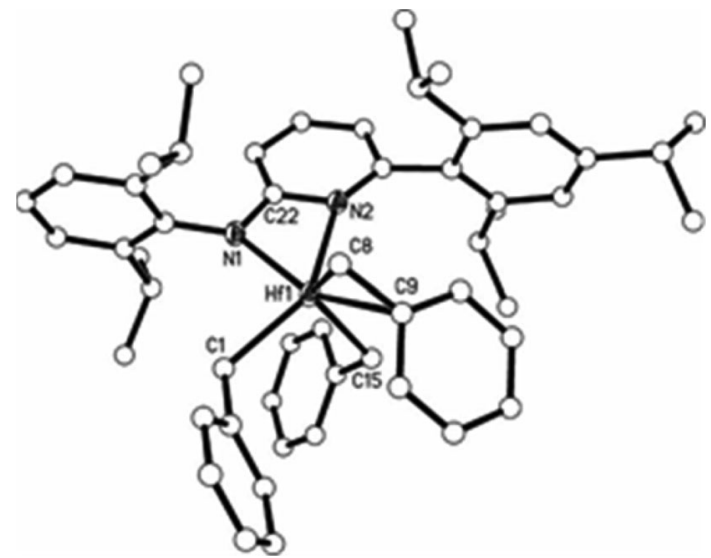

Fig. 11 Molecular structure of $\mathrm{Zr}$-complex 33

alkyls) of dry MAO and is converted into Ap-AlMe $\mathrm{Ar}_{2}$ or hetero-bimetallic complex and, thus, is less active for ethylene polymerization. Complex $\mathbf{3 9}$ when activated with dry MAO results in a single-site catalyst manifested by narrow molecular weight distribution (polydispersity $=2$, Table 2) of the resulting polymers and its catalytic activity increased with temperature. It may be deduced that its poor catalytic activity at low temperature is due to poor accessibility of MAO to chloride and, hence, less alkylation. In addition, slow alkylation at lower temperature is also responsible for broader molecular weight distribution [26]. However, slow alkylation could be overcome by premixing of 39 with MAO prior to polymerization reaction. Catalyst system based on 39 is robust and live even at higher temperature $\left(100^{\circ} \mathrm{C}\right)$ for the entire reaction time $(15 \mathrm{~min}$ s). Perfluoroborate activation protocol was employed to address the issue of ligand transfer to aluminum (complex 40) and rate-limiting effect caused by slow alkylation [26] Highly active catalyst systems were obtained when $\mathbf{4 1}$ and 42 were activated with ammonium perfluorotetraphenylborate $\left[\mathrm{R}_{2} \mathrm{~N}\left(\mathrm{CH}_{3}\right) \mathrm{H}\right]^{+}\left[\mathrm{B}\left(\mathrm{C}_{6} \mathrm{~F}_{5}\right)_{4}\right]^{-}\left(R=-\mathrm{C}_{16} \mathrm{H}_{33}-\mathrm{C}_{18} \mathrm{H}_{37}\right)$, and their activities were 3160 and $1440 \mathrm{~kg} \mathrm{PE} \mathrm{mol} \mathrm{cat}^{-1} \mathrm{~h}^{-1}$, respectively. Catalyst $\mathbf{4 1}$ was more active than $\mathbf{4 2}$ when activated with perfluoroborate and it gave long-chain $\alpha$ olefins. This trend may be because of favorable $\beta$-hydrogen elimination [26]. In case of more sterically crowded 41, $\beta$ hydrogen elimination is not favorable and gives higher molecular weight polymers. Observed broader
Scheme 17 Synthesis of $\mathrm{Zr}$ complexes 39-42; 39, 41 $\left(\mathrm{R}_{1}=\mathrm{R}_{2}=\mathrm{R}_{3}=\right.$ isopropyl); 40, $42\left(\mathrm{R}_{1}=\right.$ methyl, $\mathrm{R}_{2}=\mathrm{H}$, $\mathrm{R}_{3}=$ isopropyl)
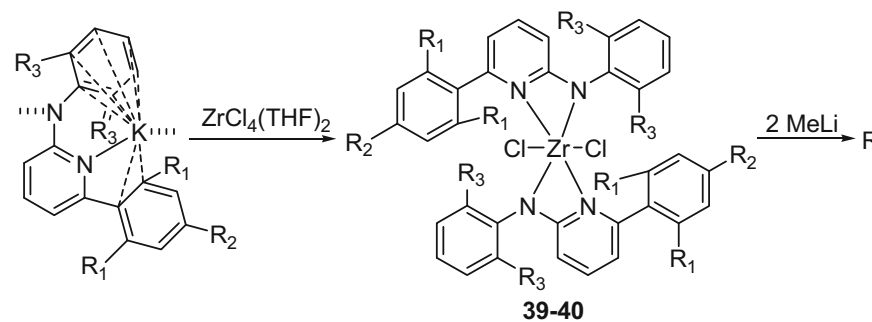
Table 2 Ethylene/styrene polymerization activity of $\mathrm{Zr}$ - and Hf-aminopyridinato complexes

\begin{tabular}{|c|c|c|c|c|c|c|}
\hline Structure \# & Temp. $\left({ }^{\circ} \mathrm{C}\right)$ & Pressure (Bar) & Activity (kg PE mol ${ }_{\text {Cat. }}^{-1} h^{-1}$ ) & $M_{\mathrm{w}} \mathrm{g} \mathrm{mol}^{-1}$ & $M_{\mathrm{w} /} M_{n}$ & Co-catalyst and ratio \\
\hline 31 & 70 & 10 & 152 & $1,380,000$ & 553 & MAO 2500 \\
\hline 32 & 25 & 1 & 181 & - & - & MAO 1000 \\
\hline 33 & 80 & 5 & 1120 & 71,800 & 21.6 & Ammonium borate 1.1 \\
\hline 34 & 50 & 5 & 640 & 328,000 & 62.6 & Ammonium borate 1.1 \\
\hline 35 & 50 & 5 & 480 & 45,200 & 14.2 & Ammonium borate 1.1 \\
\hline 36 & 80 & 5 & 520 & $1,256,000$ & 1.9 & Ammonium borate 1.1 \\
\hline 37 & 80 & 5 & 680 & 455,000 & 102.9 & Ammonium borate 1.1 \\
\hline 38 & 80 & 5 & 600 & 13,700 & 7.1 & Ammonium borate 1.1 \\
\hline 39 & 80 & 5 & 2760 & $5,355,000$ & 2.0 & MAO 500 \\
\hline 40 & 80 & 5 & 320 & 675,000 & 14.6 & MAO 500 \\
\hline 41 & 80 & 5 & 3760 & $1,009,000$ & 176.7 & Ammonium borate 1.1 \\
\hline 42 & 80 & 5 & 4440 & 967,000 & 1.9 & Ammonium borate 1.1 \\
\hline 43 & 80 & 5 & 1200 & $1,080,000$ & 3.1 & Ammonium borate 1.2 \\
\hline $57^{\mathrm{a}}$ & 75 & - & 1100 & 84,000 & 1.66 & MAO 1500 \\
\hline $58^{\mathrm{a}}$ & 75 & - & 2980 & 30,000 & 1.94 & MAO 1500 \\
\hline $59^{\mathrm{a}}$ & 75 & - & 5000 & 960,000 & 1.24 & MAO 1500 \\
\hline 73 & 50 & 2 & 5500 & - & - & Ammonium borate 1.1 \\
\hline 74 & 80 & 2 & 2600 & 5000 & 3.5 & Ammonium borate 1.1 \\
\hline 75 & 90 & 2 & 450 & 58,000 & 3.8 & Ammonium borate 1.1 \\
\hline 76 & 50 & 2 & 740 & 2500 & 2.5 & Ammonium borate 1.1 \\
\hline 77 & 50 & 2 & 140 & 36,000 & 27.6 & Ammonium borate 1.1 \\
\hline
\end{tabular}

a Styrene polymerization

polydispersity may be rationalized to rapid precipitation of polymer as a result of diffusion-controlled process which could be avoided by reducing the catalyst concentration $[23,26]$. In addition, lowering the catalyst concentration results into the living polymerization process with high ethylene consumption. Catalysts 39 and $\mathbf{4 0}$ activated with MAO and $\mathbf{4 1}$ and $\mathbf{4 2}$ activated with borate were inactive for polymerizing $\alpha$-olefins (propylene), and a similar behavior is reported for the lanthanide complexes as well $[26,55,60,61]$. A large number of transition metal catalysts become inactive in the presence of propylene, but they get reactivated in the presence of ethylene affording specific insertion sequences. The complexes 41 and 42 were employed for ethylene-propylene copolymerization using ammonium borate as an activator [26]. The analysis of the resultant polymer indicated ethylene homopolymerization instead of copolymerization, and content of propylene in the resultant polymer was less than $1 \%$. Furthermore, even applying higher pressure of propylene, ethylene polymerizes selectively with these catalysts and the ethylene polymerization activities for $\mathbf{4 1}$ and $\mathbf{4 2}$ were 5400 and $5700 \mathrm{~kg} \mathrm{PE} \mathrm{mol}$ Cat. $^{-1} \mathrm{~h}^{-1}$, respectively, and these activities were found similar in the presence and absence of propylene. Thus, highly selective polymerization of ethylene is possible in a mixture of ethylene/propylene probably due to both steric and electronic factors of these complexes and this substrate selectivity is also similar to zeolite-based catalysts [26]. It might also be deduced that electronic factors dominate over steric factors since selectivity was not observed for more sterically crowded Zr-complexes [26].

\section{Hafnium complexes}

The pioneering work for the synthesis of Hf-complexes was carried out by Polamo and synthesized these complexes by adding the hafnium tetrachloride in the molten ligand [24]. The chemistry of Hf-complexes with aminopyridinato ligands has been less explored as compared to $\mathrm{Ti}$ - and $\mathrm{Zr}$-complexes of these ligands and only homoleptic complexes were reported.

\section{Synthesis of Hf-trialkyl complexes with bulky aminopyridine ligands}

Noor et al. have reported the first examples of the fully characterized heteroleptic Hf-complexes (43-45, Fig. 12) with aminopyridinato ligands. These complexes were synthesized through toluene elimination pathway 
(Scheme 15), and their structural aspects are close to already reported $\mathrm{Zr}$-complexes [30]. The reported yields of these complexes are from 60 to $96 \%$. Similarly, the synthesis of zwitterionic complexes $\mathbf{4 6}-\mathbf{4 8}$ has been described in Scheme 16.

\section{Olefin polymerization with $H f$-complexes 43-45}

The catalysts $\mathbf{4 3 - 4 5}$ have been employed for the ethylene polymerization [30]. The maximum ethylene polymerization activity $\left(533 \mathrm{~kg} \mathrm{PE} \mathrm{mol} \mathrm{Cat}^{-1} \mathrm{~h}^{-1}\right)$ was observed for complex 43 at $80{ }^{\circ} \mathrm{C}$ using ammonium borate as co-catalyst; however, addition of tri-isobutylaluminum (TIBA) as scavanger prior to catalytic reaction enhanced the activity to $1200 \mathrm{~kg} \mathrm{PE} \mathrm{mol} \mathrm{Cat}^{-1} \mathrm{~h}^{-1}$. This catalyst was inactive for propylene polymerization. However, catalyst $\mathbf{4 3}$ was active (4889 kg PE mol$_{\text {Cat. }}^{-1} \mathrm{~h}^{-1}$ ) for copolymerization reaction of ethylene with propylene when activated with ammonium borate using TIBA as a scavenger. Higher molecular weight $\left(M_{\mathrm{w}}=94,600 \mathrm{~g} \mathrm{~mol}^{-1}\right)$ polymer with narrow molecular weight distribution was observed; however, increasing the propylene pressure did not enhance the activity; instead, a decrease in molecular weight $\left(M_{\mathrm{w}}=76,000 \mathrm{~g} \mathrm{~mol}^{-1}\right)$ of the polymer was observed. [30]. The catalyst $\mathbf{4 3}$ produced long chain $\left(M_{\mathrm{w}}=94,600 \mathrm{~g} \mathrm{~mol}^{-1}\right)$ ethylene propylene copolymer in comparison to $33\left(M_{\mathrm{w}}=14,700 \mathrm{~g} \mathrm{~mol}^{-1}\right)$ and this behavior is plausibly due to less favorable $\beta$-hydrogen elimination for 43. In addition to this, narrow molecular weight distribution (2.4) was observed for 43. Ligand frame work and polymerization conditions in both $\mathbf{3 3}, \mathbf{4 3}$ are same th-ough both have different metals, e.g. $\mathbf{3 3}$ has $\mathrm{Zr}$ and $\mathbf{4 3}$ has Hf. It may also be deduced that Hf prefers to produce longer chain polymer contrary to $\operatorname{Zr}[26,30]$. Higher copoymerization activity together with higher molecular weight and narrow molecular weight distribution of complex $\mathbf{4 3}$ indicates its potential to be further exploited for polymeriztion studies.

\section{Synthesis of Hf-trialkyl complexes with electron-rich bulky ligands}

Hf-complexes (49-56) with bulky and electron-rich ligands were quantitatively synthesized under established toluene elimination procedure (Scheme 18) with overall distorted octahedral geometry (Fig. 13) and shorter amido-N-Hf bond than the pyridine- $\mathrm{N}-\mathrm{Hf}$ bond indicating the location of negative charge on amido nitrogen atom [34]. Zr-complexes (33-38) and Hf-complexes (43-48) showed moderate activities for ethylene polymerization which has been presumed due to poor stability in the presence of aluminum alkyls [26, 30, 34]. Kempe et al. hypothesized that diamine (containing an amine function at two and six position of pyridine ring)-functionalized ligands (electron rich-ligands) could enhance the stability of complex, and, hence, synthesized Hf-complexes containing electron-rich ligands through toluene elimination route [34]. Molecular structure of $\mathbf{4 9}$ has very similar crystallographic parameters compared to $\mathbf{4 3}$ but structurally different from previous examples as all three benzyls are $\eta^{1}$-coordinated with Hf-metal center. Interestingly, this molecule has a shorter bond length (C26$\mathrm{N} 1=1.379 \AA$ ) which is less than a $\mathrm{C}-\mathrm{N}$ single-bond length $(1.48 \AA)$ and greater than a $\mathrm{C}=\mathrm{N}$ double-bond length $(1.29 \AA)$. The sum of angles around N1 is equal to $351^{\circ}$ indicating an almost planar nitrogen atom. Shorter N1-C26 bond length together with planar N1 indicates that the lone pair of $\mathrm{N} 1$ is involved in bonding with $\mathrm{C} 26$, and thus, enhancing the electron-donating capability of amine-functionnalized ligand [34] (Fig. 14).

Fig. 12 Structures of $\mathrm{Zr}$ complexes

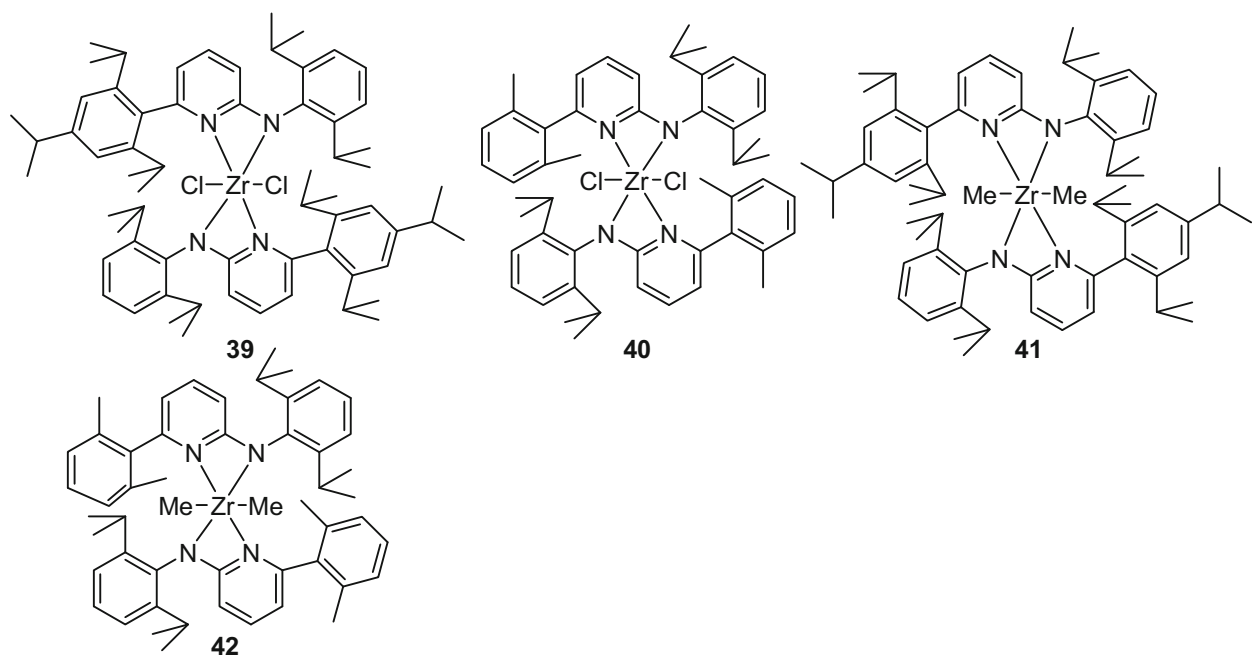


Scheme 18 Synthesis of Hftrialkyl complexes 49-56
Fig. 13 Structures of Hfcomplexes 43-48

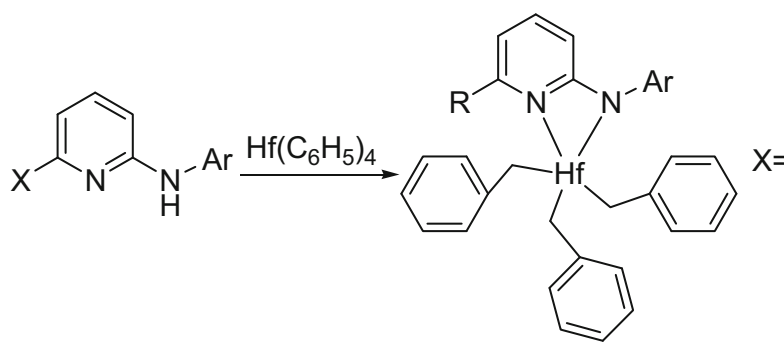

49-56<smiles>CCc1cccc(C(C)(C)C)c1</smiles>

51

54

55

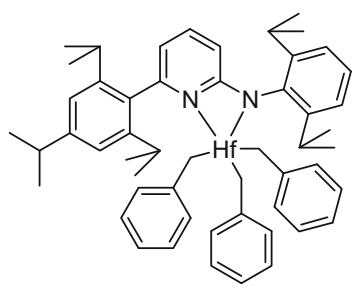<smiles></smiles><smiles></smiles>

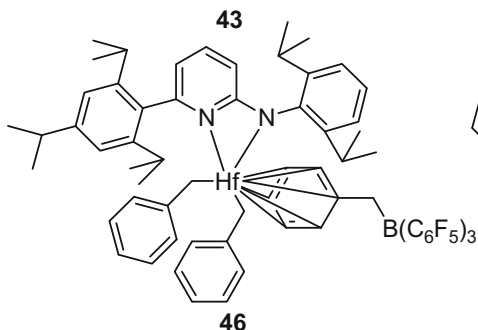

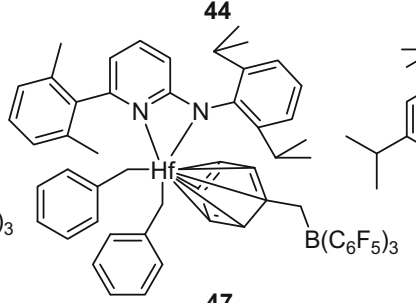

47<smiles>C1COCCN1</smiles><smiles>C1CCNC1</smiles>

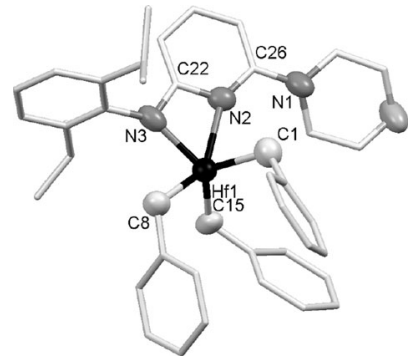

Fig. 14 Molecular structure of Hf-trialkyl complex (52)

Ethylene polymerization with Hf-complexes (49-56)

Hf-complexes 49-56 were inactive for ethylene polymerization in the presence of trimethylaluminum-containing MAO, while low activities were observed with dry MAO [34] (Scheme 19). Researchers suspected that a fast reaction is taking place between traces of $\mathrm{AlMe}_{3}$ of MAO and the Hf-complexes, and this hypothesis was proved to be true by reacting Hf-complexes with $\mathrm{AlMe}_{3}$ (NMR-scale reactions) (Fig. 15). These proton NMR spectra indicate that Ap-Hf-complex is fastly converted into aluminum-Hf-
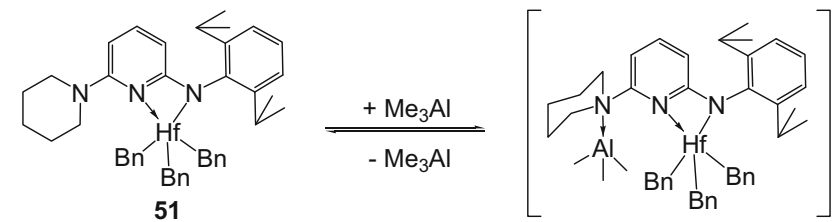

48
Scheme 19 Ligand transfer reaction with complex $\mathbf{5 1}$

hetero-bimetallic complex which is later converted into the Ap-aluminum complex [34]. In addition, borate activation in the presence of an aluminum scavenger did not improve their activity, presumably due to ligand transfer from Hf to Al during catalytic reaction, and Hf-complex without aminopyridinato ligand was inactive [34]. Such ligand transfer reactions were also observed in case of $\mathrm{Ti}$ - 
Fig. $15{ }^{1} \mathrm{H}$ NMR spectra $\left(\mathrm{C}_{6} \mathrm{D}_{6}, 26^{\circ} \mathrm{C}, 0-8 \mathrm{ppm}\right)$ of complex 51; bottom to top $(2 \mathrm{a}=$ complex 51),

$2 \mathrm{a}+30$ eq. TMA after $5 \mathrm{~min}$ and after $16 \mathrm{~h}, 3 \mathrm{c}=$ formation of aluminium complex

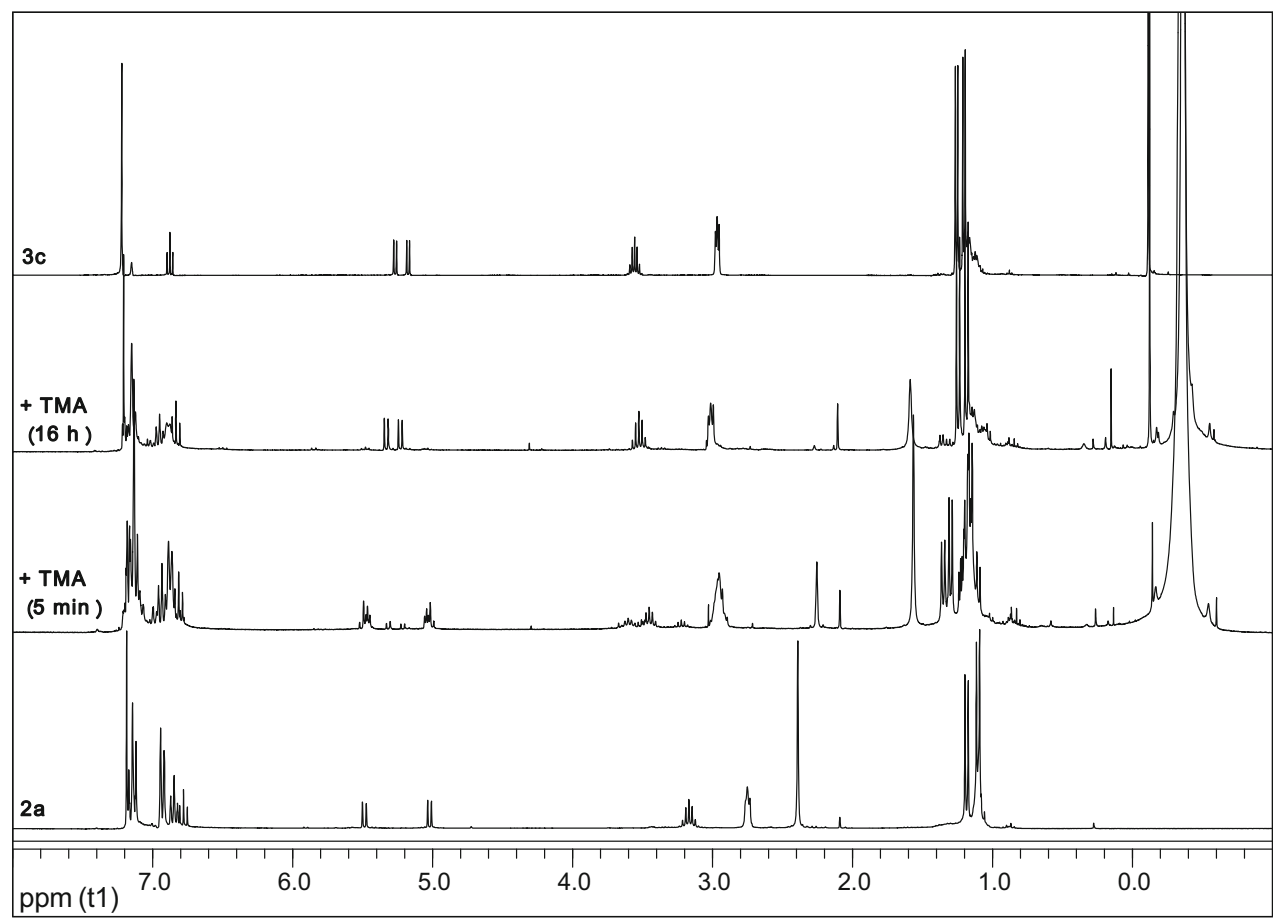

complexes with electron-rich ligands [33, 34, 44]. However, the rate of ligand transfer was found faster in case of Hf-complexes than Ti-complexes, and in both cases, the ligand framework is the same which concludes that more electrophilic Ti(IV) catalysts are more stabilized by electron-rich ligands but complexes containing electron-rich ligands with less electrophilic metal (Hf) are less stable [34, 44]. Presumably, different ionic radius size of Hf than Ti might also affect complex stability. Faster ligand transfer observed upon treatment with $\mathrm{AlMe}_{3}$, gives a rationale that more electron donating ligands might be unsuitable to develop more active Hf-catalysts (Fig. 15) [34]. Another important consideration for very low ethylene polymerization of complexes $\mathbf{4 9 - 5 6}$ could be the less bulky ligands as compared to the steric bulk of the ligands in Hf-complexes 43-45. The catalytic potential of these complexes could be further enhanced by making suitable adjustments in steric bulk of the ligands, and in this regard, the introduction of isopropyl groups on pyridine and phenyl rings could be advantageous (Table 3 ).

\section{Group-IV mixed ligand complexes}

\section{$\mathrm{N}$-trimethylsilylamido complexes for styrene polymerization}

For the synthesis of silylamido ligands, 6-(2-(diethylboryl)phenyl)pyridin-2-amine was reacted with $n$-BuLi at $50{ }^{\circ} \mathrm{C}$ to afford the corresponding lithium salt which upon reaction with trimethylsilyl chloride gave compound $2 \mathbf{2 a}$ (85\% yield) [63]. This compound was lithiated at $-37^{\circ} \mathrm{C}$ with $n$-BuLi and its subsequent reaction with $\mathrm{Cp} * \mathrm{TiCl}_{3}$ afforded complex 57 in $45 \%$ yield (Scheme 20, Fig. 16). The yield of the ligand is good enough; however, the yield of the complex is lower [63-65].

The complexes $\mathbf{5 8}$ and $\mathbf{5 9}$ were synthesized with a similar procedure (Scheme 20) used for complexes $64 / 65$ except that trimethylsilyl chloride is used instead of chloro(cyclopenta-2,4-dienyl)dimethylsilane for introduction of tri-methyl silyl group here [63].

Syndiotactic polystyrene (SPS) is an important polymer with broad range of applications due to its high melting point. This polymer is resistant to water. In addition to this, syndiotactic polystyrene is also resistant to many organic compounds at room temperature [66, 67]. The pioneering work in this field was accomplished by Ishihara et al. using Ti-catalysts, and later on, Zambelli et al. have used tetrabenzyl Ti-complexes to obtain syndiotactic polystyrene. Recent studies have shown that zirconocenes are less effective for SPS polymerization [66].

Homopolymerization of styrene was achieved by nonbridged half titanocene complexes (57) bearing an aminoborane moiety and aminoborane-free complexes $\mathbf{( 5 8 ,}$ 59) using MAO as co-catalyst [66]. In addition, using similar conditions with complexes $\mathbf{5 7}, \mathbf{5 8}$ and $\mathbf{5 9}$ (catalyst: co-catalyst: styrene $=1: 1500: 15,000, \quad T=75{ }^{\circ} \mathrm{C}$ ) gave good activity $\left(1100,2980\right.$ and $5000 \mathrm{~kg} \mathrm{~mol}_{\text {cat }}^{-1} \mathrm{~h}^{-1}$, respectively), and increase in temperature increased catalytic activity but decreased the number-average molecular 
Table 3 Activities of Ti- and Hf-complexes (copolymerization)

\begin{tabular}{|c|c|c|c|c|c|c|c|}
\hline \multirow[t]{2}{*}{ Structure \# } & \multirow[t]{2}{*}{ Temp $\left({ }^{\circ} \mathrm{C}\right)$} & \multicolumn{2}{|c|}{ Pressure (Bar) } & \multirow[t]{2}{*}{ Activity $\left(\mathrm{kg} \mathrm{PE} \mathrm{mol} \mathrm{Cat}^{-1} \mathrm{~h}^{-1}\right)$} & \multirow[t]{2}{*}{$M_{\mathrm{w}} \mathrm{g} \mathrm{mol}^{-1}$} & \multirow[t]{2}{*}{$M_{\mathrm{w}} / M_{n}$} & \multirow[t]{2}{*}{ Co-catalyst and ratio } \\
\hline & & Ethene & Propene & & & & \\
\hline 13 & 50 & - & 5 & 200 & - & - & MAO 500 \\
\hline 13 & 50 & 5 & 2 & 32,000 & 104,374 & 2.1 & MAO 500 \\
\hline 14 & 50 & 5 & 2 & 29,600 & 103,502 & 2.0 & MAO 500 \\
\hline 15 & 50 & 5 & 2 & 30,600 & 120,954 & 2.1 & MAO 500 \\
\hline 16 & 50 & 5 & 2 & 14,600 & 87,162 & 1.9 & MAO 500 \\
\hline $13^{\mathrm{a}}$ & 50 & 5 & 2 & 33,000 & 133,287 & 2.4 & MAO 500 \\
\hline $13^{\mathrm{b}}$ & 50 & 5 & - & 11,400 & - & - & MAO 500 \\
\hline $13^{\mathrm{c}}$ & 50 & 5 & 2 & 14,600 & 56,261 & 1.9 & MAO 500 \\
\hline 33 & 80 & - & 5 & 100 & - & - & Ammonium borate 1.1 \\
\hline 33 & 80 & 5 & 3 & 6200 & 14,700 & 11.6 & Ammonium borate 1.1 \\
\hline 33 & 80 & 5 & 4 & 5000 & 14,300 & 8.0 & Ammonium borate 1.1 \\
\hline 41 & 80 & 10 & 5 & 57,000 & 755,700 & 113.1 & Ammonium borate 1.1 \\
\hline 42 & 80 & 10 & 5 & 54,000 & 8960 & 2.2 & Ammonium borate 1.1 \\
\hline 43 & 80 & - & 5 & 110 & - & - & Ammonium borate 1.1 \\
\hline 43 & 80 & 5 & 3 & 4889 & 94,600 & 2.4 & Ammonium borate 1.1 \\
\hline 43 & 80 & 5 & 4 & 4889 & 76,000 & 2.4 & Ammonium borate 1.1 \\
\hline
\end{tabular}

a $10 \mathrm{~mL}$ of 1-hexene

b $10 \mathrm{~mL}$ of $\mathrm{ENB}$

c $1 \mathrm{~mL}$ of $\mathrm{ENB}$

Scheme 20 Structures of Ticomplexes 57-59 [41a]<smiles>CCCCC(C)(C)c1ccccc1-c1cccc(N[Si](C)(C)C)c1</smiles>

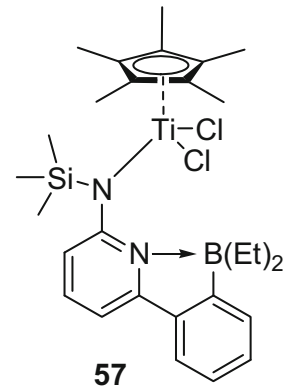
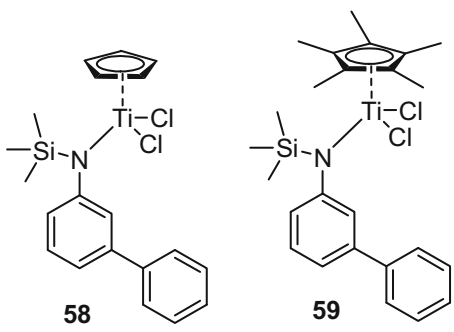

Fig. 16 Structures of Ti-complexes 58-59 [41a]

weight $\left(M_{n}\right)$ because temperature enhances the activity of catalytic species but electronic and steric factors of cyclopentadienyl become less favorable for higher molecular weight polymers [63]. The catalytic species become more active at higher temperature because of more favorable alkylation by MAO. However, the decrease in $M_{n}$ of resulting polymers is due to the cyclopentadienyl ligand in complex $\mathbf{5 8}$ which on electronic and steric grounds is less favorable for getting high-molecular-weight polymers, and thus, $M_{n}$ is decreased [63]. It can be deduced that methyl groups on cyclopentadienyl ligand in complex 59 enhance the electron-donating effect of the ligand which by stabilizing the complex results into the formation of higher molecular weight polymers. Furthermore, catalysts $\mathbf{5 8}$ and 59 (both free of aminoborane moiety) showed much higher activity than the complexes having aminoborane moiety (complex 57). Low polydispersities of the polymers were observed which indicate the single-site nature of these catalysts. Higher $M_{n}$ obtained for complexes 57 and 59 could be explained by steric hindrance due to the methyl 
groups on $\mathrm{Cp}$ ligand which mimics the $\beta$-hydride elimination resulting into the formation of long-chain syndiotactic polystyrene [63, 66, 74]. Decrease in ligand steric bulk decreased the activity as well as $M_{n}$, and thus, it could also be inferred that cationic catalyst is better protected with sterically bulky ligands. Although the aminoborane ligand is a bulky one, itis not involved in the protection of active metal center and results in a poor activity for complex 57. Activities of complexes 57, 58 and 59 are far better than analogous ansa-bridged Ti-complexes $[29,63,66]$. In all these polymerizations, almost $90 \%$ polymer content was syndiotactic which indicates the greater potential of these catalysts for producing syndiotactic polystyrene.

\section{Imido-pyridine Ti(IV) complexes}

Mixed ligand complexes of Ti(IV) complexes have been synthesized by reacting the pro ligands 2-amino-3-pi-coline and 2-amino-5-picoline with $n$-BuLi which upon subsequent treatment with $\left[\mathrm{TiCl}_{3}\left(\eta^{5}-\mathrm{C}_{5} \mathrm{Me}_{5}\right)\right]$ afforded complexes 61-64 as the final product (Fig. 17) [65]. For the synthesis of complexes $\mathbf{6 1}$ and $\mathbf{6 2}$, ligand and Ti-precursor were reacted in 2:1, while for complexes 63 and 64, this ratio was $4: 1$ (Scheme 21). The main shortcoming of this synthesis is the lower yield (32-43\%) of the resulting complexes which could be attributed to the formation of side products. However, novel structural features of these complexes are interesting; for example, geometry of Ti-Lihetero-bimetallic compound (33) was found to be with piano stool structure which is analogous to Ti-complexes with $\mathrm{Cp}$ ligands $[66,67]$. In addition to this, these complexes have applications in ring-opening metathesis, industrial production of acrylonitrile, small molecules activation and for olefin polymerization [68, 69]. We could suggest that substituted picoline might also be worth investigating. These structurally interesting complexes have broad spectrum of applications ranging from synthesis of organometallic compounds to small organic molecules, and such picolines could also be applied for olefin

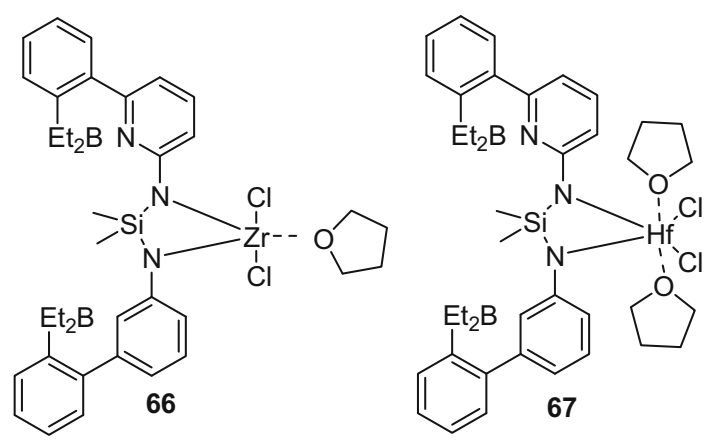

Fig. $17 \mathrm{Zr}$ and Hf-complexes 66-67 polymerization [68]. Similar complexes containing aminopyridine ligands have been reported by Dow/Symx and were active in olefin polymerization [69].

\section{Mixed-ligand Ti-catalysts for simultaneous ring- opening metathesis polymerization}

For ligand synthesis, $m$-bromoaniline was reacted with phenyl boronic acid to afford a 3-biphenylamine (85\% yield), and the reaction was catalyzed by $\mathrm{Pd}\left(\mathrm{PPh}_{3}\right)_{4}$. The 3-biphenylamine was further reacted with $n$-BuLi to afford its lithium salt which on reacting with chloro(cyclopenta2,4-dienyl)dimethylsilane resulted into the ligand $2 \mathrm{a}$ in $84 \%$ yield (Scheme 22) [73]. This ligand was treated with $n$-BuLi in 1:2, and the resulting lithium salt was reacted with $\mathrm{TiCl}_{3}$.3THF to synthesize the complex $64(65 \%$ yield). The main advantage of this synthesis is the higher yield of ligand precursors and a moderate yield of complex 64. The main disadvantage of this reaction is the multistep synthesis and use of costly palladium catalyst. In addition to this, the palladium catalyst could not be fully separated from the ligand precursor and may act as an impurity in the further catalytic reactions. Moreover, the $n$-BuLi used for the ligand and complex synthesis needs very low temperature and limits the scope of this reaction for large-scale synthesis of ligands and complexes of this type [73].

The $\operatorname{Pd}(0)$-catalyzed reaction of 2-bromo-6-pyridine amine with 2-bromopheylboronic acid resulted into 6-(2Bro-mophenyl)pyridin-2-amine in $53 \%$ yield, and its further $\mathrm{ZnI}_{2}$-catalyzed reaction with $1,1^{\prime}$-Ethylenebis $\left(N, N^{\prime}\right.$ 1,1-tetramethylsilanamine) resulted into ligand $\mathbf{2 b}$ [73]. The subsequent reaction of ligand 1 with $n$-BuLi in the presence of diethylmethoxyborane resulted into 6-(2-(Diethylboryl)phenyl)pyridin-2-amine which was again reacted with $n \mathrm{BuLi}$ followed by reaction with $\mathrm{Cp} * \mathrm{Me} 2 \mathrm{SiCl}$ resulting into ligand 2 . This ligand was deprotonated with $n$-BuLi and was reacted with $\mathrm{TiCl}_{3} 3 \mathrm{THF}$ to afford complex 65 in $38 \%$ yield (Scheme 23). In this reaction, $\mathrm{PbCl}_{2}$ was used as an oxidizing agent to convert Ti(III) into Ti(IV) [73].

Polymerization reactions such as ring-opening metathesis polymerization (ROMP) of cyclic olefins, copolymeriztion of cyclic olefins with ethylene and homopolymerization reactions of cyclic olefins are used to produce poly-olefins on commercial scale. Copolymerization reactions are more desirable as more valuable properties (molecular weight, tacticity, mechanical strength) of the resulting polymers could be fine-tuned by suitable design of ligands and corresponding complexes [66-69, 73]. Formation of both vinyl insertion polymerization (VIP) and ring-opening metathesis polymerization (ROMP)-derived polymeric structures from a cyclic olefin has attracted much interest in recent years [73]. In addition, copolymerization of a cyclic olefin with an

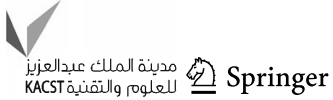


Scheme 21 Ti-complexes 60-63

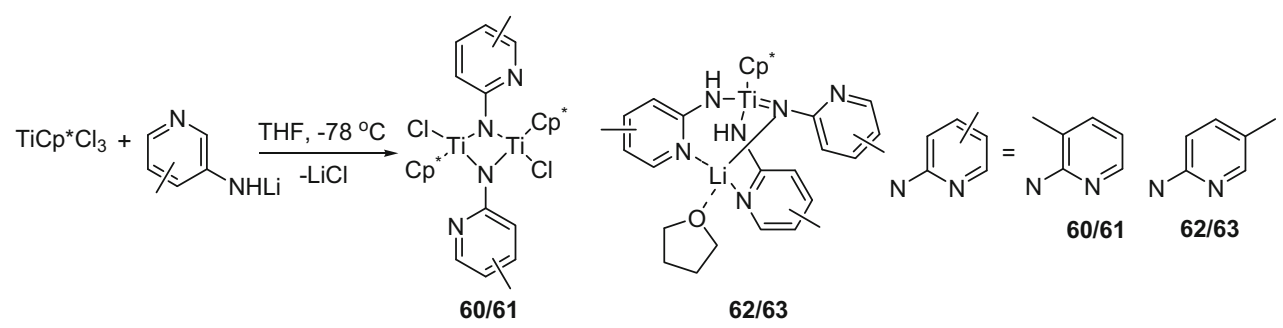

Scheme 22 Ti-complexes 64<smiles>CC1=C(C)C([Si](C)(C)Cl)C([Si](C)(C)Cl)C1=C(C)C1=C(C)C(C)=C(C)C1[Si](C)(C)Nc1cccc(-c2cccc(-c3cccc(N)c3)c2)c1</smiles>

Scheme 23 Ti-complexes 65

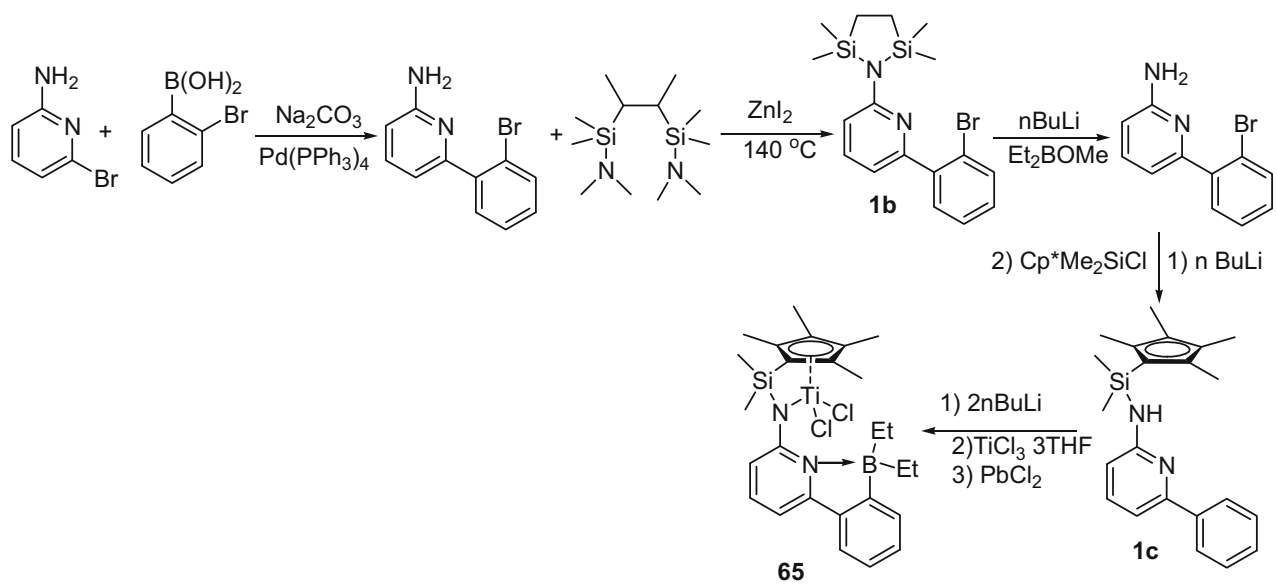

acyclic one to architect a high-molecular-weight polymer having both ROMP- and VIP-derived structures in the same polymer backbone is highly desirable [73]. Such structural changes for ROMP-derived polymers make them stable in the presence of oxygen. These types of polymers offer further functionalization through halogenation, epoxidation and vicinal dihydroxylation. Recently, Buchmeiser and coworkers have synthesized the amine/borane-containing half sandwich-Ti complexes (64-65) [73]. Among them, 65 has the capability to abstract a proton and accomplish $\alpha$ hydrogen elimination through a six-membered transition state and its boryl group is in competition for free lone pair of electrons which makes the $\alpha$-hydrogen elimination process temperature-dependent. Calatyst $\mathbf{6 5}$ catalyzed the homopolymerization of NBE with MAO (Ti: MAO: $\mathrm{NBE}=1: 1000: 1000)$ and gave Poly(NBE) $\mathrm{ROMP}$ at $50{ }^{\circ} \mathrm{C}$, but, upon increasing NBE concentration to 10,000 equivalents, produced the mixture of both ROMP- and VIP-derived poly(NBE), and both ROMP and VIP sequences occurred in the same polymer. An increase in temperature resulted into a decrease in $M_{n}$ and an increase in PDI and this trend is attributed to a higher fraction of pyridyl moiety which is responsible for an increase in $\alpha$-elimination [73]. This $\alpha$ elimination shortens the chain length of polymers as well as $M_{n}$. Further increase in NBE concentration at the same temperature resulted into poly $(\mathrm{NBE})_{\mathrm{ROMP}}$ fraction in the polymer (up to $71 \%$ ). Also, it has been found that increase in MAO concentration stabilizes the cationic metal center and thus increases the activity, lowers PDI and increases poly($\mathrm{NBE})_{\mathrm{ROMP}}$ content, and this trend is related to $\alpha$-elimination which results into pyridinium moieties that react irreversibly with MAO to produce methane and Ti-alkylidene to react with ethylene, and the polymer chain is cleaved from metal center [73]. This results into a polymer with higher poly $(\mathrm{NBE})_{\mathrm{ROMP}}$ but a lower $M_{n}$ value. ${ }^{13} \mathrm{C}-\mathrm{NMR}$ (measurement was made at $80{ }^{\circ} \mathrm{C}$ ) data of the polymeric mass when compared with the literature, were indicative of poly $(\mathrm{NBE})_{\mathrm{ROMP}-a l t-p o l y}(\mathrm{NBE})_{\mathrm{VIP}}$ sequences, and these studies indicate the incorporation of poly $(\mathrm{NBE})_{\mathrm{ROMP}}$ units into main polymer chain. Hence, NMR studies exclude the 
formation of two polymers, poly(NBE) $\mathrm{ROMP}$ and poly$(\mathrm{NBE})_{\mathrm{VIP}}$-co-poly $(\mathrm{E})$ as well as formation of vinyl terminated polymer then what really happens is then depicted in Scheme 24 [73]. Reaction of cationic (VIP active species) with NBE, followed by ( $\alpha$-elimination) results into a disubstituted species (Ti-alkylidene) and its formation is more probable as compared to the formation of mono-substituted alkylidene under $\alpha$-elimination after ethylene insertion. Furthermore, it has also been revealed that the proton stays at pyridine nitrogen for a certain time and could be donated back to Ti-alkylidene to reestablish the VIP active species. Providing higher concentration of NBE, another monomer could be inserted followed by the insertion of ethylene. Through the above-mentioned mechanism, the proposed structure of the polymer is poly(NBE) ${ }_{\text {ROMP }}$ poly $(\mathrm{NBE})_{\mathrm{VIP}^{-}}$ co-poly (E). Aminoborane-free Ti-complex 64 was also synthesized to study the effect of boryl moiety in the polymerization, and this complex produced the polymer of the type poly(-NBE) $)_{\text {vip-co-poly }}(\mathrm{E})$ with no poly-(NBE) $)_{\text {ROMP }}$ sequences [73].

\section{Group-4 silylamido complexes}

Y. Zou et al. have synthesized Zr- and Hf-complexes, and upon activation with MAO, these complexes were active for ethylene polymerization and complex 66 produced $160 \mathrm{~kg} \mathrm{~mol}_{\text {cat }}^{-1} \mathrm{~h}^{-1}$ bar $^{-1}$ polyethylene [81]. This complex produced very linear PE with higher melting points in the range of $134-139^{\circ} \mathrm{C}$ which indicate high-density polyethylene (HDPE). Hf-catalyst $\mathbf{6 7}$ was less active (40 $\mathrm{kg} \mathrm{mol}_{\text {cat }}^{-1} \mathrm{~h}^{-1} \mathrm{bar}^{-1}$ ) for the ethylene polymerization but produced very high molecular weight polyethylene
(UHMWPE) with $M_{n}=4,700,000 \mathrm{~g} \mathrm{~mol}^{-1}$ and molecular weight distribution $=1.3$ [75-81]. Presumably, the greater ionic radius and less electrophilicity of electron-deficient Hf-centre in $\mathbf{6 7}$ is helpful for getting very high molecular weight polymer. Whereas smaller ionic radius and greater electrophilicity in case of $\mathrm{Zr}$-complex $\mathbf{6 6}$ enhances its activity but produces polymers of lower molecular weight which might be attributed to the faster chain transfer rate in case of 66 [72-74, 81].

Copolymerization of ethylene was achieved with CPE catalyzed by $\mathbf{6 6}$, and when this reaction was carried out in toluene at $25{ }^{\circ} \mathrm{C}$, activity was $360 \mathrm{~kg} \mathrm{~mol}_{\text {cat }}^{-1} \mathrm{~h}^{-1} \mathrm{bar}^{-1}$ (catalyst:co-catalyst:CPE = 1:2000:1000) [81]. ${ }^{1} \mathrm{H}-\mathrm{NMR}$ studies of the resultant polymer did not show CPE incorporation into polymer chain. However, upon increasing the temperature $\left(50{ }^{\circ} \mathrm{C}\right)$ and $\mathrm{CPE}$ concentration $(200,000)$, the activity increased to $8100 \mathrm{~kg} \mathrm{~mol}_{\text {cat }}^{-1} \mathrm{~h}^{-1} \mathrm{bar}^{-1}$ (catalyst:co-catalyst:CPE $=1: 2000: 200,000) .{ }^{1} \mathrm{H}-\mathrm{NMR}$ studies of the resultant polymers also indicated that hardly $0.1 \mathrm{~mol} \% \mathrm{CPE}$ is incorporation in the polymer chain. Further increase in temperature (to $65^{\circ} \mathrm{C}$ ) resulted in a decrease in activity and $M_{n}$ as a consequence of dominant elimination reaction. Plausibly, the role of CPE in such a polymerization is the chain-stabilizing ligand; it serves as a chain transfer agent having reversible coordination to cationic Zr-metal center [81]. During the chain growth, most probably, the last alkene unit is replaced by the CPE unit which gets inserted into the $\mathrm{Zr}-\mathrm{H}$ bond and that starts the growth of a new polymer chain. Interestingly, narrow molecular weight distribution (1.4-1.8) was observed for polymers obtained from complexes 66 and 67. The complex 66 was active $\left(3040 \mathrm{~kg} \mathrm{~mol}_{\text {cat }}^{-1} \mathrm{~h}^{-1} \mathrm{bar}^{-1}\right)$ for
Scheme 24 Proposed mechanism for $\mathbf{6 5}$ catalyzed formation of poly $(\mathrm{NBE})_{\mathrm{ROMP}^{-}}$ co-poly $(\mathrm{NBE})_{\mathrm{VIP}^{-}}{ }^{-c o-p o l y}(\mathrm{E})$
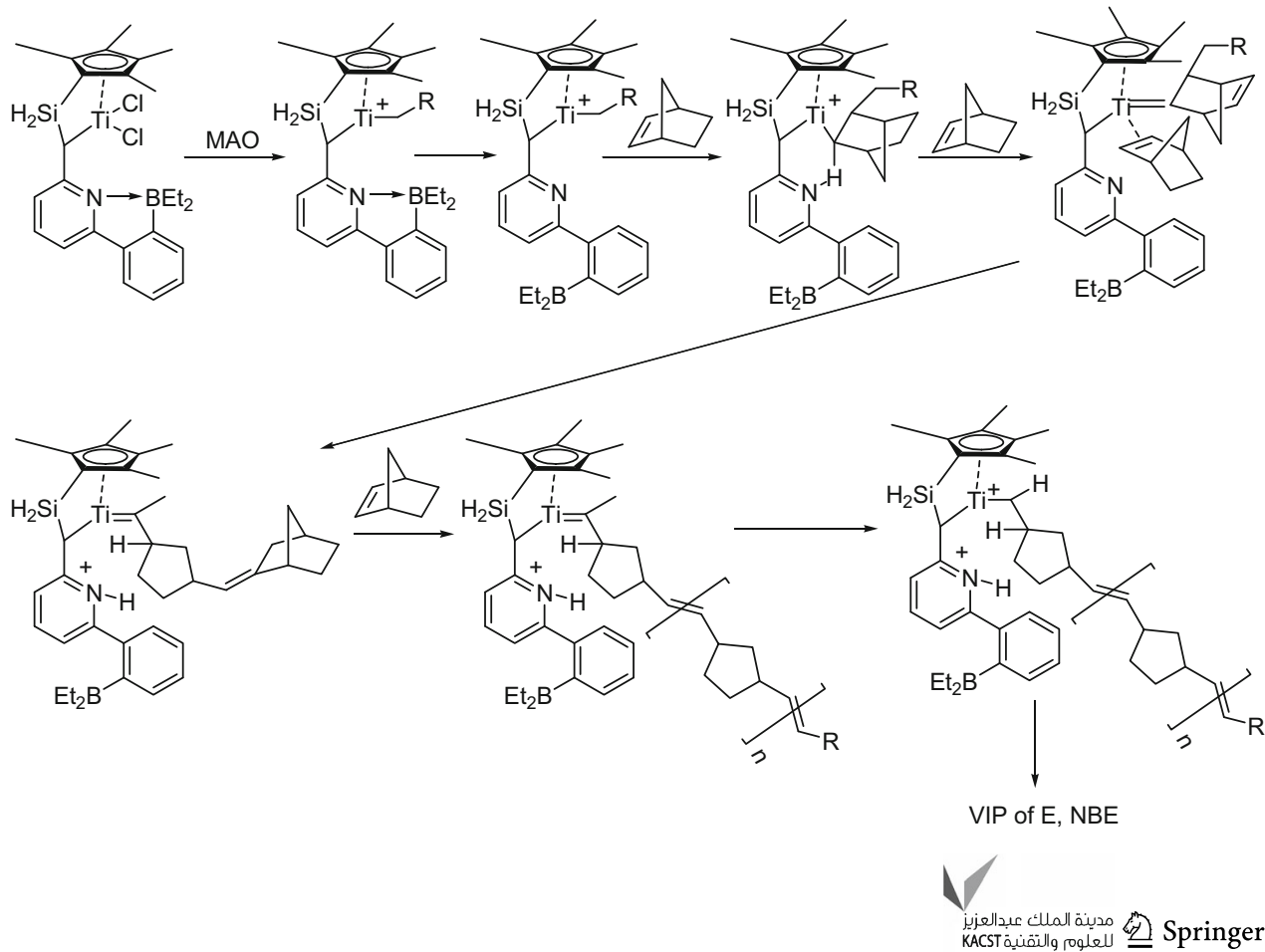
ethylene-norbornene copolymerization using a higher NBE concentration (catalyst:cocatlyst: $\mathrm{NBE}=1: 2000: 2000$ ) and behaved as a single-site catalyst for this polymerization $(\mathrm{PDI}=1.2)$. The NMR studies of copolymer obtained have shown $18 \mathrm{~mol} \%$ incorporation of NBE in the polymer chain [81]. Notefully, catalytic activities of 66 and 67 are due to the presence of aminoborane ligand [81]. The model compounds synthesized without aminoborane moiety were quite less reactive for polymerization reactions. The researchers focused only on aminoborane complexes of $\mathrm{Zr}$ and Hf for polymerization of ethylene and copolymerization of ethylene with CPE and NBE. It could be proposed that the syntheses of similar Ti-complexes as well as and their activity comparison with $\mathrm{Zr}$ and $\mathrm{Hf}$ complexes might be of great importance. In addition, some more monomers such as propylene could also be considered for polymerization reactions, and the set of conditions employed for ethylene polymerization $(500 \mathrm{~mL}$ reactor and ethylene pressure $=4$ bar) are less suitable for such polymerization reactions. Furthermore, large-sized reactor and higher ethylene pressure may give better results [78-81].

\section{Synthesis of mixed-ligand (Cp*-Ap) Hf-complexes}

Kempe et al. have synthesized mixed-ligand Hf-complexes (68-72) by reacting the corresponding Ap ligand with $\mathrm{Cp} * \mathrm{HfMe}_{3}$ in toluene at room temperature (Scheme 25, Fig. 18) [31]. The main purpose for the synthesis of these complexes was their application in ethylene polymerization and coordinative chain transfer polymerization (CCTP). The polymers obtained in this polymerization possess contain a main group metal at one end of the chain which could be further functionalized to get valuable products. For example, this polymerization affords long-chain aluminum alkyls which upon oxidation could be converted into long-chain aliphatic alcohols [31]. These alcohols have wide range of applications such as in metal/polymer/leather processing, in paints and industrial coating materials. Such alcohols could even be more beneficial if their chain length is greater than 22 carbon atoms [80]. Long-chain aluminum alkyls and, hence, long-chain aliphatic alcohols could be

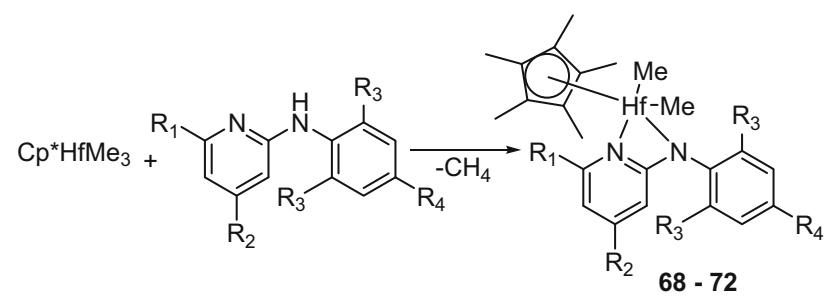

Scheme 25 Synthesis of mixed ligand Hf-complexes 68-72; 68 $\left(\mathrm{R}_{1}=\mathrm{R}_{2}=\mathrm{R}_{4}=\mathrm{H}, \quad \mathrm{R}_{3}=\mathrm{i}-\mathrm{pr}\right), \quad 69 \quad\left(\mathrm{R}_{1}=\mathrm{Cl}, \quad \mathrm{R}_{2}=\mathrm{R}_{4}=\mathrm{H}\right.$, $\mathrm{R}_{3}=\mathrm{i}$-pr), $70\left(\mathrm{R}_{1}=\mathrm{Br}, \mathrm{R}_{2}=\mathrm{R}_{4}=\mathrm{H}, \mathrm{R}_{3}=\mathrm{i}\right.$-pr), $71\left(\mathrm{R}_{1}=\mathrm{Me}\right.$, $\mathrm{R}_{2}=\mathrm{R}_{4}=\mathrm{H}, \mathrm{R}_{3}=\mathrm{i}$-pr $)$ and $\mathbf{7 2}\left(\mathrm{R}_{1}=\mathrm{H}, \mathrm{R}_{2}=\mathrm{R}_{3}=\mathrm{R}_{4}=\mathrm{Me}\right)$ conveniently produced by the process of coordinative chain transfer polymerization (CCTP). For the process of CCTP, a metal catalyst and a chain transfer agent (CTA) is used, and so far, many transition/rare earth metals complexes in combination with magnesium, zinc and aluminum alkyls (as chain transfer agent) have been used [81].

Ethylene polymerization with mixed-ligand $\left(C p^{*}-A p\right) H f$ complexes $68-72$

Hf-complexes (68-72) were employed for ethylene polymerization using MAO as co-catalyst [31]. Catalyst 68 was active for ethylene polymerization with polydispersity index less than 2, whereas catalysts 69-72 were not active under the applied conditions $\left(50{ }^{\circ} \mathrm{C}, 15 \mathrm{~min}\right.$ reaction time); however; they were more active on increasing temperature and reaction time plausibly because, reaction time and temperature speeds up the reaction between catalyst and MAO which is beneficial for activity enhancement [31]. Cationic Hf-complex 68 was most active for ethylene polymerization. Complex $\mathbf{6 8}$ has more favorable distinct structural features than complexes 68-72, for example, it has one unsubstituted ortho position which facilitates ethylene access to the metal center, whereas on the other hand, aminopyridinato ligand on it stabilizes the cationic metal center, and thus, these structural features of $\mathbf{6 8}$ enhance its catalytic activity.

\section{Coordinative chain transfer polymerization (CCTP) by complex 68}

The CCTP is advantageous to control the architecture and microstructure of polymers. In contrast to living polymerization where only one catalytic species produces one polymer chain, in CCTP, several polymer chains could be grown on one catalyst species and molecular weight of the resulting polymer could also be controlled [81]. CCTP involves a transition/rare earth metal complex and a chain transfer agent (CTA). Mostly, the main group alkyls are used as CTA. In this polymerization, metal catalyst acts as an active species, while CTA acts as an inactive (dormant) species. In this way, several polymer chains could grow on one catalyst molecule; however, the chain termination process during this polymerization should be negligible [80-82]. Thus, polymers of approximately equal chain length with narrow molecular weight distribution are obtained. The polymer chain ends up with the main group metal used, and further functionalization of this group could provide valuable products. A faster chain transfer reaction ensures the occurrence of chain growth reaction on the main group metal [80]. In previous studies, Kempe et al. have reported the application of yttrium aminopyridinato complexes for CCTP and obtained aluminum- 
Fig. 18 Structures of Hfcomplexes 68-72

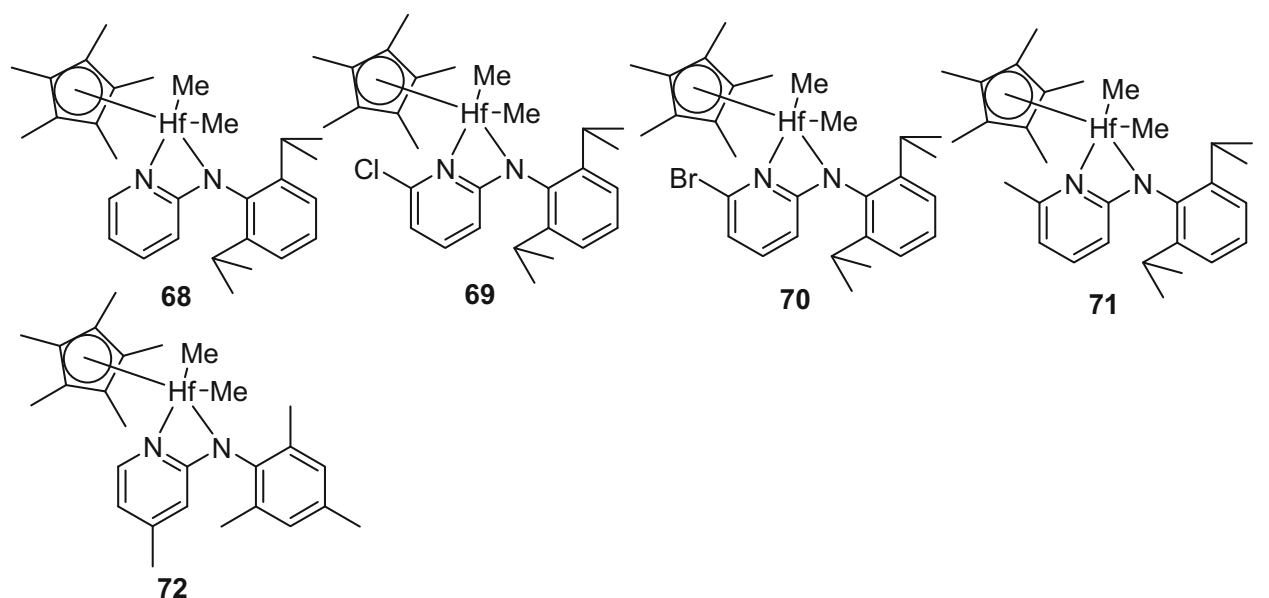

terminated polyethylene having $M_{n}=15,600 \mathrm{~g} \mathrm{~mol}^{-1}$ with lower polydispersity index (1.4). In following studies, Kempe et al. have employed complexes 68-72 for ethylene polymerization studies, and only complex 68 has shown good activity, and this complex was subjected to CCTP using triethyl aluminum as chain transfer agent, and the effect of different parameters such as temperature, catalyst/ CTA ratio, ethylene pressure and reaction time has been investigated [31]. The activity of the complex 68 was low at $50{ }^{\circ} \mathrm{C}$ and 2 bar ethylene pressure but increased to $1960 \mathrm{~kg} \mathrm{~mol}_{\text {cat }}^{-1} \mathrm{~h}^{-1}$ when activated with ammonium borate at $80{ }^{\circ} \mathrm{C}$, but the resultant polymer had a broader molecular weight distribution. It has been noticed that resulting polymer gets precipitated out during the reaction which inhibits the chain transfer rate; however, it can be overcome by increasing the temperature [55b]. Also, a bimodal distribution and substantial amount of precipitated polymer was found [31]. Higher pressure has a pronounced effect on activity, molecular weight and polydispersity. Increasing the pressure to 5 bar at $50{ }^{\circ} \mathrm{C}$ reduced the activity to $700 \mathrm{~kg} \mathrm{~mol}$ cat $^{-1} \mathrm{~h}^{-1}$ but decreased the molecular weight distribution equal to 2. Normally, in CCTP, the chain transfer and catalyst ratios range from 50 to 100 except for $n$-butylethyl magnesium/samarocene system with a ratio of 1-1000 and diethyl zinc/zirconocene dichloride with a ratio of 1-2800 were used. Hf-catalysts with higher tri-ethylaluminum/hafnocene ratio (500) have shown increase in polymerization activity because of more alkylation. Chain transfer agent affects the molecular weights and polydispersity of the polymers. Narrow polydispersity and low molecular weights were obtained with higher amounts of chain transfer agent, while broader polydispersity and high molecular weights were observed with less amount of chain transfer agent [31]. Catalyst $\mathbf{6 8}$ and CTA were added in different ratios, and catalyst-to-CTA ratio (1:500) gave the maximum activity $\left(5500 \mathrm{~kg} \mathrm{~mol}_{\text {cat }}^{-1} \mathrm{~h}^{-1}\right)$ and polydispersity index was found to be 1.5 .

\section{Hafnium aminopyridinate-F1 hybrid catalysts}

Fujita and coworkers pioneered the synthesis of phenoximine (F1 ligands)-based group-IV complexes (F1 catalysts) which proved to be very good olefin polymerization catalysts [99]. Recently, Kol et al. have combined F1 ligands with other ligands to synthesize half salan and half salen-type ligands and prepared corresponding Ti-complexes and they proved to be very efficient catalysts for 1-hexene and propylene polymerization (For example, complex 73) [100]. These catalysts are also active for isospecific polymerization of 1-hexene (Fig. 19). Catalyst $\mathbf{7 3}$ was employed for 1-hexene polymerization using $\mathrm{B}\left(\mathrm{C}_{6} \mathrm{~F}_{5}\right)_{3}$ as a co-catalyst and its activity was found to be $154 \mathrm{~kg} \mathrm{~mol}_{\text {cat }}^{-1} \mathrm{~h}^{-1}$ at $65^{\circ} \mathrm{C}$. Though this is a low activity, yet higher than that of similar reported catalysts. Very low polydispersity value (1.04) indicated the living polymerization by $\mathbf{7 3}$ and very high molecular weight $\left(M_{\mathrm{w}}=13,200,000\right)$ indicated the partial activation of $\mathbf{7 3}$. Catalyst $\mathbf{7 3}$ has the bulkiest adamantyl group which resulted into the poly-1-hexene polymer with highest tactictiy $[\mathrm{mmmm}]=88 \%$ and similar trend for adamantyl group has already been reported for other unsymmetrical ligands. The similar catalyst with less bulky ligands resulted into lower tacticity of the polymer. Such catalyst systems are advantageous because of their simple synthetic procedures and are beneficial for living polymerization of 1-hexene. Bulkier groups such as adamantyl on ligand framework are good for impressive catalytic activity and for obtaining the polymer of required tacticity. However,

Fig. $19 \mathrm{R}^{1}=$ adamantyl, $\mathrm{R}^{2}=$ methyl
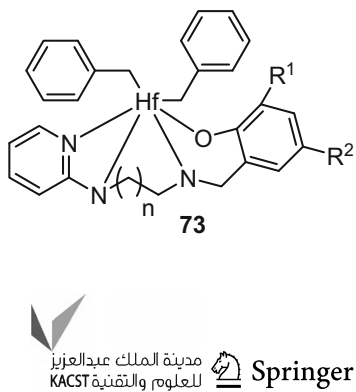
further modifications are required in the ligand design to enhance the catalytic activity $[99,101]$.

\section{Group-IV metal complexes bearing the aminoborane motif}

Ligand precursor 1c was synthesized and treated with $n$ $\mathrm{BuLi}$ to get the corresponding lithium salt which upon treatment with $\mathrm{ZrCl}_{4} \cdot 2 \mathrm{THF}$ and $\mathrm{HfCl}_{4} \cdot 2 \mathrm{THF}$ resulted into the corresponding $\mathrm{Zr}$ and Hf-catalysts $\mathbf{7 4}$ and $\mathbf{7 5}$ (Scheme 26) [102]. The main advantage of this synthesis is the synthesis of new complexes which have applications in ring-opening metathesis and vinyl insertion polymerization. However, the synthesis of ligand involves multiple steps. Although the synthesis of complexes is single step, yield is very low. The reported yield of Hf-complex is only $9.2 \%$, whereas the yield of $\mathrm{Zr}$ complex is only $18 \%$ [102]. The poor yields of these complexes could be attributed to the reduction to $\mathrm{Zr}$ (IV) and $\mathrm{Hf}(\mathrm{IV})$ to $\mathrm{Zr}$ (III) and $\mathrm{Hf}$ (III) by the lithium salt of the ligand. The complexes have been synthesized by adding the lithium salt of the ligand into the solution of $\mathrm{Zr} / \mathrm{Hf}$ tetrachloride salt solution. It is suggested that instead of this, addition of metal salt solution to the lithiated ligand might be helpful for getting better yield. The reaction for the synthesis of these complexes has been carried out at a low temperature $\left(-35^{\circ} \mathrm{C}\right)$. It is suggested that a very low temperature $\left(-78^{\circ} \mathrm{C}\right)$ might be favorable to obtain better yield [102].

In these both complexes, one THF molecule is coordinated to the respective metal center affording pentagonal bipyramidal geometry to the respective complex. In the previously reported other similar complexes, the fluorenyl moiety is coordinated with the metal center in an $\eta^{5}$ - coordination mode, but it is coordinated in an $\eta^{1}$-coordination in the present examples [102]. The $\eta^{1}$-coordination instead of $\eta^{5}$-coordination is probably due to the coordination of other donor groups prior to fluorenyl group coordination and such a bonding mode provides less electron density to electrophilic $\mathrm{Zr}$ atom which thus makes a compensation of electron density from pyridine ring and hence reducing electron density on pyridine nitrogen which makes pyridine nitrogen unable to coordinate with $\mathrm{B}$ atom. The $\mathrm{Zr}$ complex 76 upon activation with MAO has been found active for copolymerization of ethylene with norborn-2-ene (NBE) via ring-opening polymerization and vinyl insertion polymerization (VIP) (Fig. 20) [19, 28]. Double bonds in the copolymers could also be further functionalized [87]. Catalysts $\mathbf{7 4}$ and $\mathbf{7 5}$, activated with MAO were found to be active for homopolymerization of NBE. Catalyst $\mathbf{7 4}$ was less active $\left(6 \mathrm{~kg} \mathrm{~mol}_{\text {cat }}^{-1} \mathrm{~h}^{-1}\right.$ at $\left.65^{\circ} \mathrm{C}\right)$ but produced high molecular weight polymer $\left(M_{n}=160,000 \mathrm{~g} \mathrm{~mol}^{-1}\right)$ with narrow molecular weight distribution, possibly due to more steric congestion on the $\mathrm{Zr}$ metal center. Catalyst $\mathbf{7 4}$ was more active $\left(48 \mathrm{~kg} \mathrm{~mol}_{\text {cat }}^{-1} \mathrm{~h}^{-1}\right.$ at $\left.65{ }^{\circ} \mathrm{C}\right)$ and polymers obtained in this polymerization afforded both ring-opening metathesis polymers (ROMP) and vinyl insertion polymers (VIP). Some other $\mathrm{Zr}$ and $\mathrm{Hf}$ catalysts with no 6-[2-( $\left.\mathrm{R}_{2} \mathrm{~B}\right)$ phenyl]pyrid-2ylamido motif were also synthesized and applied for NBE polymerization, but they were not effective for ROMP process. Hence, it could be concluded that $6-\left[2-\left(R_{2-}\right.\right.$ B)phenyl]pyrid-2-ylamido motif in the ligand framework has a decisive role in making $\mathrm{Zr}$ and $\mathrm{Hf}$ catalysts ROMPactive. Catalyst system 74/MAO was also applied for copolymerization of NBE with ethylene and found that the activity of catalyst decreases with increasing concentration of NBE; however, this effect was counter-balanced with
Scheme 26 Synthesis of complexes 74-75

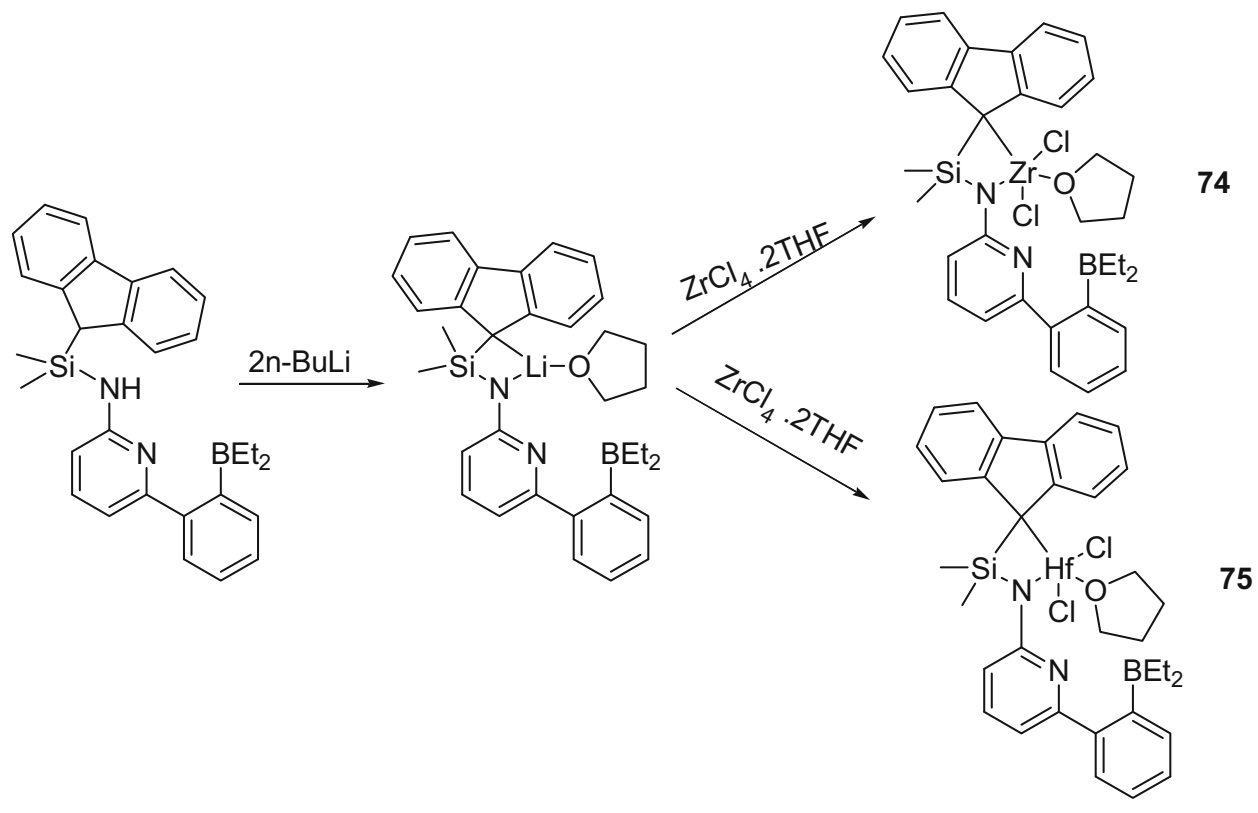


Fig. 20 Molecular structure of Zr-complex 76<smiles>CC1=CC([Z7](F)F)([Si](C)(C)Nc2cccc(-c3ccccc3C(C)C)n2)c2ccccc21</smiles>

76

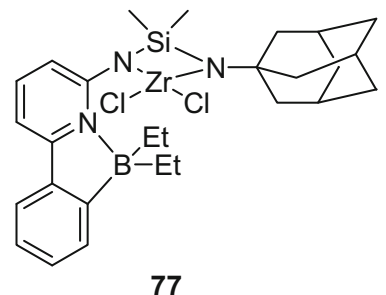

77<smiles></smiles>

Fig. $21 \mathrm{Zr}$ and Ti-complexes 77-78

copolymerization reactions, but polymer yields were lower. When catalyst $\mathbf{7 8}$ was used for the copolymerization reaction (cat:MAO:NBE = 1:2000:20,000) using 4 bar ethylene pressure at $50{ }^{\circ} \mathrm{C}$, a low polymer yield $\left(25 \mathrm{~kg} \mathrm{~mol}^{-1} \mathrm{~h}^{-1}\right.$ $\mathrm{bar}^{-1}$ ) was obtained. Using similar conditions (cat:MAO:NBE $=1: 2000: 20,000)$ and changing the temperature to $70^{\circ} \mathrm{C}$, the polymer yield decreased to $20 \mathrm{~kg} \mathrm{~mol}^{-1} \mathrm{~h}^{-1} \mathrm{bar}^{-1}$ however, further increasing temperature to $90{ }^{\circ} \mathrm{C}$, there was no further decrease in polymer yield [78]. With this catalyst system, there is a decrease in catalyst activity with increasing temperature and keeping all other conditions constant. Therefore, it could be inferred that this catalyst is becoming less stable at higher temperature and increasing NBE concentration reduces the activity primarily, because the active site gets blocked with NBE. Also, increasing steric bulk of the ligand decreases the catalyst activity because of blocking active sites. Polydispersity index of the obtained polymer at different temperatures is near to 2 which indicates that $\mathbf{7 8}$ is a single-site homogenous catalyst. Catalyst $\mathbf{7 7}$ was employed for ethylene-NBE (cat:MAO:NBE $=1: 2000: 10,000$, ethylene $=4$ bar, $T=$ $65^{\circ} \mathrm{C}$ ) copolymerization when activated by MAO and afforded copolymer yield $\left(75 \mathrm{~kg} \mathrm{~mol}_{\text {Cat. }}^{-1} \mathrm{~h}^{-1}\right)$. Increasing temperature to $80{ }^{\circ} \mathrm{C}$, polymer yield increased to $140 \mathrm{~kg} \mathrm{~mol}_{\text {Cat. }}^{-1} \mathrm{~h}^{-1}$ whereas increasing NBE concentration (1:2000:20,000) decreased the polymer's yield to $100 \mathrm{~kg} \mathrm{~mol}_{\text {Cat. }}^{-1} \mathrm{~h}^{-1}$ [78]. Thus, higher temperature $\left(80^{\circ} \mathrm{C}\right)$ is beneficial but higher NBE concentration is a limiting factor for higher polymer yield. Activity of this complex and similar complexes is lower due to coordination of NBE with active metal center and that could be enhanced with increasing catalyst and co-catalyst concentration.

\section{Group-IV metals hydroamination and hydroaminoalkylation catalysts}

\section{2,6-bis(phenylamino)pyridinato titanium catalyst}

Complex 79 was synthesized in $80 \%$ yield with the reaction of $N_{2}, N_{6}$-diphenylpyridine-2,6-diamine with $\mathrm{Ti}\left(\mathrm{NMe}_{2}\right)_{4}$ at room temperature and it proved to be an efficient catalyst for the hydroaminoalkylation of styrene

[78]. These catalysts were found to be active for such 
Scheme 27 Synthesis of Ticomplex 79

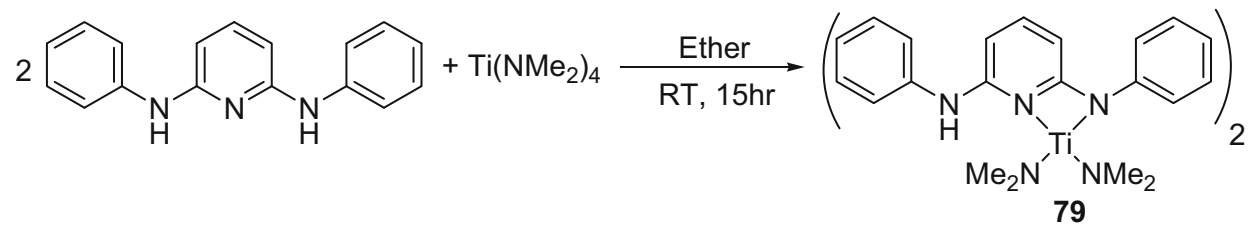

and (E)-1-phenyl-1, 3-butadienes with a variety of substrates (Scheme 27) [105]. Reactions of styrene with different secondary amines were made; however, yields were dependent on the steric bulk of amines (less sterically hindered amines were more reactive, while more sterically hindered were less reactive).

\section{2-Aminopyridinate Ti-complexes for the catalytic hydroamination of primary aminoalkenes}

Among group-IV metals $\mathrm{MNMe}_{2}[\mathrm{M}=\mathrm{Ti}, \mathrm{Zr}, \mathrm{Hf}]$ complexes, Ti-complexes have shown higher catalytic activity than $\mathrm{Zr}$ and $\mathrm{Hf}$ complexes but $\mathrm{Ti}$ and $\mathrm{Zr}$-complexes have drawback of giving hydroaminoalkylation product in addition to desired hydroamination product. However, Ticomplexes are advantageous for the hydroamination of alkynes because of their low cost, very low toxicity, good stability and better functional group tolerance [106]. The updated research on the application of Ti-complexes for hydroamination catalysis evidenced that chelating ligands attached to the metal center play a decisive role to control the regio-selectivity (Fig. 22) [106]. Most of these ligands have hard donor functionalities such as $\mathrm{N}$ and $\mathrm{O}$ which presumably, fine-tune the metal center for exclusive formation of regioselective product. Also, metallocene catalysts are helpful for getting anti-Markonikov product and pyrrolyl/imidazole ligands-based catalysts are suitable for Markonikove products. Imidazole ligand-based Ti-complexes have recently been used by Yang Zho et al. for intermolecular hydroamination of alkynes with amines which gave impressive results, for example, complex 80 produced $99 \%$ Markonikove product with hydroamination reaction of 1-octyne with 2, 4-chloroaniline and $100 \%$ Markonikove product with hydroamination reaction of 1-octyne and ani-line [106].

There is an immense need for the ligands which could enhance the chemoselectivity of Ti-complexes for

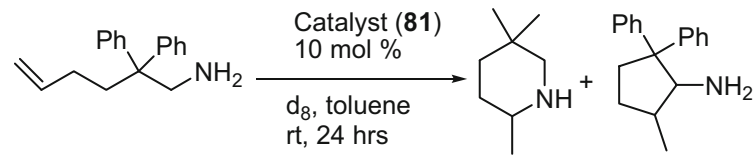

Scheme 28 Screening of complex 81 for hydroamination reaction

hydroamination products and chelating ligands containing a hard donor $\mathrm{O}$ or $\mathrm{N}$ moiety always remain a preferable choice for hydroamination catalysis [87, 105, 106]. Recently reported catalyst $\mathbf{8 1}$ was found to be more active than $\left[\mathrm{TiNMe}_{2}\right]_{4}$ for the hydroamination reaction of 2 , 2-diphenyl-5-hexenyl-1-amine at room temperature (Scheme 28) [69]. Room temperature activity of group-IV metal complexes is rare and recent examples for such catalysis have been reported for $\mathrm{Zr}$-complexes which are very much similar to $\mathbf{8 1}$ [106]. Complex $\mathbf{8 1}$ has been found to be active at broad range of temperature and, also, is more active than a vast range of other Ti-complexes. Catalyst $\mathbf{8 1}$ made achievable the hydroamination of most challenging substrates such as the selective formation of azepane. Catalyst $\mathbf{8 1}$ was found active for various substituted piperidines and primary amines but inactive for other secondary amines. Synthesis of complex $\mathbf{8 1}$ is simple, onestep, and high yielding; however, the complete removal of released diethylamine remains a challenge with this synthesis. It might be deduced that the change of steric bulk of the ligand and making variation in electron-donating ability of the ligands (with different substituents on the phenyl groups and substituting the phenyl ring with a heterocycle) could give more prominent results for hydroboration catalysis [106] (Table 5).

\section{Hydroaminoalkylation using Ti-catalysts}

High-yielding synthesis of amines is an important area both because of its economic value as well as application in medicines, and till now, $\mathrm{Ru}, \mathrm{Ir}, \mathrm{Ti}, \mathrm{Zr}$, catalysts are the

Fig. 22 Ti-complexes 80-83

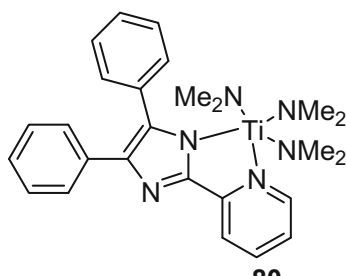

80

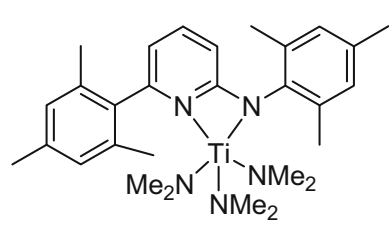

81

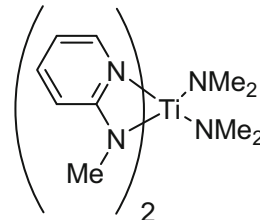

82<smiles></smiles>

83 
Table 5 Group-IV catalysts for hydroamination catalysis

\begin{tabular}{lc}
\hline Catalyst & Yield $(\%)^{\mathrm{a}}(\mathrm{HA}: \mathrm{HAA})$ \\
\hline 81 & $86(1: 0)$ \\
$\mathrm{Ti}\left(\mathrm{NMe}_{2}\right)_{4}$ & $50(9: 1)$ \\
$\mathrm{Zr}\left(\mathrm{NMe}_{2}\right)_{4}$ & $27(1: 0)$ \\
$\mathrm{Hf}\left(\mathrm{NMe}_{2}\right)_{4}$ & $2(1: 0)$ \\
\hline
\end{tabular}

HA hydroamination, HAA hydroamination alkylation

a Yield determined by proton NMR

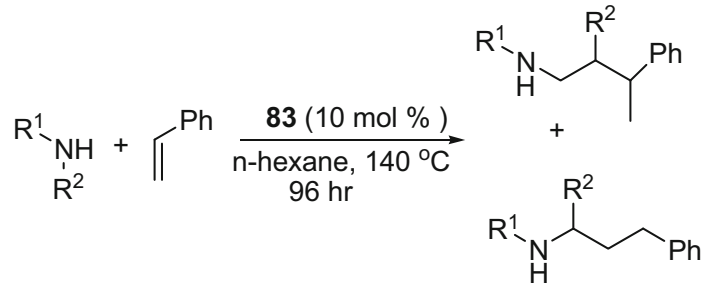

Scheme 29 Hydroaminoalkylation of styrene

major players [95, 105-107]. However, these catalysts are associated with certain limitations; for example, $\mathrm{Zr}$-catalyst $\mathrm{Ind}_{2} \mathrm{TiMe}_{2}$ predominantly gives branched product by the reaction of 1 -alkenes and secondary amines ( $N$-methylaniline) [107-110]. Hydroaminoalkylation reactions of group IV metals-based complexes are rare and are active for styrene polymerization, but they produce branched products instead of desired linear hydroaminoalkylated products of alkenes which are industrially more important. Dolfer's group has utilized 2-aminopyridinato Ti-complexes 82 and 83 to prepare hydroaminoalkylation products in 55 and $10 \%$ yields, respectively, using in situ generated complex (10 mol\% $\mathrm{TiNMe}_{4}$ and $10 \mathrm{~mol} \%$ 2-Me ApH, $15 \mathrm{~h}$ stirring at room temperature) followed by the addition of styrene and $\mathrm{N}$-methylaniline at $105{ }^{\circ} \mathrm{C}$ for $96 \mathrm{~h}$ in toluene (Scheme 29) [105]. Its yield was further optimized by elevating the temperature to $140{ }^{\circ} \mathrm{C}$, and increasing catalyst loading $(20 \mathrm{~mol} \%)$ also enhanced the yield of linear product. Regioselectivity for linear product is dependent on the steric bulk of $N$-alkyl substituent on aniline nitrogen and optimal regioselectivity was obtained with $N$-pro-pylaniline and $N$-benzylaniline (91:9 for linear product). Catalysts 82 and $\mathbf{8 3}$ are also effective for hydroaminoalkylation reaction of dialkyl amines with styrene (Scheme 30). Also, electronic and steric properties of the substituted styrenes affect the hydroaminoalkylation reaction, para-substituted OMe group prevents hydroamination reaction, whereas $\mathrm{CF}_{3}$ group enhances the yield of para product [105] (Table 6).

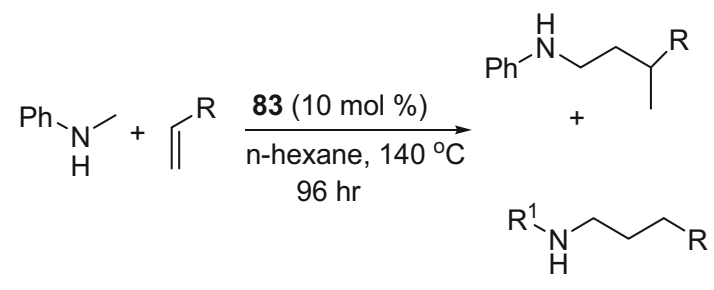

Scheme 30 Hydroaminoalkylation of various alkenes

Table 6 Hydroaminoalkylation of alkenes

\begin{tabular}{|l|l|l|l|l|}
\hline Catalyst & Substrate & Product & Condition & Yield \% \\
\hline 1 & & & \\
\hline 2
\end{tabular}

Conclusion

Immense need for the improved olefin-polymerizing catalysts has attracted extensive research with prime focus upon group-IV metals and variety of aminopyridinato ligands. Many and diverse ligand systems have been utilized to prepare variety of Ti-complexes for olefins homopolymerization and copolymerization. The mainly focused Ti-aminopyridinato complexes have also been applied for hydroamination and hydroaminoalkylation catalysis which provided impressive results. Aminopyridinato/mixed ligands Ti-complexes have also been found active for polymerrizing 1-octene, 1-hexene and ethylene norbornene which are generally difficult to polymerize. Also, many Zr- and Hf-complexes have been designed and synthesized which generally give lesser catalytic activities, but Hf-complexes high-molecular-weight polymers. Also, hafnium mixed-ligand complexes (Ap and $\mathrm{Cp}$ ligands) have shown impressive results for coordinative chain polymerization (CCTP). Though Ti-complexes have been much more investigated, $\mathrm{Zr}$ - and Hf-complexes are more stable to air and moisture. Still, it is a challenge to develop catalysts which would have cost-effective synthesis, very high activity/selectivity and higher temperature tolerance. The catalysts developed (with various ligand systems) for homo- and co-polymerization give moderate to high activities, but the higher polydisperisities of the resultant polymers are the crucial problems which could be rationalized with weaker pyridine metal bond and are still 
unresolved. In addition, catalytic activities of these groupIV metal-based amido complexes are not high enough which may be connected to the poor complex stability, primarily in the presence of aluminum alkyl (even in traces) that breaks the metal ligands bond to insert itself. Suitable changes in the ligand to fine-tune the electronic and steric properties could be critical since electron-donating groups on the ligand decrease the catalytic activity and increase the polymer chain length; thus, electronwithdrawing groups could enhance the polymer chain length. Mixed-ligand complexes such as aminopyridinato and phenolato ligands-based catalysts could be synthesized and utilized for olefin polymerization. Ti-complexes have also been found useful for the activation of small molecules. This could be proposed that metal-ligand nitrogen (M-N bond) strengthening could stabilize the catalysts against traces of Al-Alkyls and that might be possible through optimization of $\mathrm{N}$-containing ligand systems. Furthermore, stability of these complexes against moisture and air should also be investigated.

Open Access This article is distributed under the terms of the Creative Commons Attribution 4.0 International License (http:// creativecommons.org/licenses/by/4.0/), which permits unrestricted use, distribution, and reproduction in any medium, provided you give appropriate credit to the original author(s) and the source, provide a link to the Creative Commons license, and indicate if changes were made.

\section{References}

1. Williams JC, Starke EA (2013) Progress in structural materials for aerospace systems. Acta Mater 51:5775-5799

2. Chung TM (2013) Functional polyolefins for energy applications. Macromolecules 46:6671-6698

3. Shamiri A et al (2014) The influence of Ziegler-Natta and metallocene catalysts on polyolefin structure, properties, and processing ability. Materials 7:5069-5108

4. Takeuchi D (2010) Recent progress in olefin polymerization catalyzed by transition metal complexes: new catalysts and new reactions. Dalton Trans 39:311-328

5. Coates GW (2002) Polymerization catalysis at the millennium: frontiers in stereoselective, metal-catalyzed polymerization. Dalton Trans 2002:467-475

6. Fink G, Mülhaupt R, Brintzinger HH (2012) Ziegler catalysts: recent scientific innovations and technological improvements. Springer Science \& Business Media, Germany

7. Zhang HX et al (2012) A simple modification makes a big improvement to Ziegler-Natta catalyst. J Polym Sci Part A Polym Chem 50:4805-4808

8. Vestberg T, Denifl P, Wilén CE (2008) Porous versus novel compact Ziegler-Natta catalyst particles and their fragmentation during the early stages of bulk propylene polymerization. J Appl Polym Sci 110:2021-2029

9. Abboud M, Denifl P, Reichert KH (2005) Advantages of an emulsion-produced Ziegler-Natta catalyst over a conventional Ziegler-Natta catalyst. Macromol Mater Eng 290:1220-1226

10. Severn JR, Chadwick JC (2008) Tailor-made polymers: via immobilization of alpha-olef-in polymerization catalysts, vol 2008. Wiley, USA
11. Kissin YV, Mirabella FM, Meverden CC (2005) Multi-center nature of heterogeneous Ziegler-Natta catalysts: TREF confirmation. J Polym Sci Part A Polym Chem 43:4351-4362

12. Ferraro A et al (2006) Advances in Ziegler-Natta catalysts for polypropylene. Kinet Catal 47:176-185

13. Corriu RJ, Lancelle-Beltran E, Mehdi A et al (2002) Ordered mesoporous hybrid materials containing cobalt(II) schiff base complex. J Mater Chem 12:1355-1362

14. Brintzinger $\mathrm{HH}$ et al (1995) Stereospecific olefin polymerization with chiral metallocene catalyst. Angew Chem Int Ed 34:1143-1170

15. Chen EYX, Marks TJ (2000) Cocatalysts for metal-catalyzed olefin polymerization: activators, activation processes and structure-activity relationships. Chem Rev 100:1391-1434

16. Mukhopadhyay K, Sarkar BR, Chaudhari RV (2002) Anchored Pd complex in MCM-41 and MCM-48: novel heterogeneous catalysts for hydrocarboxylation of aryl olefins and alcohols. J Am Chem Soc 124:9692-9693

17. Alt HG (1999) The heterogenization of homogeneous metallocene catalysts for olefin polymerization. J Chem Soc Dalton Trans (11):1703-1710. doi:10.1039/A808812H

18. Kaminsky W (2004) The discovery of metallocene catalysts and their present state of the art. J Polym Sci Part A Polym Chem 42:3911-3921

19. Matyjaszewski K, Xia J (2001) Atom transfer radical polymerization. Chem Rev 101:2921-2990

20. Rosenthal U, Pellny PM, Kirchbauer FG, Burlakov VV (2000) What do titano-and zirconocenes do with diynes and polyynes? Acc Chem Res 33:119-129

21. Spencer LP, Winston S, Fryzuk MD (2004) Tridentate amido carbene ligands in early-transition-metal coordination chemistry. Organometallics 23:3372-3374

22. Glatz $\mathrm{G}$ et al (2010) Copper-containing $\mathrm{SiCN}$ precursor ceramics $(\mathrm{Cu} @ \mathrm{SiCN})$ as selective hydrocarbon oxidation catalysts using air as an oxidant. Chem A Eur J 16:4231-4238

23. Westmoreland I et al (2003) Chiral titanium bis (aminopyridinates) based on a biaryl backbone. Organometallics 22:2972-2976

24. Polamo M, Leskelä M (1996) Syntheses and crystal structures of phenyl (2-pyridyl) ami-do complexes of zirconium(IV), niobium(V) and tantalum(V). J Chem Soc Dalton Trans (23):4345-4349. doi:10.1039/DT9960004345

25. Guérin F, McConville DH, Payne NC (1996) Conformationally rigid diamide complexes: synthesis and structure of titanium(IV) alkyl derivatives. Organometallics 15:5085-5089

26. Kretschmer WP et al (2007) Highly active/selective and adjustable zirconium polymeriz-ation catalysts stabilized by aminopyridinato ligands. J Organomet Chem 692:4569-4579

27. Gibson VC, Spitzmesser SK (2003) Advances in non-metallocene olefin polymerization catalysis. Chem Rev 103:283-315

28. Collins RA, Russell AF, Mountford P (2015) Group 4 metal complexes for homo-geneous olefin polymerisation: a short tutorial review. Appl Petrochem Res 5:153-171

29. Kempe R (2003) The strained $\eta^{2}-\mathrm{N}_{\text {Amido }}-\mathrm{N}_{\text {Pyridine }}$ coordination of aminopyridinato ligands. Eur J Inorg Chem 2003:791-803

30. Noor A et al (2008) Synthesis and structure of zirconium and hafnium polymerisation catalysts stabilised by very bulky aminopyridinato ligands. Eur J Inorg Chem 2008:5088-5098

31. Haas I, Kretschmer WP, Kempe R (2011) Synthesis of aluminaterminated linear PE with a hafnium aminopyridinate catalyst. Organometallics 30:4854-4861

32. Noor A, Kempe R (2008) Acetylenetitanium complex stabilized by aminopyridinato ligands. Eur J Inorg Chem 2008(15): 2377-2381

33. Hafeez M, Lippert S, Bauer T, Kretschmer WP (2015) Synthesis, structural investigations and ethylene polymerization of titanium complexes with tripodal oxazoline ligands. J Iran Chem Soc 12:957-966 
34. Hafeez M, Kretschmer WP, Kempe R (2012) Hafnium trialkyls stabilized by bulky, electron-rich aminopyridinates. Z Anorg Allg Chem 638:324-330

35. Duan XE et al (2012) Metal (Mg, Fe Co, Zr and Ti) complexes derived from aminosilyl substituted aminopyridinato ligand: synthesis, structures and ethylene polymerization behaviors of the group 4 complexes. Dalton Trans 41:9460-9467

36. Chen J, Yuan L (2014) Dimeric zirconium complex bearing a dianionic ansa-bis (aminopyridinato) ligand. Mendleev Commun 24:114-116

37. Noor A, Kretschmer WP, Glatz G, Kempe R (2011) Highly active titanium-based olefin polymerization catalysts bearing bulky aminopyridinato ligands. Inorg Chem 50:4598-4606

38. Hillebrand G, Spannenberg A, Arndt P, Kempe R (1997) Titanium and niobium complexes stabilized by tris(aminopyridinato) ligands: evidence of variable denticity in trianionic polydentate ligands. Organometallics 16:5585-5588

39. Talja $M$ et al (2005) Synthesis, structure and polymerization behavior of tri-and dichloro-aminopyridinato complexes of titanium. Inorg Chim Acta 358:1061-1067

40. Fandos $R$ et al (2005) Synthesis and characterization of titanium and tantalum complexes with di (2-pyri-dyl) amine (dpa): molecular structures of $\mathrm{Cp}^{*} \mathrm{TaCl}_{3}(\mathrm{dpa})$ and $\mathrm{Ti}\left(\mathrm{NMe}_{2}\right)_{2}(\mathrm{dpa})_{2}$. J Organomet Chem 690:4828-4834

41. Smolensky E, Kapon M, Woollins JD, Eisen MS (2005) Formation of elastomeric polypropylene promoted by a dynamic octahedral titanium complex. Organometallics 24:3255-3265

42. Talja M et al (2008) Synthesis, characterization and ethylene polymerization activity of titanium aminopyridinato complexes. Inorg Chim Acta 361:2195-2202

43. Zi G et al (2010) Synthesis, structure, and catalytic activity of titanium(IV) and zirconium(IV) amides with chiral biphenyldiamine-based ligands. J Organomet Chem 695:730-739

44. Hafeez M, Kretschmer WP, Kempe R (2011) Titanium complexes stabilized by bulky electron-rich aminopyridinates and their application in ethylene and styrene polymerization. Eur $\mathbf{J}$ Inorg Chem 2011:5512-5522

45. Smolensky E, Kapon M, Eisen MS (2007) Intermolecular hydroamination of methylene-cyclopropane catalyzed by group IV metal complexes. Organometallics 26:4510-4527

46. Talja M, Polamo M, Leskelä M (2008) Bis (alkylphenylaminopyridinato) titanium dichlorides as ethylene polymerization catalysts. J Mol Catal A Chem 280:102-105

47. Kempe R, Arndt P (1996) Mononuclear titanium complexes that contain aminopyridinato ligands. Inorg Chem 35:2644-2649

48. Liddle ST, Arnoldb PL (2007) Synthesis and characterisation of yttrium complexes supp-orted by the $\beta$-diketiminate ligand $\left\{\operatorname{ArNC}\left(\mathrm{CH}_{3}\right) \mathrm{CHC}\left(\mathrm{CH}_{3}\right) \mathrm{NAr}\right\}^{-}\left(\mathrm{Ar}=2,6-\mathrm{Pr}_{2}^{\mathrm{i}} \mathrm{C}_{6} \mathrm{H}_{3}\right)$. Dalton Trans (30):3305-3313. doi:10.1039/B706971E

49. Rodrigues AS, Kirillov E, Carpentier JF (2008) Group 3 and 4 single-site catalysts for stereospecific polymerization of styrene. Coord Chem Rev 252:2115-2136

50. Schellenberg J (2009) Recent transition metal catalysts for syndiotactic polystyrene. Prog Polym Sci 34:688-718

51. Collins S (2011) Polymerization catalysis with transition metal amidinate and related complexes. Coord Chem Rev 255:118-138

52. Wang $Y$ et al (2011) Synthesis and characterization of trichlorotitanium 2-(2-pyridinyl-iminomethyl) phenolates and their ethylene (co-) polymerization behavior. Polymer 52:3732-3745

53. Cariou R, Gibson VC, Tomov AK, White AJ (2009) Group 4 metal complexes bearing new tridentate (NNO) ligands: benzyl migration and formation of unusual $\mathrm{C}-\mathrm{C}$ coupled pro-ducts. J Organomet Chem 694:703-716
54. Gott Al et al (2008) Constrained geometry aminooxazolinate ligands giving chiral zir-coniumguanidinates; catalytic cyclohydroamination. Dalton Trans (22):2983-2990. doi:10.1039/ b803831g

55. Mitani M et al (2002) Living polymerization of ethylene catalyzed by titanium complexes having fluorine containing phenoxyimine chelate ligands. J Am Chem Soc 124:3327-3336

56. Huang Z et al (2008) Synthesis and characterization of a series of 2-aminopyridine nickel (II) complexes and their catalytic properties toward ethylene polymerization. J Polym Sci Part A Polym Chem 46(5):1618-1628

57. O'Shaughnessy PN et al (2002) Chiral biarylamido complexes of zirconium. Organometallics 21:4496-4504

58. Cosham SD et al (2014) Synthesis, structural and thermal characterisation of titanium-silylamido complexes. J Organomet Chem 772:27-33

59. Chan MC et al (2006) Polymerization of higher $\alpha$-olefins with a bis(Phenoxyimine)Ti complex/i-Bu3Al/Ph3CB(C6F5)4: formation of stereo- and regioirregular High molecular weight polymers with high efficiency. Organometallics 25:785-792

60. Döring C, Kretschmer WP, Kempe R (2010) Aminopyridinatestabilized lanthanoid complexes: synthesis, structure and polymerization of ethylene and isoprene. Eur J Inorg Chem 2010:2853-2860

61. Scott NM, Kempe R (2005) Di-and trivalent lanthanide complexes stabilized by sterically demanding aminopyridinato ligands. Eur J Inorg Chem 200:1319-1324

62. Skvortsov GG et al (2007) Intramolecular (sp3-hybridized) $\mathrm{CH}$ Activation: yttrium alkyls versus transient yttrium hydrides. Organometallics 26:5770-5773

63. Flores JC, Chien JC, Rausch MD (1995) [ $N, N^{\prime}$-bis (trimethylsilyl) benzamidinato] titanium and-zirconium compounds. Synthesis and application as precursors for the syndiospecific polymerization of styrene. Organometallics 14:1827-1833

64. Camadanli S et al (2011) Homopolymerization of ethylene, 1-hexene, styrene and copolymerization of styrene with 1 , 3-cyclohexadiene using (h5-tetramethylcyclopenta-dienyl) dimethylsilyl $\left(\mathrm{N}-\mathrm{Ar}^{\prime}\right)$ amido-TiCl2-/MAO $\quad\left(\mathrm{Ar}^{\prime}=6-(2-(\mathrm{di}-\right.$ ethylboryl) phenyl) pyr-id-2-yl, biphen-3-yl). Molecules 16:567-582

65. Pedrosa $\mathrm{S}$ et al (2015) Imido-pyridine Ti(iv) compounds: synthesis of unusual imido-amido hetero-bimetallic derivatives. Dalton Trans 44:11119-11128

66. Flores JC, Chien JC, Rausch MD (1995) ( $N, N^{\prime}$-dimethyl- $p$ toluamidinato) trichlorotitanium: synthesis, structure, and polymerization catalysis. Organometallics 14:2106-2108

67. Liguori D, Grisi F, Sessa I, Zambelli A (2003) Low-temperature polymerization of olefins in the presence of titanium monoamidinate/MAO catalyst. Macromol Chem Phys 204:164-170

68. Feil F, Harder S (2003) New stereochemical assignments of ${ }^{13} \mathrm{C}$ NMR signals for pre-dominantly syndiotactic polystyrene. Macromolecules 36:3446-3448

69. Ishihara N, Seimiya T, Kuramoto M, Uoi M (1986) Crystalline syndiotactic polystyrene. Macromolecules 19:2464-2465

70. Oga K, Shiono T (1997) Ziegler-Natta catalysts for olefin polymerizations. Prog Polym Sci 22:1503-1546

71. Mc Guinness DS (2010) Olefin oligomerization via metallacycles: dimerization, trimerization, tetramerization, and beyond. Chem Rev 111:2321-2341

72. Cabrera AR et al (2011) Synthesis and characterization of materials prepared via the copolymerization of ethylene with 1-octadecene and norbornene using a [( $\pi$-cyano-nac-nac $) \mathrm{Cp}]$ zirconium complex. J Polym Sci Part A Polym Chem 49:1535-1542 
73. Kempe R, Noss H, Irrgang T (2002) Towards f and d electron interactions in amido metal complexes. J Organomet Chem 647:12-20

74. Delferro M, Marks TJ (2011) Multinuclear olefin polymerization catalysts. Chem Rev 111:2450-2485

75. Burlakov V et al (1994) Novel acetylene complexes of titanocene and permethyl-titanocene without additional ligands. Synthesis spectral characteristics and X-ray diffraction study. J Organomet Chem 476:197-206

76. Schumann H (1984) Organolanthanoid-Verbindungen. Angew Chem 96:475-493

77. Schumann H, Meese-Marktscheffel JA, Esser L (1995) Synthesis, structure, and reactivity of organometallic pi-complexes of the rare earths in the oxidation state $\mathrm{Ln}^{3+}$ with aromatic ligands. Chem Rev 95:865-986

78. Xu G et al (2014) Poly(ethylene)-co-poly (norborn-2-ene) prepared by group IV bisamido and half-Sandwich amido complexes with pendant aminoborane groups: vinyl insertion vs ring-opening metathesis polymerization. Macromol Chem Phys 215:893-899

79. Narayana GV et al (2014) Stereospecific styrene polymerization by methylalumoxane-activated Ti(IV) $N$-trimethylsilylamido complexes bearing the $N$-biphenyl or $N$-(6-(2-(diethylboryl) phenyl)-Pyrid-2-yl) motif. Macromol Chem Phys 215:2007-2013

80. Buchmeiser MR et al (2011) A catalyst for the simultaneous ring-opening metathesis polymerization/vinyl insertion polymerization. Angew Chem Int Ed 50:3566-3571

81. Zou Y et al (2011) Group 4 dimethylsilylenebisamido complexes bearing the 6-[2-(diethylboryl) phenyl] pyrid-2-yl motif: synthesis and use in tandem ring-opening metathesis/vinyl-insertion copolymerization of cyclic olefins with ethylene. Chem A Eur J 17:13832-13846

82. Narayana GV et al (2014) Access to ultra-high-molecular weight poly (ethylene) and activity boost in the presence of cyclopentene with group 4 bis-amido complexes. Chem Plus Chem 79:151-162

83. Luconi L et al (2012) Facing unexpected reactivity paths with $\mathrm{Zr}$ IV-pyridylamido polymerization catalysts. Chem A Eur J 18:671-687

84. Li X, Hou Z (2008) Organometallic catalysts for copolymerization of cyclic olefins. Coord Chem Rev 252:1842-1869

85. Kaminsky W (2008) Trends in polyolefin chemistry. Macromol Chem Phys 209:459-466

86. Jun SH et al (2013) Preparation of phosphine-amido hafnium and zirconium complexes for olefin polymerization. Organometallics 32:7357-7365

87. Sasol olefins \& surfactants, Annual Review 2010

88. Valente A, Mortreux A, Visseaux M, Zinck P (2013) Coordinative chain transfer polymerization. Chem Rev 113:3836-3857

89. Sita LR (2009) Ex Uno Plures ("Out of One, Many"): new paradigms for expanding the range of polyolefins through reversible group transfers. Angew Chem Int Ed 48:2464-2472

90. Amin SB, Marks TJ (2008) Versatile pathways for insitu polyolefin functionalization with heteroatoms: catalytic chain transfer. Angew Chem Int Ed 47:2006-2025

91. Kretschmer WP et al (2006) Reversible chain transfer between organoyttrium cations and aluminum: synthesis of aluminumterminated polyethylene with extremely narrow molecularweight distribution. Chem Eur J 12:8969-8978
92. Fontaine PP et al (2013) Synthesis and scale-up of iminoenamido hafnium and zirconium olefin polymerization catalysts. Organometallics 32:2963-2972

93. Figueroa R et al (2011) Synthesis of imino-enamido hafnium and zirconium complexes: a new family of olefin polymerization catalysts with ultrahigh-molecular-weight capabilities. Organometallics 30:1695-1709

94. Froese RD et al (2010) Imino-amido Hf and $\mathrm{Zr}$ complexes: synthesis, isomerization, and olefin polymerization. Organometallics 30:251-262

95. Zi G, Zhang F, Song H (2010) Highly enantioselective hydroaminoalkylation of secondary amines catalyzed by group 5 metal amides with chiral biarylamidate ligands. Chem Commun 46:6296-6298

96. Zi G et al (2010) Synthesis and characterization of group 4 metal amides with new C2-symmetric binaphthyldiamine-based ligands and their use as catalysts for asymmetric hydroamination/cyclization. Dalton Trans 39:4048-4061

97. Britovsek GJ, Gibson VC, Wass DF (1999) The search for newgeneration olefin polymerization catalysts: life beyond metallocenes. Angew Chem Int Ed 38:428-447

98. Kuhlman RL, Wenzel TT (2008) Investigations of chain shuttling olefin polymerization using deuterium labeling. Macromolecules 41:4090-4094

99. Haas I et al (2013) Aminopyridinate-FI hybrids, their hafnium and titanium complexes, and their application in the living polymerization of 1-hexene. Chem A Eur J 19:14254-14262

100. Press K et al (2011) Salalen titanium complexes in the highly isospecific polymerization of 1-hexene and propylene. Angew Chem 123:3591-3594

101. Elkin T, Eisen MS (2015) Amidinate group 4 complexes in the polymerization of olefins. Catal Sci Technol 5:82-95

102. Wang $M$ et al (2015) Group 4 metal complexes bearing the aminoborane motif: origin of tandem ring-opening metathesis/ vinyl-insertion polymerization. Polym Chem 6:3290-3304

103. Buchmeiser MR (2013) Tandem ring-opening metathesis/vinyl insertion polymerization-derived poly (olefin)s. Curr Org Chem 17:2764-2775

104. Carrow BP, Nozaki K (2014) Transition-metal-catalyzed functional polyolefin synthesis: effecting control through chelating ancillary ligand design and mechanistic insights. Macromolecules 47:2541-2555

105. Dörfler J et al (2014) A 2, 6-bis (phenylamino) pyridinato titanium catalyst for the highly regioselective hydroaminoalkylation of styrenes and 1,3-butadienes. Angew Chem Int Ed 53:7918-7922

106. Preuß T, Saak W, Doye S (2013) Titanium-catalyzed intermolecular hydroaminoalkylation of conjugated dienes. Chem A Eur J 19:3833-3837

107. Zhao Y et al (2011) Titanium and zirconium amido complexes supported by imidazole-containing ligands: syntheses, characterization and catalytic activities. RSC Adv 2:144-150

108. Chong E et al (2013) 2-Aminopyridinate titanium complexes for the catalytic hydroamination of primary aminoalkenes. Organometallics 32:1858-1865

109. Helgert TR, Hollis TK, Valente EJ (2012) Synthesis of titanium CCC-NHC pincer complexes and catalytic hydroamination of unactivated alkenes. Organometallics 31:3002-3009

110. Bexrud JA et al (2009) Selective $\mathrm{C}-\mathrm{H}$ activation $\alpha$ to primary amines bridging metalla-aziridines for catalytic, intramolecular $\alpha$-alkylation. J Am Chem Soc 131:2116-2118 